\title{
Development and validation of a modular hybrid electric vehicle simulation model
}

\author{
William Frederick Kellermeyer III \\ West Virginia University
}

Follow this and additional works at: https://researchrepository.wvu.edu/etd

\section{Recommended Citation}

Kellermeyer, William Frederick III, "Development and validation of a modular hybrid electric vehicle simulation model" (1998). Graduate Theses, Dissertations, and Problem Reports. 918.

https://researchrepository.wvu.edu/etd/918

This Thesis is protected by copyright and/or related rights. It has been brought to you by the The Research Repository @ WVU with permission from the rights-holder(s). You are free to use this Thesis in any way that is permitted by the copyright and related rights legislation that applies to your use. For other uses you must obtain permission from the rights-holder(s) directly, unless additional rights are indicated by a Creative Commons license in the record and/ or on the work itself. This Thesis has been accepted for inclusion in WVU Graduate Theses, Dissertations, and Problem Reports collection by an authorized administrator of The Research Repository @ WVU. For more information, please contact researchrepository@mail.wvu.edu. 


\title{
Development and Validation of a Modular Hybrid Electric Vehicle Simulation Model
}

\author{
Thesis \\ Submitted to the College of Engineering and Mineral Resources \\ of West Virginia University \\ Department of Mechanical and Aerospace Engineering \\ Morgantown, West Virginia 26505-6106 \\ In Partial Fulfillment of the requirements \\ For the Degree of Master of Science \\ in \\ Mechanical Engineering \\ By \\ William F. Kellermeyer III \\ Morgantown, West Virginia \\ May 1998
}

Committee Chairman: Dr. Chris Atkinson

Committee Members: Dr. Victor Mucino

Dr. Nigel Clark 


\title{
Development and Validation of a Modular Hybrid Electric Vehicle Simulation Model
}

\author{
William F. Kellermeyer III
}

(ABSTRACT)

With an ever-increasing number of vehicles on the road, an increase in the number of vehicle miles traveled each year, and the threat of decreasing oil reserves, the demand for more fuel efficient, lower pollutant emitting vehicles, is more prominent than ever before. Due to concerns over the trade deficit caused by the importation of oil (estimated at $\$ 50$ billion in 1997), the US government and the three major domestic auto manufacturers formed the Partnership for a New Generation of Vehicles (PNGV) in 1993. This partnership between government and industry has the ultimate goal of producing a low emissions vehicle capable of three times present day fuel economy with little or no sacrifice in consumer acceptability. Electric vehicles offer the promise of zero tail-pipe emissions, but present day battery technology limits their range to $10 \%-15 \%$ of a conventional gasoline-powered or diesel-powered vehicle. As an interim measure perhaps, most major automobile manufacturers have designed or are developing hybrid electric vehicles. Traditionally, conventional vehicles achieve a fuel economy increase by resorting to an under-sized internal combustion engine. This reduces the vehicle's performance, while typically increasing emissions and reducing consumer acceptability. Hybrid electric vehicles (HEVs) have the capability of significantly increased fuel economy with little or no loss in performance. HEVs are defined as vehicles that have two power sources, one commonly being an internal combustion engine (ICE), and the other being an electric motor. There are three major types of HEVs, namely series, 
coupling a motor to the transmission and an ICE to an alternator; parallel, coupling a motor and an ICE together to the transmission; and a combination, coupling a motor, alternator, and engine such that the powertrain can operate in any of several modes. There seems to be no limit to the possible complexity of HEVs. Correct component sizing (engine, motor, alternator, and energy storage) and configuration becomes very difficult to design or even to define. To attempt to bring rigor and analysis to the design process, accurate simulation programs are crucial. Most HEV simulation programs are written for very specific component configurations and only allow changes in component sizes. These programs prove helpful only if one designs a component configuration similar to the one already simulated. A modular based program such as the one developed here allows simpler reconfiguration of the components for an accurate simulation of almost any component configuration design. This HEV simulation program allows for simulation of all three types of hybrids, with several engine types and configurations, and several transmissions. Vehicle efficiency and performance can be predicted with the Federal Test Procedure, the Highway Fuel Efficiency Test, the US06 and the Japanese 10-15 Mode driving cycles. Comparisons are made with published results for several conventional vehicles and those HEVs tested and reported to date. 


\section{Table of Contents}

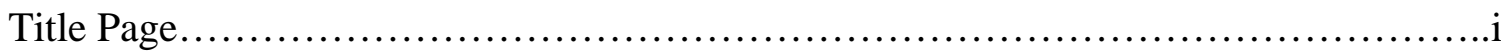

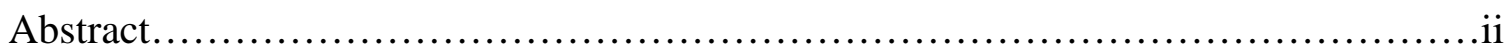

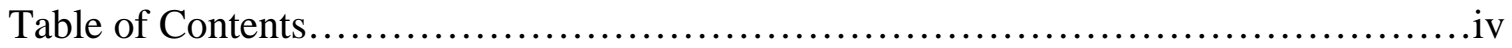

List of Tables...........................................................vii

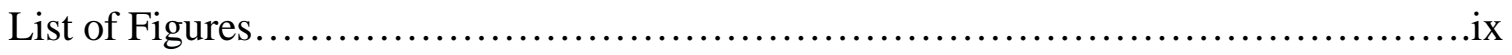

Nomenclature ................................................................

1. Introduction.............................................................

1.1. PNGV Goals ......................................................

1.2. Hybridization as an Approach to Meet PNGV Goals.........................

1.2.1. The Advantages and Disadvantages of Series HEVs.............6

1.2.2. The Advantages and Disadvantages of Parallel HEVs............7

1.2.3. The Potentials of Combination Parallel/Series and Multi Mode HEVs.................................................... 8

1.3. The Objectives of this Modular HEV Simulation Program................11

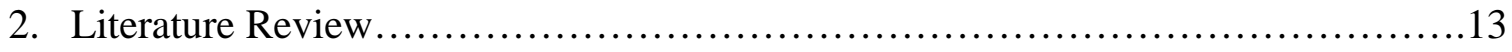

2.1. HEV Simulation Programs........................................13

2.2. Component Modeling............................................... 15

3. Vehicle Simulation................................................... 17

3.1. Approach.................................................... 17

3.1.1. Inputs and Outputs.....................................18

3.1.2. Brief Description of the Modular Simulation...................21

3.2. Vehicle Dynamics Derivation......................................... 27 


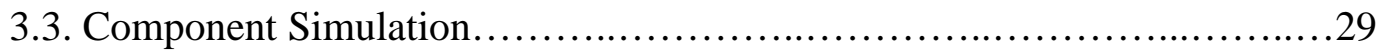

3.3.1. Engine Efficiency Replication .................................29

3.3.2. Motor and Controller Efficiency Replication....................33

3.3.3. Transmission Behavior Replication...............................34

3.3.3.1. Manual and Automatic Transmission.......................34

3.3.3.2. Continuously Variable Transmission.......................38

3.3.3.3. Planetary Gear Set....................................42

3.3.4. Battery Simulation...........................................44

3.3.5. Energy and Efficiency Calculations.............................51

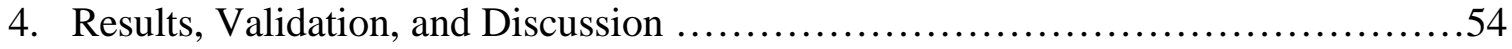

4.1. Simulation and Comparison of Several Conventional Vehicles ..............54

4.2. Simulation and Comparison of Series Vehicles..........................62

4.3. Simulation and Comparison of Parallel Vehicles............................66

4.4. Simulation and Comparison of Combination HEVs........................68

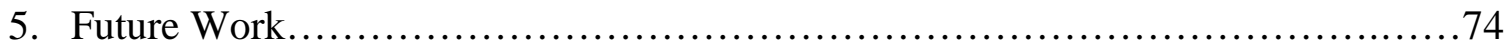

5.1. Energy Storage Simulation............................................ 74

5.1.1. Improved Battery Simulation................................74

5.1.2. Advanced Energy Storage System...........................75

5.2. Improved Cycle Simulation..........................................76

5.3. Emissions Predictions............................................. 76

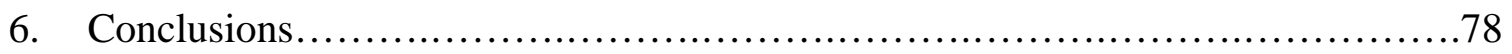

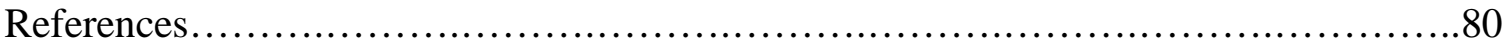


Bibliography. .81

Appendix A: Main Program Module................................................82

Appendix B: Conventional Powertrain Simulation Module..........................85

Appendix C: Series Powertrain Simulation Module.................................87

Appendix D: Parallel Powertrain Simulation Module................................91

Appendix E: Toyota Prius Powertrain Simulation Module............................95

Appendix F: Engine Efficiency Map Look-Up Module.................................100

Appendix G: Transmission Efficiency Replication Module......................... 102

Appendix H: Continuously Variable Transmission Three Dimensional Efficiency Look-up Module.................................................107

Appendix I: Battery Simulation Module........................................ 107 


\section{List of Tables}

Table 1.2.3.1: Toyota Prius Planetary Gear Connections..............................9

Table 1.2.3.2: Comparison of Hybrid Vehicle Design Types...............................10

Table 1.3.1: Table of Existing Electric and Hybrid Electric Vehicles.....................12

Table 3.1.1.1: Table Highlighting Drive Cycle Characteristics.........................19

Table 3.3.1.1: Table of Simulated Engines...............................................

Table 4.1.1: Actual and Simulated Fuel Economy for 1996 Volkswagen Passat..........54

Table 4.1.2: Constant Velocity Fuel Consumption Simulation for 1996 Volkswagen

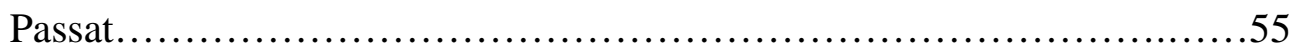

Table 4.1.3: Vehicle Parameter Values for Simulation of 1996 Volkswagen Passat......55

Table 4.1.4: Actual and Simulated Fuel Economy for the Ford P2000..................57

Table 4.1.5: Constant Velocity Fuel Consumption Simulation for Ford P2000...........57

Table 4.1.6: Vehicle Parameter Values for Simulation of Ford P2000.................57

Table 4.1.7: Actual and Simulated Fuel Economy for 1996 Saturn Coupe................58

Table 4.1.8: Vehicle Parameter Values for Simulation of 1996 Saturn Coupe...........58

Table 4.1.9: Actual and Simulated Fuel Economy for 1996 Chevrolet Lumina............59

Table 4.1.10: Vehicle Parameter Values for Simulation of 1996 Chevrolet Lumina......59

Table 4.1.11: Actual and Simulated Fuel Economy for 1994 Mercury Sable..............60

Table 4.1.12: Vehicle Parameter Values for Simulation of 1994 Mercury Sable.........60

Table 4.1.13: Simulated Fuel Economy for the 1994 Mercury Sable AIV ................61

Table 4.2.1: Actual and Simulated Fuel Economy for 1997 WVU FutureCar............62

Table 4.2.2: Actual and Simulated Electrical Efficiency for 1997 WVU FutureCar.....63 
Table 4.2.3: Constant Velocity Fuel Consumption Simulation for 1997 WVU FutureCar

Table 4.2.4: Vehicle Parameter Values for Simulation of 1997 WVU FutureCar.......63

Table 4.3.1: Actual and Simulated Fuel Economy for 1998 WVU FutureCar...........66

Table 4.3.2: Actual and Simulated Fuel Economy for 1998 WVU FutureCar...........66

Table 4.3.3: Vehicle Parameter Values for Simulation of 1998 WVU FutureCar.......67

Table 4.4.1: Actual and Simulated Fuel Economy for the Toyota Prius.................69

Table 4.4.2: Constant Velocity Fuel Consumption Simulation for the Toyota Prius.....69

Table 4.4.3: Vehicle Parameter Values for Simulation of Toyota Prius................69 


\section{List of Figures}

Figure 1.2.1: Power Requirements versus Speed for Typical Driving Conditions.........4

Figure 1.2.2: Acceleration versus Speed for Typical Driving Conditions................5

Figure 1.2.1.1: Power Flow Diagram for a Typical Series HEV ...................... 7

Figure 1.2.2.1: Power Flow Diagram for a Typical Parallel HEV ......................

Figure 1.2.3.1: Power Flow Diagram for the Toyota Prius...........................10

Figure 3.1.1.1: Federal Urban Driving Schedule Speed versus Time Trace..............19

Figure 3.1.1.2: Highway Fuel Economy Test Speed versus Time Trace...............20

Figure 3.1.1.3: US 06 Speed versus Time Trace...............................20

Figure 3.1.1.4: Japanese 10/15 Mode Speed versus Time Trace.......................21

Figure 3.1.2.1: Basic Modular Flowchart.........................................23

Figure 3.1.2.2: CONV Powertrain Flowchart.....................................24

Figure 3.1.2.3: SER and PAR Powertrain Flowchart.................................25

Figure 3.1.2.4: PARSER Powertrain Flowchart....................................26

Figure 3.3.1.1: Thermal Efficiency Contour of 1.6L Spark Ignited Gasoline Engine for a

Given Engine Torque and Speed.................................. 32

Figure 3.3.1.2: Thermal Efficiency Contour of 1.9L Compression Ignition Engine for a

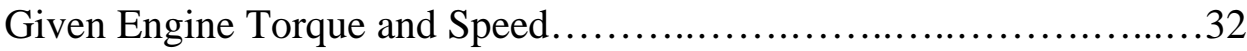

Figure 3.3.1.3: Thermal Efficiency Contour of 1.6L Spark Ignited Natural Gas Engine for a Given Engine Torque and Speed..................................33

Figure 3.3.2.1: Efficiency Contour of Motor and Controller Combination for a Given

Motor Torque and Speed........................................ 34 
Figure 3.3.3.1.1: Manual Transmission Gear Efficiencies...............................36

Figure 3.3.3.1.2: Automatic Transmission Gear Efficiencies versus Input Speed..........36

Figure 3.3.3.1.3: Gear Selection Process................................................. 37

Figure 3.3.3.1.4: Gear Selection with Respect to Engine Operation......................38

Figure 3.3.3.2.1: Three-Dimensional CVT Power Loss Matrix..........................40

Figure 3.3.3.2.2: Surface Plot of CVT Efficiency for 0.6:1 Belt Ratio.....................40

Figure 3.3.3.2.3: CVT Ratio Selection Flowchart....................................41

Figure 3.3.3.3.1: Planetary Gear Set Force Analysis......................................44

Figure 3.3.4.1: Nominal Battery Chemical Voltage as a Function of SoC...............48

Figure 3.3.4.2: Internal Resistance Factor as a Function of SoC ........................48

Figure 3.3.4.3: Battery Pack Equivalent Circuit...................................49

Figure 3.3.4.4: Battery Efficiency versus Power Out of 324V Battery Pack.............49

Figure 3.3.4.5: Current Out of Battery Pack versus Power Out of Pack.................50

Figure 3.3.4.6: Battery Pack Voltage versus Power of Pack.............................50

Figure 3.3.5.1: SoC Correction Procedure.........................................53

Figure 4.1.1: 1996 Volkswagen Passat Engine Operation for the HWFET with Engine

Efficiency Contour................................................56

Figure 4.1.2: Conventional 1996 Chevrolet Lumina Highway Engine Operation with

Engine Efficiency Contour.......................................60

Figure 4.2.1: Net Energy Flow and Engine Operation for 1997 FutureCar on the HWFET

Figure 4.2.2: 1997 WVU FutureCar Engine Operation for the HWFET with Engine Efficiency Contour....................................................... 65 
Figure 4.2.3: 1997 WVU FutureCar Motor Operation for the HWFET with Motor Efficiency Contour.........................................665

Figure 4.3.1: Net Energy Flow for the 1998 FutureCar on the HWFET................67

Figure 4.3.2: Engine Operation of 1998 WVU FutureCar for HWFET with Engine Efficiency Contour.........................................68

Figure 4.4.1: Engine Operation for Toyota Prius on HWFET with Engine Efficiency

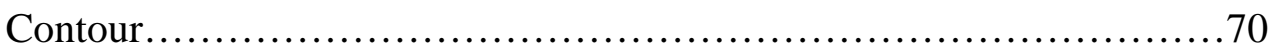

Figure 4.4.2: Component Power Operation for Toyota Prius.......................... 72

Figure 4.4.3: Component Operation for Toyota Prius..............................73 


\section{Introduction}

\subsection{PNGV Goals}

In 1993 President Bill Clinton, Vice President Al Gore, and the CEO's of Chrysler Corporation, Ford Motor Company, and General Motors Corporation announced the Partnership for a New Generation of Vehicles (PNGV). Founded with the intention of developing low pollutant emitting mid-sized passenger cars capable of three times present day fuel economy without sacrifice to consumer acceptability by the year 2004 . This fuel economy goal is based on average fuel efficiency measured on a composite of the Environmental Protection Agency (EPA) city cycle and highway fuel efficiency test (HWFET), of the Chrysler Intrepid, Ford Taurus, and the General Motors Chevrolet Lumina which implies a goal of $80 \mathrm{mpg}$ (of gasoline). Acceptable vehicle performance must meet or exceed that of today's comparable vehicles with little or no increase in purchase or operating costs. The PNGV was also formed to improve significantly national competitiveness in automotive manufacturing and to implement commercially viable innovations from ongoing research in conventional vehicles. [1]

\subsection{Hybridization as an Approach to Meet PNGV Goals}

Ultimately pure electric vehicles will likely meet and exceed PNGV goals of performance and efficiency given significant improvements in battery storage capacity. For now electrical energy storage greatly limits the range achievable by pure electric vehicles. HEVs will bridge the gap from conventional vehicles to pure electric vehicles. HEVs have the capability of greatly improving fuel economy with no sacrifice to range 
since the range of an HEV is limited by the amount of fuel carried. HEVs are typically designed with the following criteria in mind (in order of importance):

1) Fuel Efficiency,

2) Emissions, and

3) Performance, while keeping a regard for cost, complexity and transparency to the driver. Transparency implies that an average driver will not drive the vehicle any differently than he or she would drive the comparable conventional vehicle today. Fuel efficiency is increased by operating the Internal Combustion Engine (ICE) at a much higher efficiency. Since the internal combustion engine in conventional vehicles is the greatest source of inefficiency in the vehicle, any increase in its efficiency can greatly increase the vehicle's total efficiency. Conventional vehicles have engines sized to meet their peak excepted power demand, which means that the rest of the time they are running at a fraction of their potential power output. Hybridization allows the engine to be downsized, because the electric motor can augment the peak power requirements under various driving conditions while the engine works to meet the average power requirements (say, greater than $50 \mathrm{~kW}$ ). This allows the engine to run much closer to its peak power output potential (for more of its operation) which is inherently its most efficient state. Figure 1.2.1 demonstrates power requirements versus speed for normal driving conditions for a vehicle with a mass of $1500 \mathrm{~kg}$, coefficient of drag of 0.3 and a cross-sectional area of 2.0 $\mathrm{m}^{2}$ as reflected by the cycles used for emissions and fuel economy certification namely the FTP, HWFET, and the US06. Notice how few points are at high power requirements. There are several ways to hybridize a vehicle, each with their own advantages and 
disadvantages. Hybridizing also adds the advantage of possibly capturing energy lost to braking by using the motor as a generator to slow the vehicle in the process called regenerative braking. In Figure 1.2.1. all negative power points constitute energy lost to braking in a conventional vehicle, but in an HEV some of this energy can be recaptured and stored for later use. Figure 1.2.2. demonstrates acceleration versus speed for identical vehicle and driving cycles as in Figure 1.2.1. Notice that the maximum acceleration on the FTP is limited. 


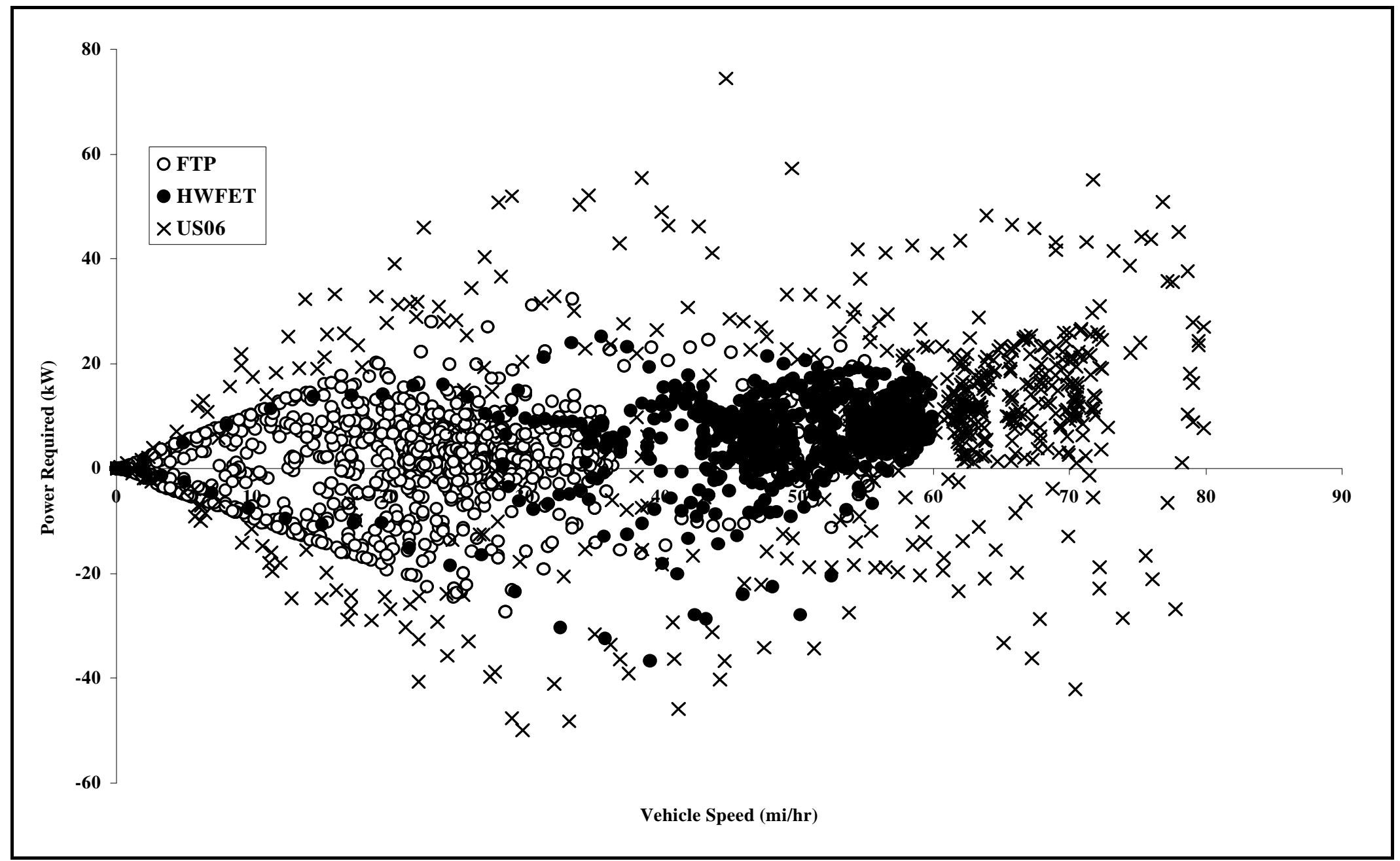

Figure 1.2.1: Power Requirements versus Speed for Typical Driving Conditions (for each second of the driving trace) for a specific vehicle with the following parameters: mass $=2,000 \mathrm{~kg}$; coefficient of aerodynamic drag=0.30; cross-sectional area $=2.05 \mathrm{~m}^{2}$; coefficient of rolling resistance 0.007 


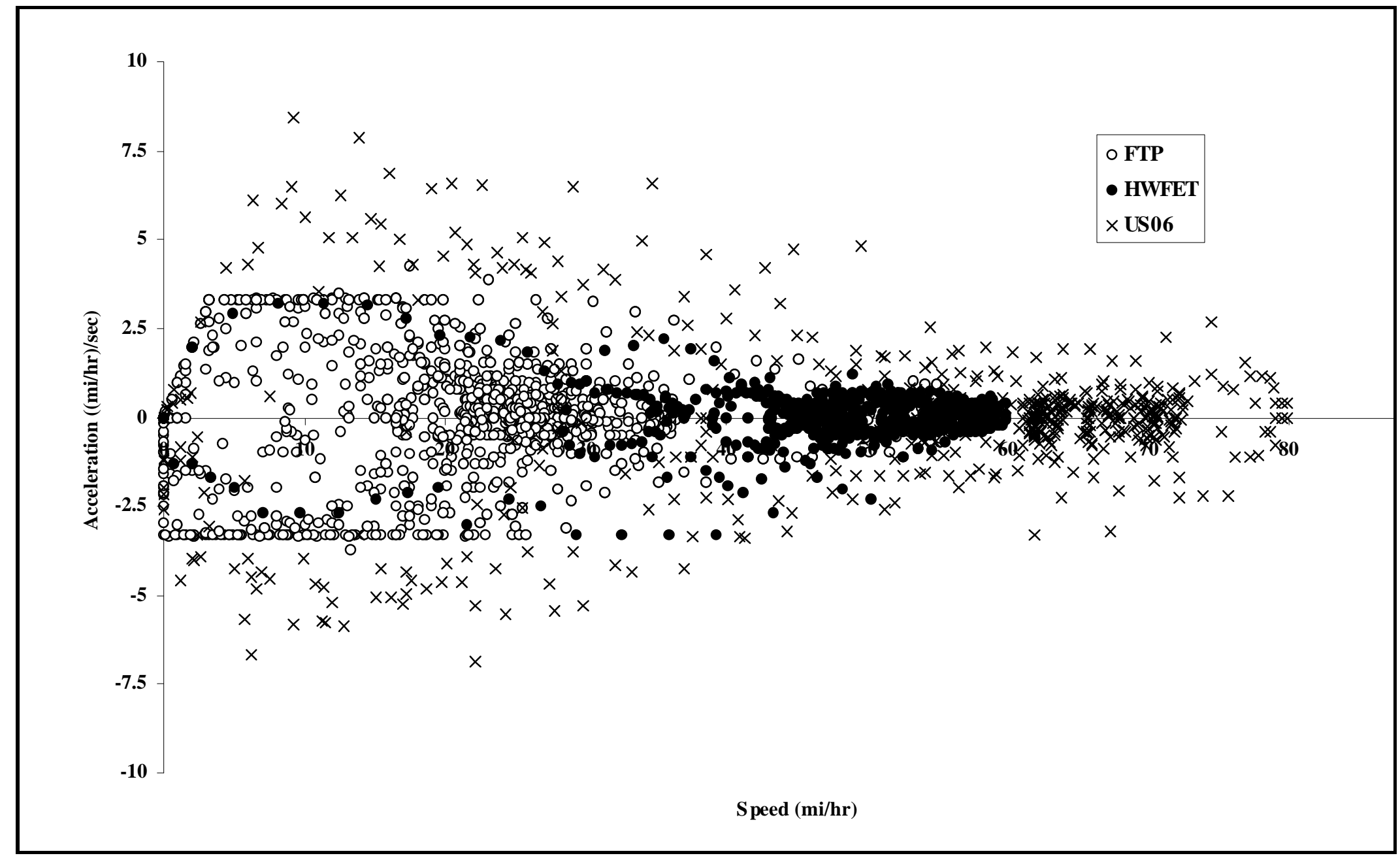

Figure 1.2.2: Acceleration versus Speed for Same Vehicle and Driving Conditions (for each second of the driving trace) 


\subsubsection{The Advantages and Disadvantages of Series HEVs}

Series HEVs have only the motor coupled to the wheels while the ICE is coupled to the alternator. This "de-coupling" of the ICE from the wheels reduces the transients seen by the ICE. The lack of transients is especially helpful from an emissions standpoint allowing optimal fueling and ignition control. (Under heavy acceleration often an engine will fuel heavily to prevent a misfire situation due to an instantaneously high air to fuel ratio.) The drawback to a series hybrid electric vehicle is the associated mechanical to electrical to mechanical energy conversion losses. The energy from the ICE is in mechanical form at the crankshaft and is immediately converted to an electrical form by an alternator undergoing losses associated with an internal resistance of the alternator, and eddy currents within the alternator. This electrical energy then must be converted back to mechanical energy at the motor undergoing further efficiency losses in the motor and its controller. From the motor the mechanical energy is transmitted into the transmission to propel the vehicle. Figure 1.2.1.1. displays the typical power flow for a series hybrid electric vehicle. 


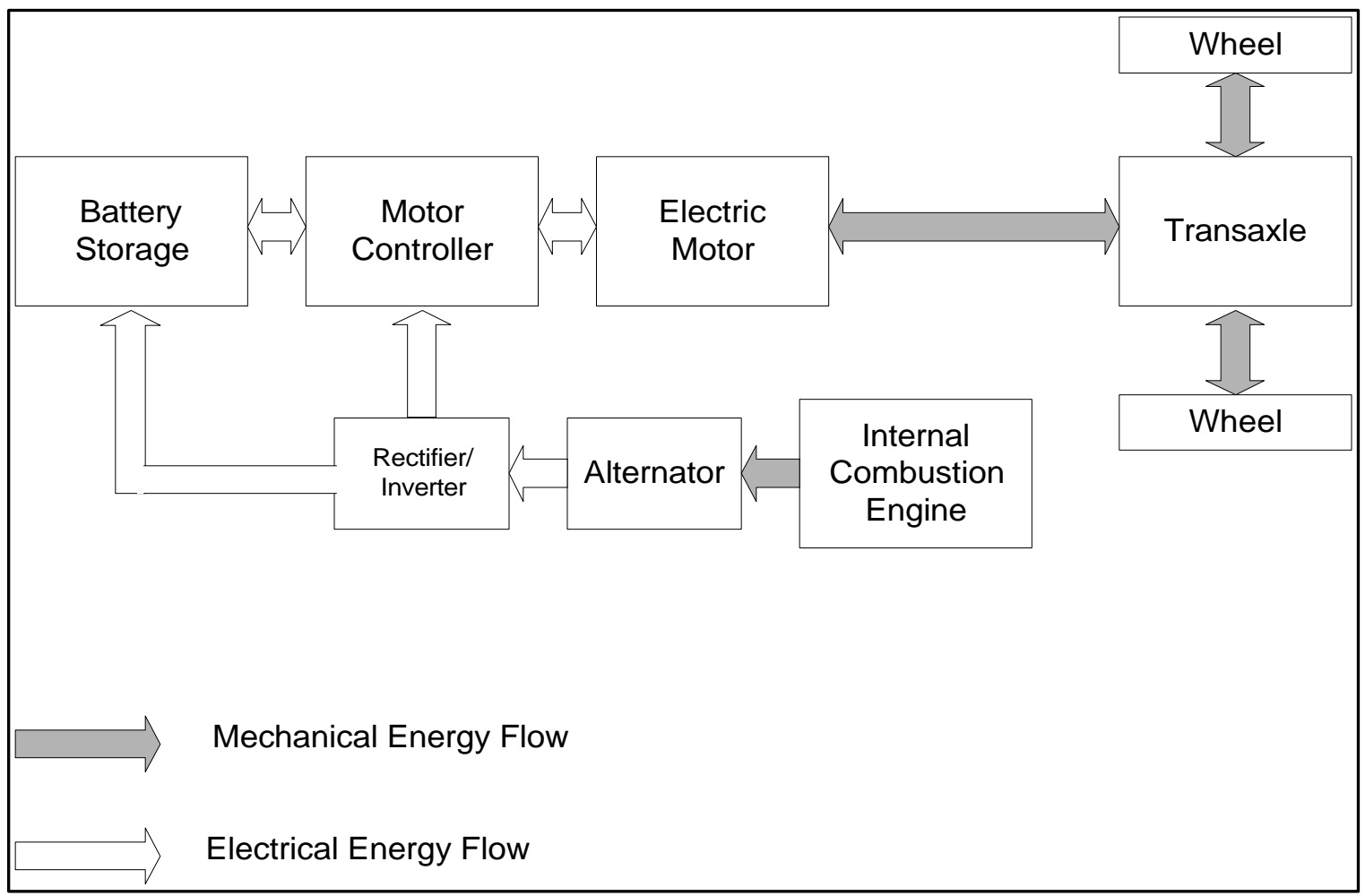

Figure 1.2.1.1: Power Flow Diagram for a Typical Series Hybrid Electric Vehicle

\subsubsection{The Advantages and Disadvantages of Parallel HEVs}

Parallel Hybrid Electric Vehicles are defined as having both the engine and an electric motor coupled directly to the wheels through some type of transmission. This direct coupling implies that the ICE does undergo significant transients in speed as the vehicle speeds up and slows down. This is detrimental to the vehicle's emissions for the reasons described in the previous section. The motor can be used to level the load seen by the ICE allowing it to operate in a more efficient state. Typically ICEs operate more efficiently at higher loads (at moderate speeds). When a low road load is required by the vehicle, instead of the engine operating inefficiently at this low load point as in a conventional vehicle, the engine can either be shut off while the motor drives the vehicle, or the engine load can be increased by the motor as it acts as a generator, in turn storing 
extra energy in the batteries for later use ( in a charge while driving mode). The greatest advantage of parallel HEVs (over series HEVs with the same size components) is in their performance. Parallel HEVs have the potential for using both their electric motor and ICE as power sources, simultaneously propelling the vehicle. Figure 1.2.2.1. demonstrates the power flow for a typical parallel HEV.

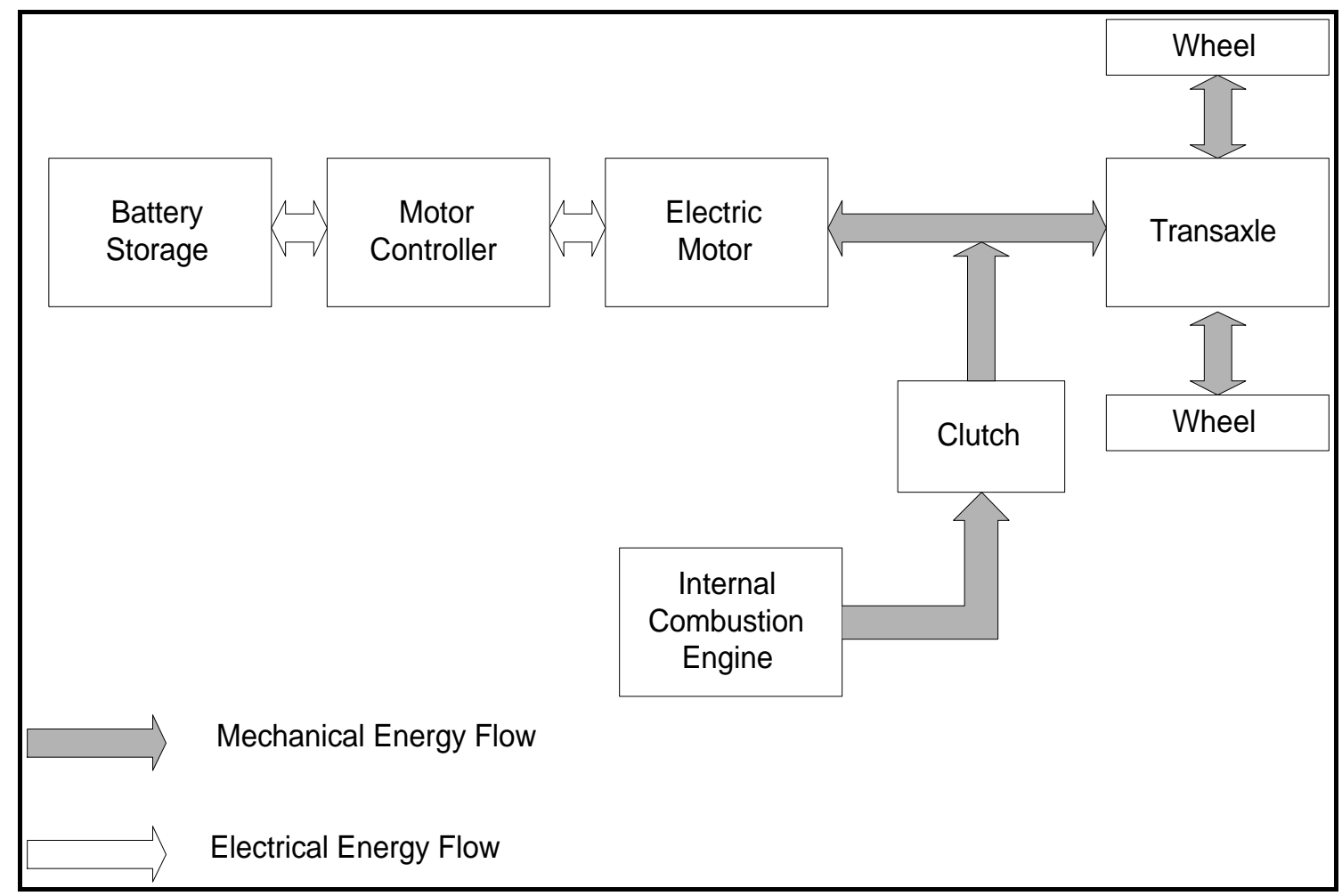

Figure 1.2.2.1: Power Flow Diagram for Typical Parallel HEV

\subsubsection{The Potentials of Combination Parallel/Series and Multi-mode HEVs}

It is possible to build a vehicle that can be operated either as a series or as a parallel or even some combination of both for different loading conditions. This would utilize the advantages of both drive-train types. There are several ways to create a drivetrain that mixes the characteristics of both a series HEV and a parallel HEV. 
One possible design is to couple all of the components with a combination of clutches that can be engaged in such a way that in one instance the powertrain is operating as a series HEV and at another instance operated as a parallel HEV. Depending on driving conditions the most advantageous individual mode could be selected. This would, however, involve even more components than either a series or a parallel further increasing the size and complexity of the powertrain.

Another possible design is the one which is employed by the recently developed Toyota Prius. The Toyota Prius couples an ICE, alternator, and motor via a planetary gear set. With this setup there are two degrees of freedom, with the alternator being used to control the extra degree of freedom. Changes in the alternator operation affect the engine operation yielding total control over the engine at all driving conditions (within reason). In this setup the vehicle does not act as a series or a parallel, but somewhere between a series and a parallel, once again taking advantage of both configurations. Figure 1.2.3.1. demonstrates the coupling employed in the Toyota Prius, with this coupling tabulated in Table 1.2.3.1. Table 1.2.3.2. compares all efficient types of hybrids to conventional vehicles in terms of fuel economy, emissions potential and ease of control, in a somewhat objective assessment of each type's advantages.

\begin{tabular}{|l|l|}
\hline Component & Input \\
\hline Generator & Sun Gear \\
\hline ICE & Planetary Carrier \\
\hline Motor and Differential Output & Ring Gear \\
\hline
\end{tabular}

Table 1.2.3.1: Toyota Prius Planetary Gear Connections 


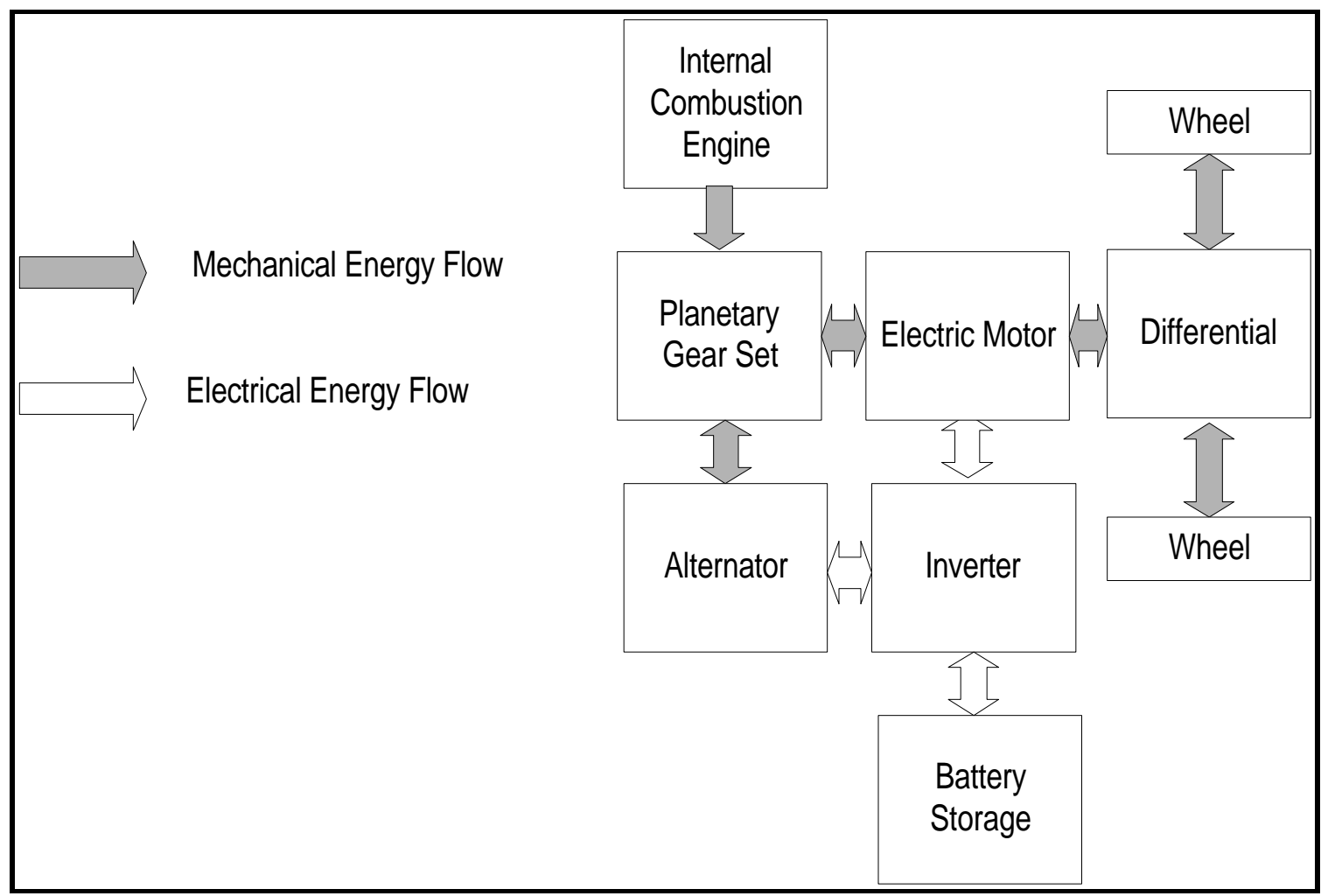

Figure 1.2.3.1: Power Flow Diagram for the Toyota Prius

\begin{tabular}{|l|l|l|l|}
\hline & Series & Parallel & Multimode \\
\hline $\begin{array}{l}\text { Highway Fuel } \\
\text { Efficiency }\end{array}$ & + & ++ & ++ \\
\hline $\begin{array}{l}\text { City Fuel } \\
\text { Efficiency }\end{array}$ & ++ & + & ++ \\
\hline $\begin{array}{l}\text { Over the Road } \\
\text { Fuel Efficiency }\end{array}$ & + & ++ & ++ \\
\hline $\begin{array}{l}\text { Low Emissions } \\
\text { Potential }\end{array}$ & ++ & + & ++ \\
\hline $\begin{array}{l}\text { Cost } \\
\text { Complexity }\end{array}$ & -- & - & -- \\
\hline Ease of Control & - & - & -- \\
\hline
\end{tabular}

Table 1.2.3.2: Comparison of Hybrid Vehicle Design Types

++ much better than similar conventional vehicle

+ better than conventional vehicle

- worse conventional vehicle

-- much worse than conventional vehicle 


\subsection{The Objectives of this Modular HEV Simulation Program}

As powertrain configurations and their design become more complex, there is an increased need to simulate their efficiency accurately to allow the evaluation of many powertrains before any are built. All near term HEVs have been designed using somewhat similar components. If these components can all be simulated individually as modules, then these modules can be used in a main program to simulate a particular vehicle powertrain configuration. When a complex powertrain configuration is considered it is far less difficult to rearrange the use of the modules than to write a completely new program. This allows quick analysis of the potentials of almost any powertrain configuration. This study details the development of such a program and validates its accuracy. 


\begin{tabular}{|l|l|l|l|}
\hline Vehicle Name & Manufacture & Type & Comments \\
\hline EV1 & General Motors & EV & $\begin{array}{l}\text { 90 mile range, in } \\
\text { production }\end{array}$ \\
\hline EV1 - Hybrid & General Motors & series HEV & gas turbine \\
\hline EV1 - Hybrid & General Motors & parallel HEV & $\begin{array}{l}\text { diesel, } \\
80 \mathrm{mpg} \text { highway }\end{array}$ \\
\hline EV1 - Hybrid & General Motors & fuel cell HEV & $\begin{array}{l}80 \mathrm{mpg} \\
\text { near zero } \\
\text { emissions }\end{array}$ \\
\hline Intrepid ESX & Chrysler & series HEV & diesel \\
\hline Intrepid ESX2 & Chrysler & parallel HEV & diesel \\
\hline Prius & Toyota & combination HEV & $\begin{array}{l}\text { advanced gasoline } \\
\text { ICE, in production }\end{array}$ \\
\hline J-mover & Honda & parallel HEV & $\begin{array}{l}\text { direct injection } \\
\text { gasoline engine } \\
\text { through a CVT, } \\
\text { ultracapacitor } \\
\text { energy storage }\end{array}$ \\
\hline E-com & Toyota & EV & $\begin{array}{l}\text { 100 km range on } \\
\text { Japanese 10/15 } \\
\text { mode cycle }\end{array}$ \\
\hline Necar 3 & Daimler Benz & fuel cell HEV & methanol reformer \\
\hline Duo & Audi & parallel HEV & in production \\
\hline
\end{tabular}

Table 1.3.1: Table of Existing Electric and Hybrid Electric Vehicles (as of August 1998) 


\section{Literature Review}

\subsection{HEV Simulation Programs}

There are several existing HEV simulation programs that have been reported in the literature. A brief review of the more important ones follows.

\section{Simplev 3.1}

Simplev 3.1 was developed by Idaho National Engineering Laboratory to model HEVs and electric vehicles. This program has a menu based interface allowing selection of various motors, alternators, engines, batteries, transmissions. It simulates the vehicle much like the program developed in this study. This program is only capable of simulating series HEVs and does not have the capability to predict parallel, and multimode HEVs. This program does not have the ability to predict emissions. [1]

\section{CarSim 2.5.4.}

CarSim 2.5.4. was developed by AeroVironment, Inc. and is very similar to Simplev 3.1. CarSim can only model series HEVs and electric vehicles, and is not capable of predicting emissions. [2]

\section{HVEC}

Lawrence Livermore National Laboratory has developed Hybrid Vehicle Evaluation Code (HVEC) to simulate series HEVs and electric vehicles. This program has the advantage of choosing a fuel cell as an energy conversion device, and a flywheel as a energy storage device if so desired. Apart from these components HVEC has the same basic capabilities as Simplev and Carsim. [2] 


\section{CSM HEV}

CSM HEV was developed by the Colorado School of Mines. This program was developed using MATLAB/Simulink, which allows easy configuration changes much like the program developed in this study. This program also has the capability to do parametric sensitivity studies through the interface. This program though is still under development and is not ready for validation against actual test data. [2]

\section{V-Elph}

V-Elph is also a MATLAB/Simulink based simulation program that was developed by Texas A\&M University. V-Elph is much like CSM HEV except with an improved user interface. The block diagram-based simulation makes it easy for the user to conceptualize the simulation process. [2]

\section{ADVISOR}

Advanced Vehicle Simulator (ADVISOR) is the most widely used and probably the most refined simulation program available today. This program was developed by the National Renewable Energy Laboratory and is programmed with the use of MATLAB/SIMULINK with a visual user interface for easy manipulation of components. ADVISOR is the primary design tool used by the PNGV. Results detained using ADVISOR have not yet been fully validated and NREL claims the program to be still in its developmental stage. [2]

\section{Feasible Design Strategies for Near-Term Hybrid Electric Vehicles}

This thesis by Wayne Taylor includes a spreadsheet-based simulation of many vehicle types. This program was capable of simulating conventional vehicles, electric vehicles and hybrid electric vehicles. The spreadsheet simulation provided reasonable 
accuracy and was written to perform parametric studies. This thesis includes an excellent overview of HEV development, and detailed parametric studies to aid in HEV design. [1]

\subsection{Component Modeling}

\section{Engine Modeling}

Most ICE models are cycle-based mathematical models, calculating in-cylinder temperatures and pressures based on crankshaft angular position and fuel burn rates. These models quickly become very complex with many adjustable parameters that must be fitted using empirical data, although with proper calibration they can yield accurate results. [3] This type of model was not implemented in this simulation because actual engine efficiency test data was available which offered higher accuracy while maintaining simplicity.

\section{Transmission Efficiency Modeling}

Several transmission efficiency models were found in this study. Manual transmissions were simulated only with gearbox efficiency losses. Several parametric studies were evaluated for gearbox inclination angle and lubricant temperature. [4] Automatic transmissions are often simulated with several separate components. The losses in the hydraulic oil pump, torque converter, and gearbox are all simulated separately in this study. This yielded an accurate and comprehensive model of a four speed automatic transmission, which was validated for a Hyundai A4BF1 transmission. [5] 


\section{Motor Efficiency Modeling}

Most literature surveyed calculated the theoretical losses in the actual motor (both the stator and rotor). Simple switching processes were described similar to the process in inverters of advanced brushless DC motors, but no losses were calculated for the switching process.

\section{Battery Efficiency Modeling}

Most literature reviewed demonstrates battery discharge characteristics at constant current discharge, which is nearly irrelevant when simulating batteries for the highly cyclic loading typical of hybrid applications. In a similar electric vehicle simulation program, batteries were simulated as two basic electrical components, one a chemical voltage source, the other an internal resistance. The internal resistance was held constant. The battery chemical voltage was a function of State of Charge (SoC). The efficiency of the pack was simulated from a power standpoint. For a given power requirement and SoC the electric circuit was solved resulting in current and voltage where efficiency was then calculated. [6] Work done at Texas A\&M University to develop battery modeling for the ELPH 2.0 includes a simulation of the effects of current rate of change on the hysteresis voltage characteristics. 


\section{Vehicle Simulation}

\subsection{Approach}

In any simulation there are multiple approaches that can achieve different results. The present simulation, being modular, can easily be rearranged thus giving a completely different result. All simulations in this study were performed with the intention of simulating vehicle efficiency under typical driving conditions. Also when creating a simulation it is important to set the level of detail desired in the beginning, on a global and local scale. It is easy to focus too heavily on a very specific aspect of the simulation while neglecting to make it general enough for comprehensiveness. Various components have different levels of importance depending on their influence on the results in the simulation. As an example, for components of least efficiency, any small change in that component's efficiency, greatly influences the vehicle's overall efficiency. In the case of most vehicles the largest loss, or the least efficient component, is the energy conversion device (most commonly an ICE). In this simulation an ICE is the only fuel-energy conversion device simulated. Even though hybridizing generally raises the efficiency of the ICE, it still remains the source of most energy losses. This implies that it is most important to reproduce the efficiency of the ICE accurately for both conventional vehicles and HEVs. In HEVs considerable energy is also lost in the energy storage device. In this study the only energy storage device simulated is a pack of lead acid batteries. The losses in the batteries are due to hysteresis losses caused by the internal resistance of the batteries. For this reason an accurate simulation of the batteries is also needed. 


\subsubsection{Inputs and Outputs}

The focus on efficiency under normal driving conditions led the design of this simulation program to use an input of transient vehicle speeds versus time, which the vehicle must follow. This trace of speed versus time is intended to reflect normal driving conditions. Two of the actual traces used are the same used by the EPA to test vehicles sold in the United States for emissions and efficiency validation and publication. The Federal Urban Driving Schedule (FUDS) was used to represent the city driving efficiency of the vehicles simulated. This trace of speed versus time which can be seen in Figure 3.1.1.1. is thought to represent typical city driving conditions. Notice the high transients with multiple stops and a low average speed. The HWFET represents typical vehicle highway driving. This trace of speed versus time which can be seen in Figure 3.1.1.2. contains fewer transients and a higher average speed. The US06 shown in Figure 3.1.1.3. is a newer driving cycle (compared to the HWFET and the FUDS which where both developed in the 1970's) thought to better reflect the driving style of today's drivers. The accelerations and top speeds are significantly greater exercising the powertrain to its limits. The Japanese 10/15 Mode driving cycle is show in Figure 3.1.1.4. is used in the program to compare vehicles only tested in Japan by this test. As the vehicles follow these traces the behavior of powertrain components are simulated. The total distance is calculated and the total energy used is calculated to find the vehicle's overall efficiency. Detailed data is stored for efficiencies of various components of key interest. These components are generally the components of least efficiency or components with high total energy loss, like the engine, batteries, motor, and transmission. 


\begin{tabular}{|l|l|l|l|l|}
\hline & FTP & HWFET & US06 & $\begin{array}{l}\text { Japanese } \\
\mathbf{1 0 / 1 5} \text { Mode }\end{array}$ \\
\hline $\begin{array}{l}\text { Idling Time } \\
(\%)\end{array}$ & 15.4 & 0.390 & 5.49 & 17.3 \\
\hline $\begin{array}{l}\text { Accelerating Time } \\
(\%)\end{array}$ & 38.2 & 32.2 & 39.4 & 11.7 \\
\hline $\begin{array}{l}\text { Decelerating Time } \\
(\%)\end{array}$ & 31.9 & 25.3 & 36.9 & 9.80 \\
\hline $\begin{array}{l}\text { Cruising Time } \\
(\%)\end{array}$ & 14.5 & 42.0 & 18.1 & 61.1 \\
\hline $\begin{array}{l}\text { Average Speed } \\
(\mathbf{m} / \mathbf{s})\end{array}$ & 8.98 & 21.6 & 21.3 & 11.89 \\
\hline $\begin{array}{l}\text { Max. Acceleration } \\
\left(\mathbf{m} / \mathbf{s}^{\mathbf{2}}\right)\end{array}$ & 1.71 & 1.48 & 3.50 & 1.80 \\
\hline $\begin{array}{l}\text { Max. Deceleration } \\
\left(\mathbf{m} / \mathbf{s}^{\mathbf{2}}\right)\end{array}$ & 1.60 & 1.53 & 2.94 & 1.80 \\
\hline $\begin{array}{l}\text { Max. Speed } \\
(\mathbf{m} / \mathbf{s})\end{array}$ & 25.3 & 26.8 & 35.7 & 19.4 \\
\hline
\end{tabular}

Table 3.1.1.1: Table Highlighting Drive Cycle Test Characteristics.

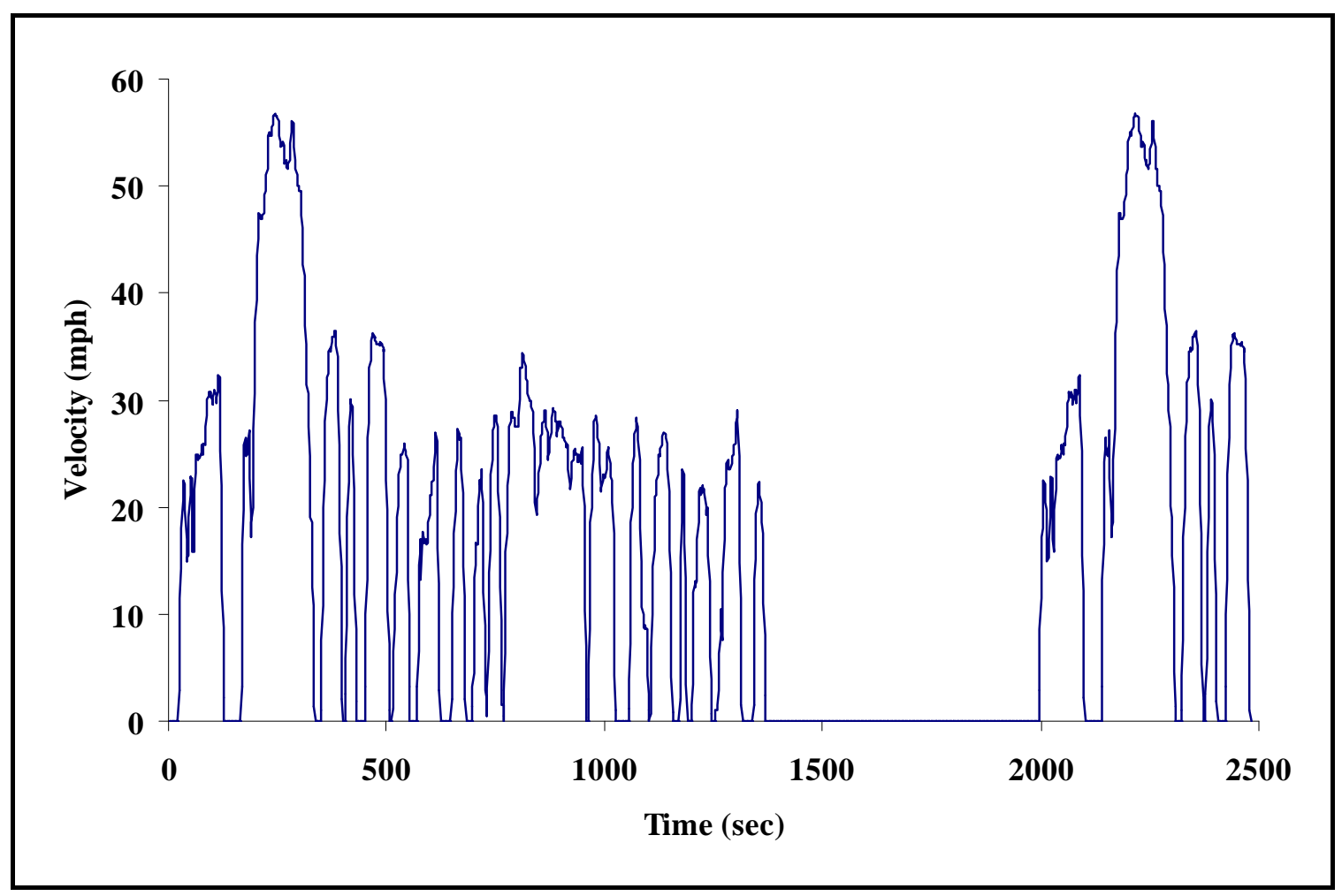

Figure 3.1.1.1: Federal Urban Driving Schedule (FUDS) Speed versus Time Trace 


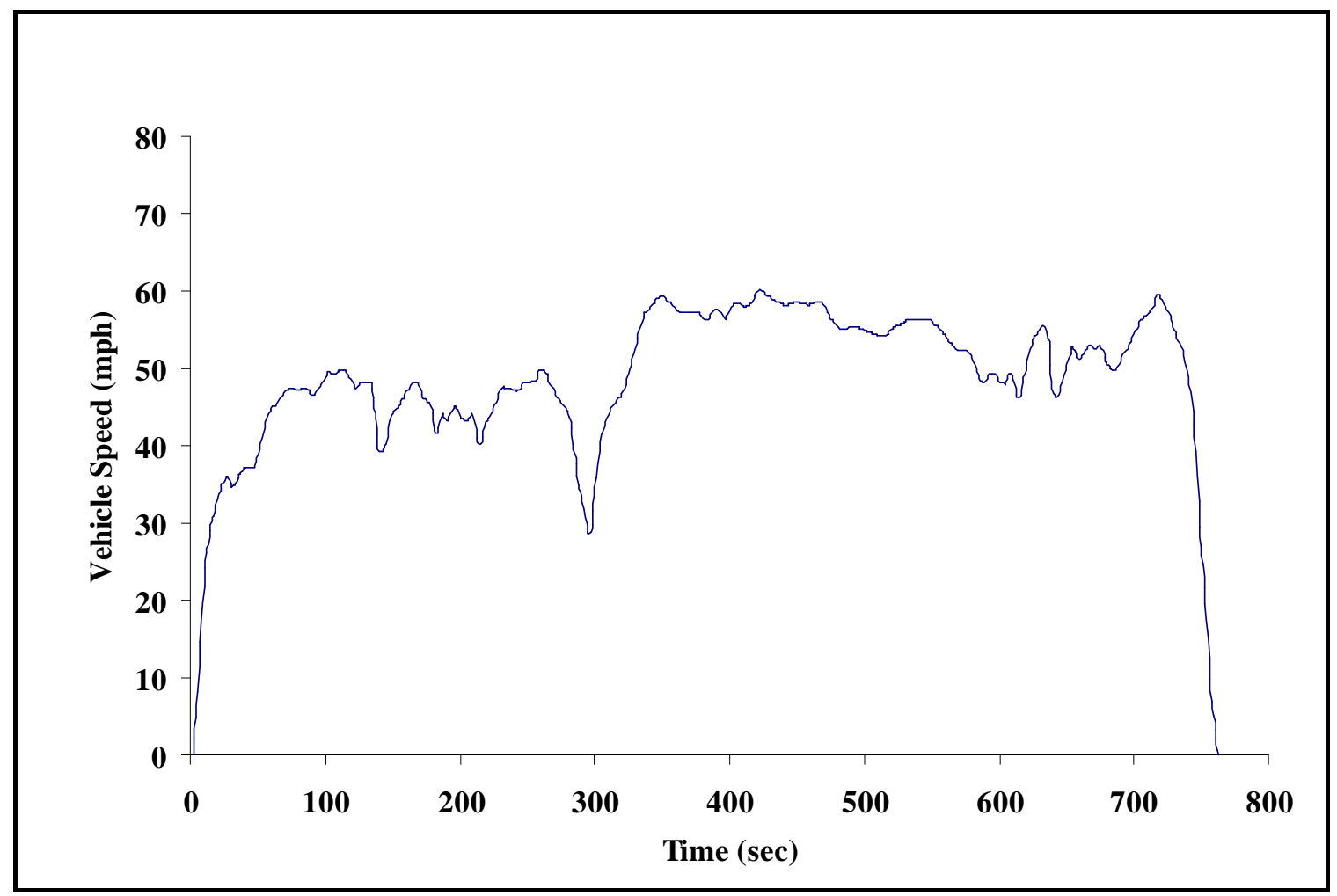

Figure 3.1.1.2: Highway Fuel Economy Test (HWFET) Speed versus Time Trace

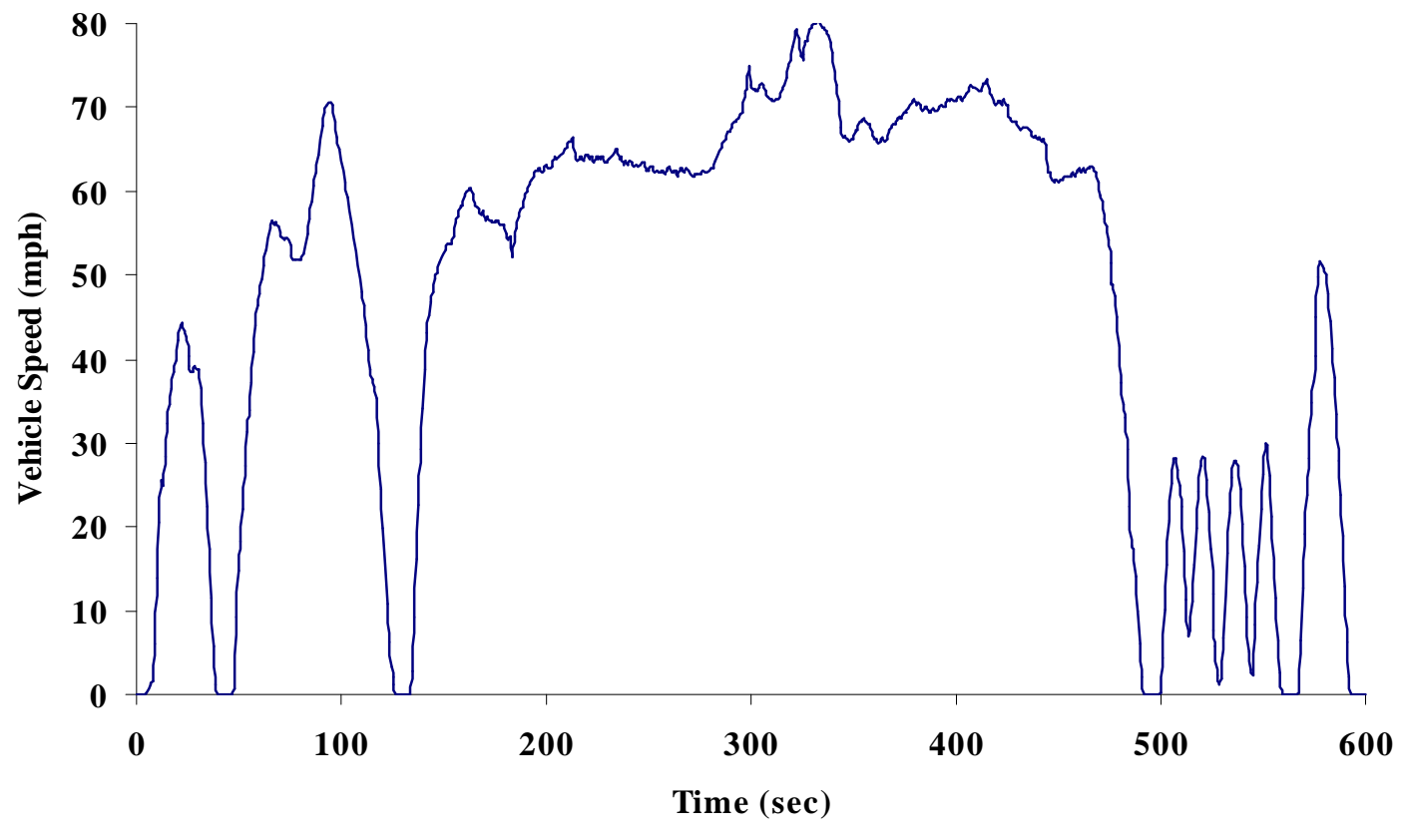

Figure 3.1.1.3: US 06 Speed versus Time Trace 


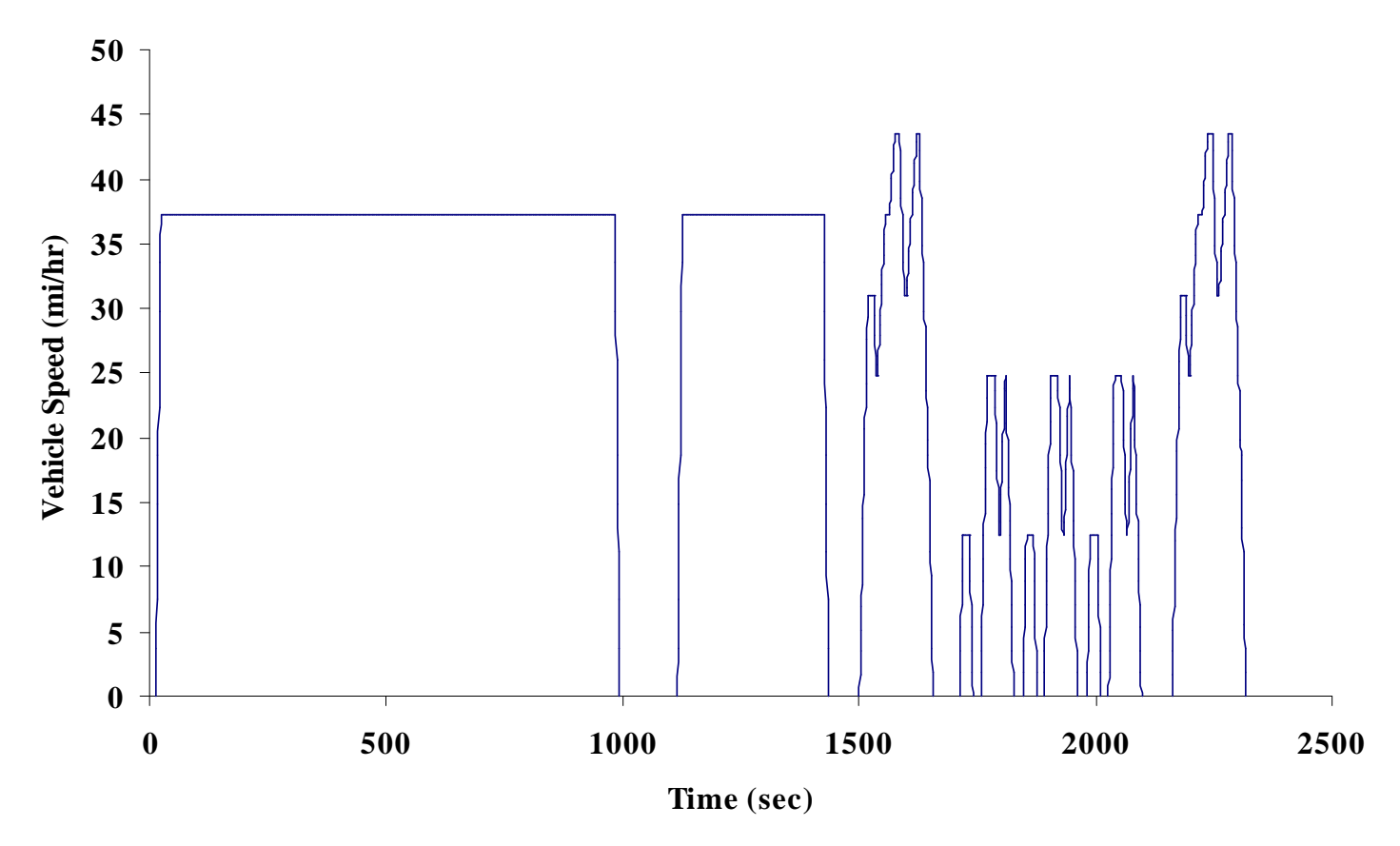

Figure 3.1.1.4: Japanese 10/15 Mode Speed versus Time Trace

\subsubsection{Brief Description of the Modular Simulation}

The main program, called CAR, provides a user interface where one can change basic vehicle and powertrain specifications. Some of these specifications are vehicle mass, coefficient of aerodynamic drag, and the cross-sectional area of the vehicle. CAR also simulates the basic vehicle dynamics and calls the appropriate powertrain to simulate. After the particular powertrain has been simulated, CAR calls a display module to graphically display the results, and stores these results in a file. Figure 3.1.2.1. contains a basic flowchart of the module CAR.

There are four various powertrain modules that can be selected. CONV simulates a conventional powertrain, engine and transmission only; SER simulates a series powertrain; PAR simulates a parallel powertrain; and PARSER simulates a combination 
series/parallel powertrain much like the Toyota Prius. Flowcharts of these powertrain configurations can be seen in Figures 3.1.2.2. through 3.1.2.4. Notice that the parallel and series flowcharts appear identical. The only difference between the two is in the calculations that will be detailed later. The accessory load added is constant at 500 watts. The braking compensation basically handles negative power requirements by use of conventional brakes, regenerative braking or a combination of both. A cold start penalty decreases the engine's efficiency at cold operating temperatures. Idle losses are compensated for to improve accuracy especially for driving cycles that have a large percentage of idle time.

Within the powertrain modules there are smaller component modules. The transmission module acts as a function using transmission type, output torque requirements and a ratio selection history to return an updated ratio selection and instantaneous power loss in the transmission. The engine module acts as a function using engine torque, engine speed and the engine efficiency table to return instantaneous efficiency. This same module is also used to calculate motor efficiency in much the same way. Simply replacing the engine efficiency map with the motor efficiency map allows the EngLU module to be used to define motor efficiency. 


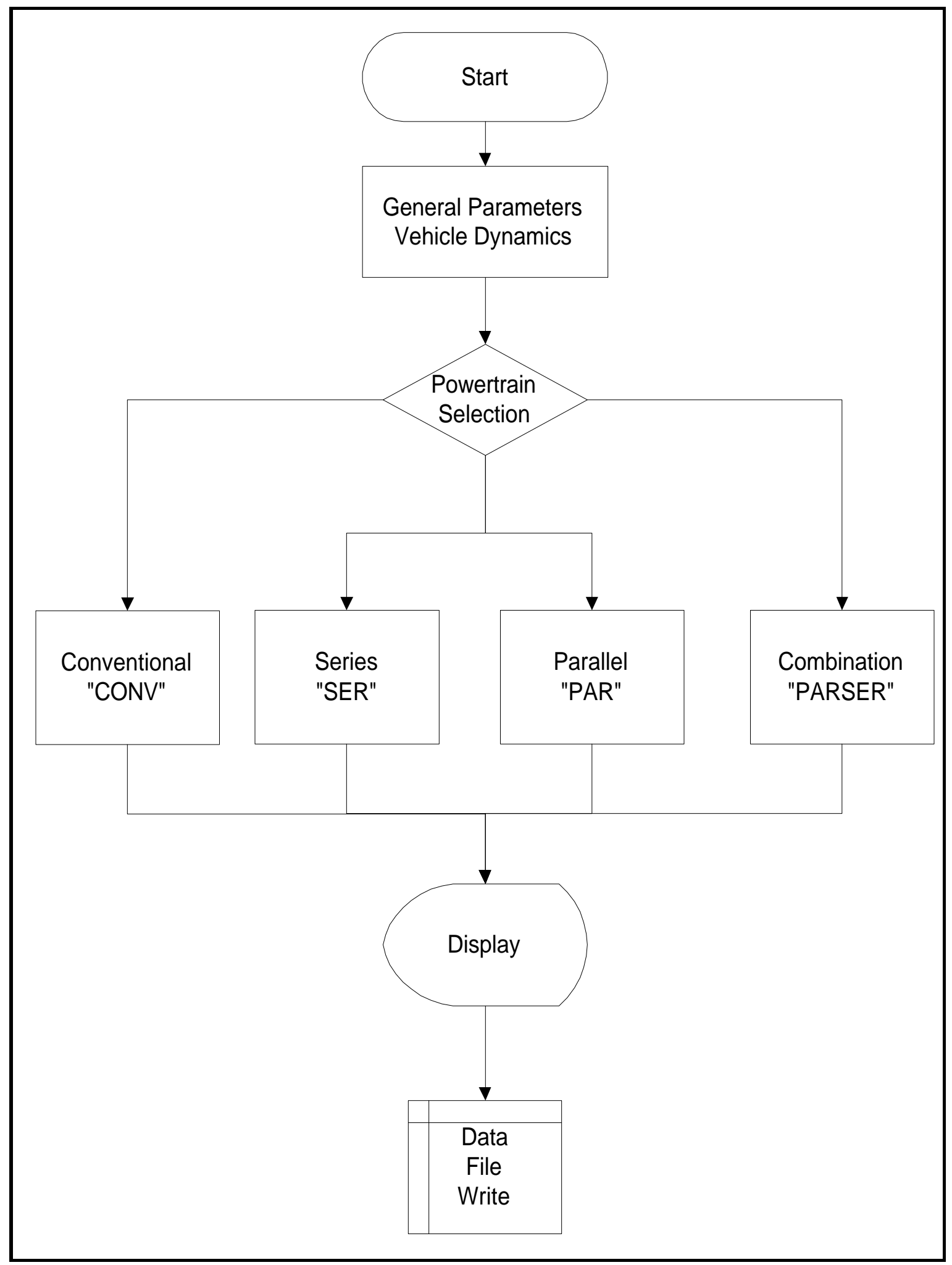

Figure 3.1.2.1: Basic Module Flowchart 


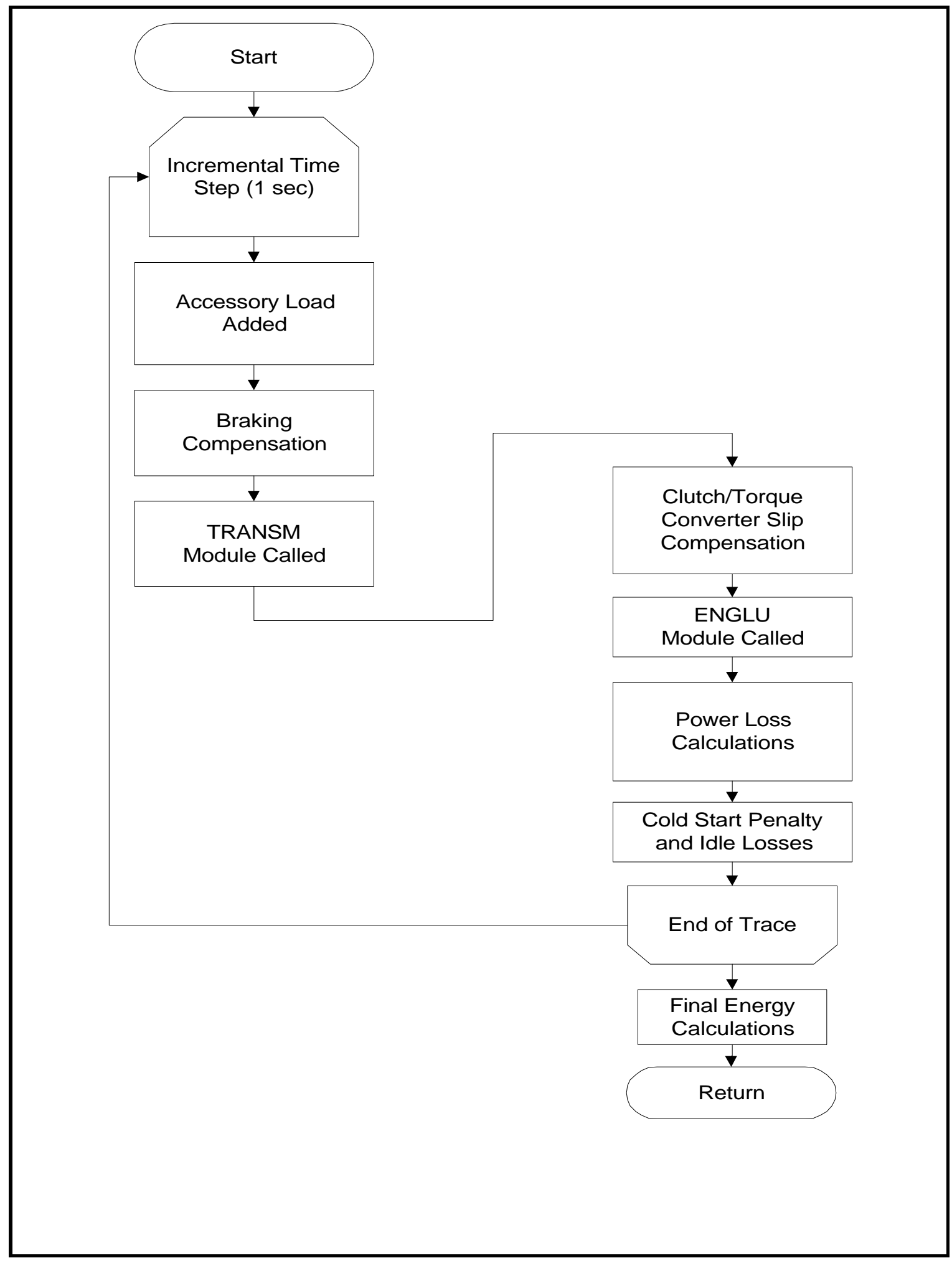

Figure 3.1.2.2: CONV Powertrain Flowchart 


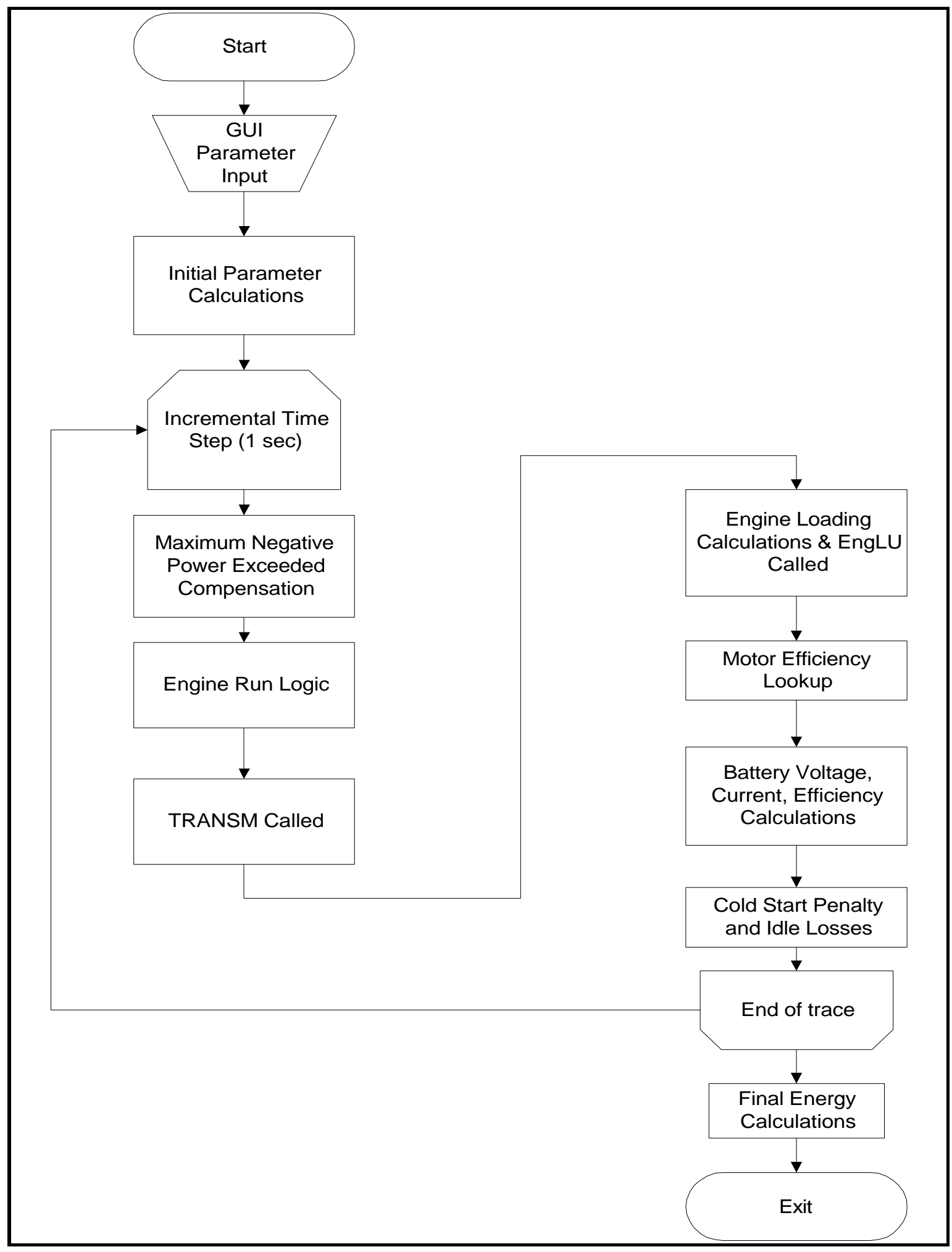

Figure 3.1.2.3: SER and PAR Powertrain Flowchart 


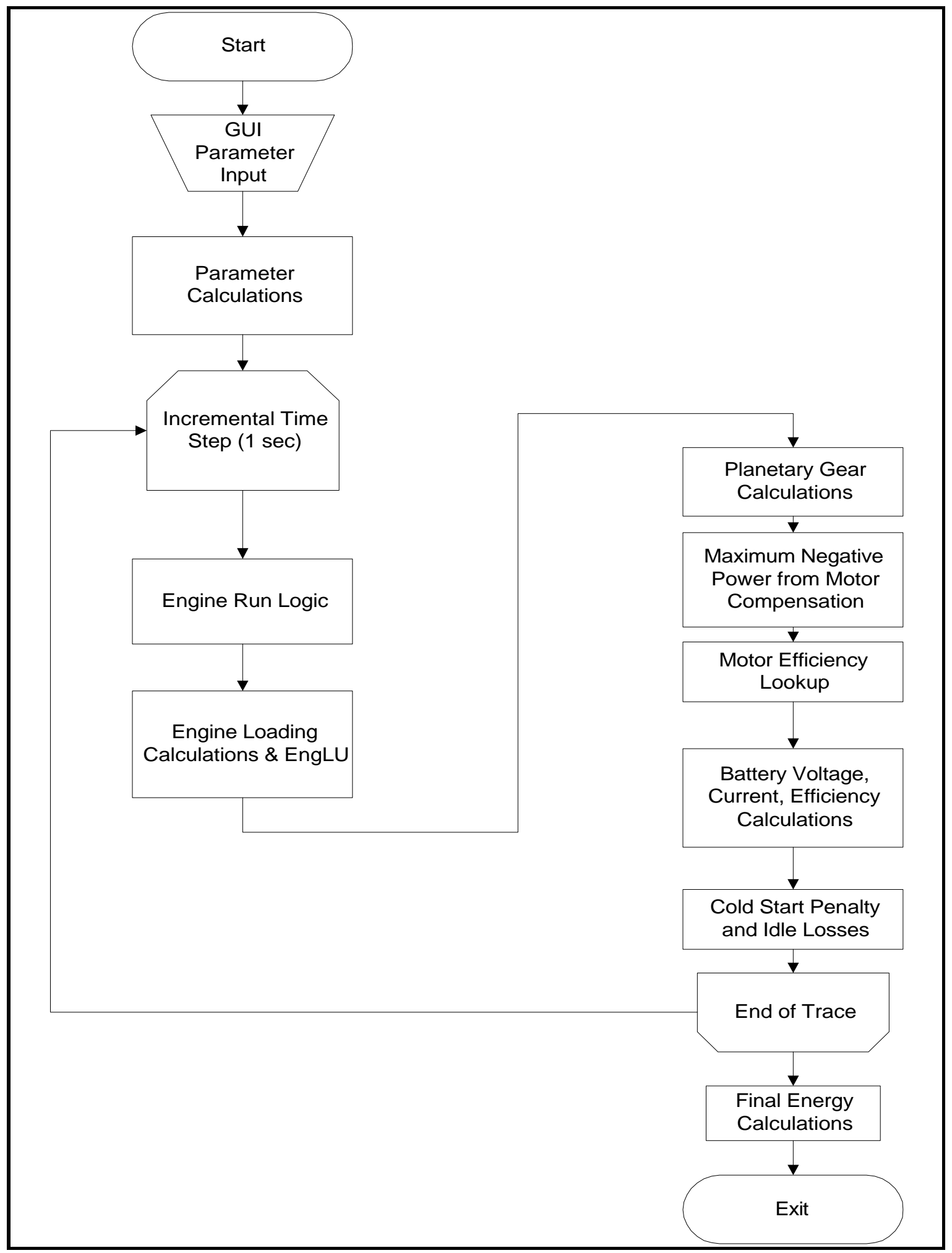

Figure 3.1.2.4: PARSER Powertrain Flowchart 


\subsection{Vehicle Dynamics Derivation}

All vehicles simulated in this study share the same basic dynamic equations resulting in a certain power required at the tires (or half shafts to be more specific), regardless of what powertrain is simulated. This simulated power requirement assumes that there are no other losses than those mentioned. For one this simulation assumes zero road grade. The derivation of this power starts with the basic equation of motion derived from Newton's third law, which states that the summation of all forces acting on a body is equal to the body's mass multiplied by the acceleration of the body.

$$
\sum F=m \cdot a
$$

where

$$
\begin{aligned}
& \mathrm{F}=\text { force acting on body } \\
& \mathrm{m}=\text { mass of body } \\
& \mathrm{a}=\text { acceleration of body }
\end{aligned}
$$

Force is measured in newtons $(\mathrm{N})$, the mass is measured in kilograms $(\mathrm{kg})$, and the acceleration is in meters per second squared $\left(\mathrm{m} / \mathrm{s}^{2}\right)$, as per Systems International (SI).

Acceleration is defined as the derivative of velocity with respect to time.

$$
a=\frac{d v}{d t}
$$


Substituting and multiplying both sides by the instantaneous velocity, $v$, to get the instantaneous power required to propel the body at that velocity and acceleration.

$v \cdot m \cdot \frac{d v}{d t}=v \cdot \sum F=P_{a}$

where $\quad \mathrm{P}_{\mathrm{a}}=$ power required to overcome inertia of the vehicle.

The total power required by the powertrain, $\mathrm{P}_{\mathrm{t}}$, consists of the sum of the inertial power, power to overcome aerodynamic drag, $\mathrm{P}_{\mathrm{ad}}$, and power to overcome the rolling resistance of the tires, $\mathrm{P}_{\mathrm{rr}}$.

$$
\begin{aligned}
& \boldsymbol{P}_{a d}=\frac{1}{2} \cdot C_{d} \cdot A_{x} \cdot \rho \cdot v^{3} \\
& \boldsymbol{P}_{r r}=\mu \cdot \boldsymbol{m} \cdot g \cdot v
\end{aligned}
$$

where

$$
\begin{array}{ll}
C_{d}=\text { coefficient of drag for the vehicle. } & \\
A_{x}=\text { cross sectional area of vehicle. } & \left(\mathrm{m}^{2}\right) \\
\rho=\text { density of air. } & \left(\mathrm{kg} / \mathrm{m}^{3}\right) \\
\mu=\text { coefficient of rolling resistance } & \\
g & =\text { acceleration of gravity } \\
\end{array}
$$

After substitution, the total power required by the powertrain is given by

$$
P_{t}=\left(v \cdot m \cdot \frac{d v}{d t}\right)+\left(\frac{1}{2} \cdot C_{d} \cdot A_{x} \cdot \rho \cdot v^{3}\right)+(\mu \cdot m \cdot g \cdot v)
$$




\subsection{Component Modeling}

\subsubsection{Engine Efficiency Replication}

When the engine is operated, its efficiency is found using a look-up table. Two tables were created for all simulations, one table representing the efficiency of a typical spark-ignited 1.6 liter twin overhead cam four cylinder gasoline engine, and the other table representing the efficiency of a 1.9 liter compression ignition direct injection turbocharged four cylinder diesel engine. Figure 3.3.1.1. shows a plot of the efficiency of the spark ignited engine, and Figure 3.3.1.2. the efficiency of the compression ignition engine. Neither engine has exhaust gas recirculation. Corrections to the tables were made for engines of different displacements and characteristics. Displacement was corrected through first changing the table from represented efficiency as a function of torque and engine speed to one that represents engine efficiency as a function of brake mean effective pressure and engine speed.

$$
\text { bmep }=\frac{T I C_{1}}{\operatorname{Disp}_{1}}
$$

where

$$
\begin{aligned}
& \text { Disp }=\text { displacement of engine } \\
& \text { TIC }=\text { torque of engine }
\end{aligned}
$$

Now the new,modified engine displacement is used to calculate and to once again represent engine efficiency as a function of torque and engine speed. [7]

$\boldsymbol{T I C}_{2}=$ bmep $\cdot$ Disp $_{2}$ 
where

$$
\begin{aligned}
& \text { Disp }_{1}=\text { displacement of engine in stored data } \\
& \text { Disp } \\
& \mathrm{TIC}_{1}=\text { displacement of engine to be simulated } \\
& \mathrm{TIC}_{2}=\text { torque of engine to be simulated }
\end{aligned}
$$

This process makes the assumption that different displacement engines when scaled share the same efficiency profile.

No detailed information was found pertaining to the efficiency of a spark-ignited engine running on compressed natural gas. Modifications were made to the original spark-ignited gasoline efficiency data to better represent the efficiency of the natural gas engine. These modifications demonstrate a significant difference between modern natural gas engines and gasoline engines. At high loads gasoline engines over-fuel thereby reducing peak combustion temperatures to protect the piston and combustion chamber surfaces from overheating. This results in a significant power increase due to extra intake charge cooling. This explains why at a given engine speed and with increasing torque the efficiency will increase to a point (usually at about $80 \%$ of wide open throttle (WOT)), then ceases to increase, or even begins to decrease. This is especially noticeable at higher engine speeds. In a natural gas engine this characteristic is not usually seen, as over-fueling is not required at WOT. The power density of the CNG engine is less than that of the comparable gasoline engine of the same displacement; but the efficiency is considered equivalent except that the efficiency of the CNG engine is greater than the gasoline in all regions where the gasoline engine would over-fueling. 
Natural gas engines were simulated as shown in Figure 3.3.1.3. This figure was based on the spark-ignited gasoline engine, without over-fueling. Table 3.3.1.1. displays all simulated engines with some basic engine characteristics. [7]

\begin{tabular}{|l|l|l|l|l|l|}
\hline Engine Type & $\begin{array}{l}\text { Displacement } \\
\text { (liter) }\end{array}$ & $\begin{array}{l}\text { Compression } \\
\text { Ratio }\end{array}$ & $\begin{array}{l}\text { Number of } \\
\text { Cylinders }\end{array}$ & Valves & Turbo \\
\hline $\begin{array}{l}\text { spark-ignited } \\
\text { gasoline }\end{array}$ & 1.25 & $10.1: 1$ & 4 & 16 & no \\
\hline $\begin{array}{l}\text { spark-ignited } \\
\text { gasoline }\end{array}$ & 1.5 & $10.1: 1$ & 4 & 16 & no \\
\hline $\begin{array}{l}\text { spark-ignited } \\
\text { gasoline }\end{array}$ & 1.6 & $10.1: 1$ & 4 & 16 & no \\
\hline $\begin{array}{l}\text { spark-ignited } \\
\text { gasoline }\end{array}$ & 3.4 & $10.1: 1$ & 6 & 18 & no \\
\hline $\begin{array}{l}\text { spark-ignited } \\
\text { natural gas }\end{array}$ & 1.5 & $12.7: 1$ & 4 & 16 & no \\
\hline $\begin{array}{l}\text { spark-ignited } \\
\text { natural gas }\end{array}$ & 1.6 & $14.2: 1$ & 4 & 16 & no \\
\hline $\begin{array}{l}\text { compression } \\
\text { ignition direct } \\
\text { injection diesel }\end{array}$ & 1.4 & --- & 4 & 12 & yes \\
\hline $\begin{array}{l}\text { compression } \\
\text { ignition direct } \\
\text { injection diesel }\end{array}$ & 1.9 & --- & 4 & 12 & yes \\
\hline
\end{tabular}

Table 3.3.1.1: Table of Simulated Engines 


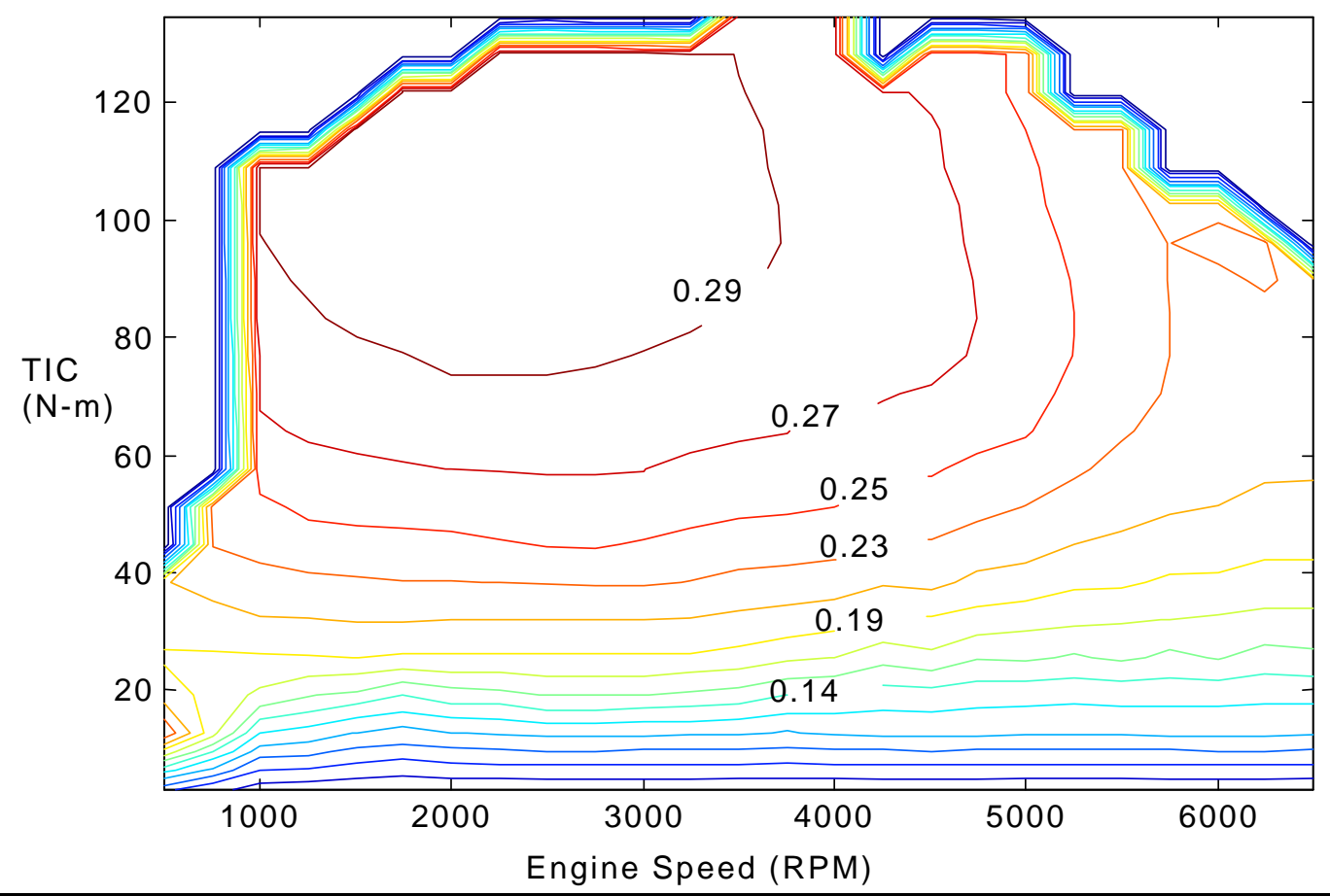

Figure 3.3.1.1: Thermal Efficiency Contour of a 1.6 liter Spark Ignited Gasoline Engine for a Given Engine Torque and Speed (the "halo" effect is a product of plotting and does not reflect actual used data)

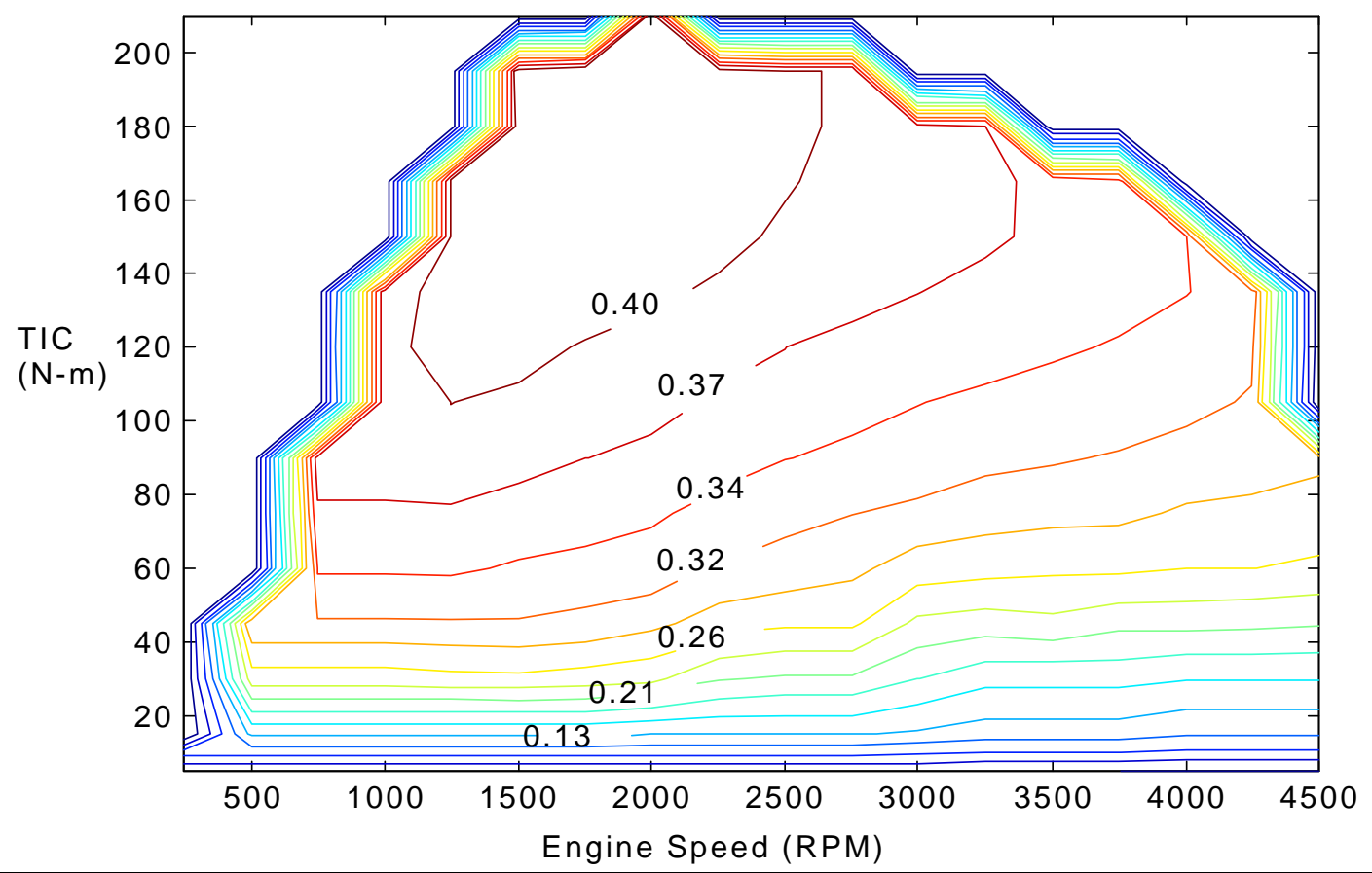

Figure 3.3.1.2: Thermal Efficiency Contour of 1.9 liter Compression Ignition Engine for a Given Engine Torque and Speed 


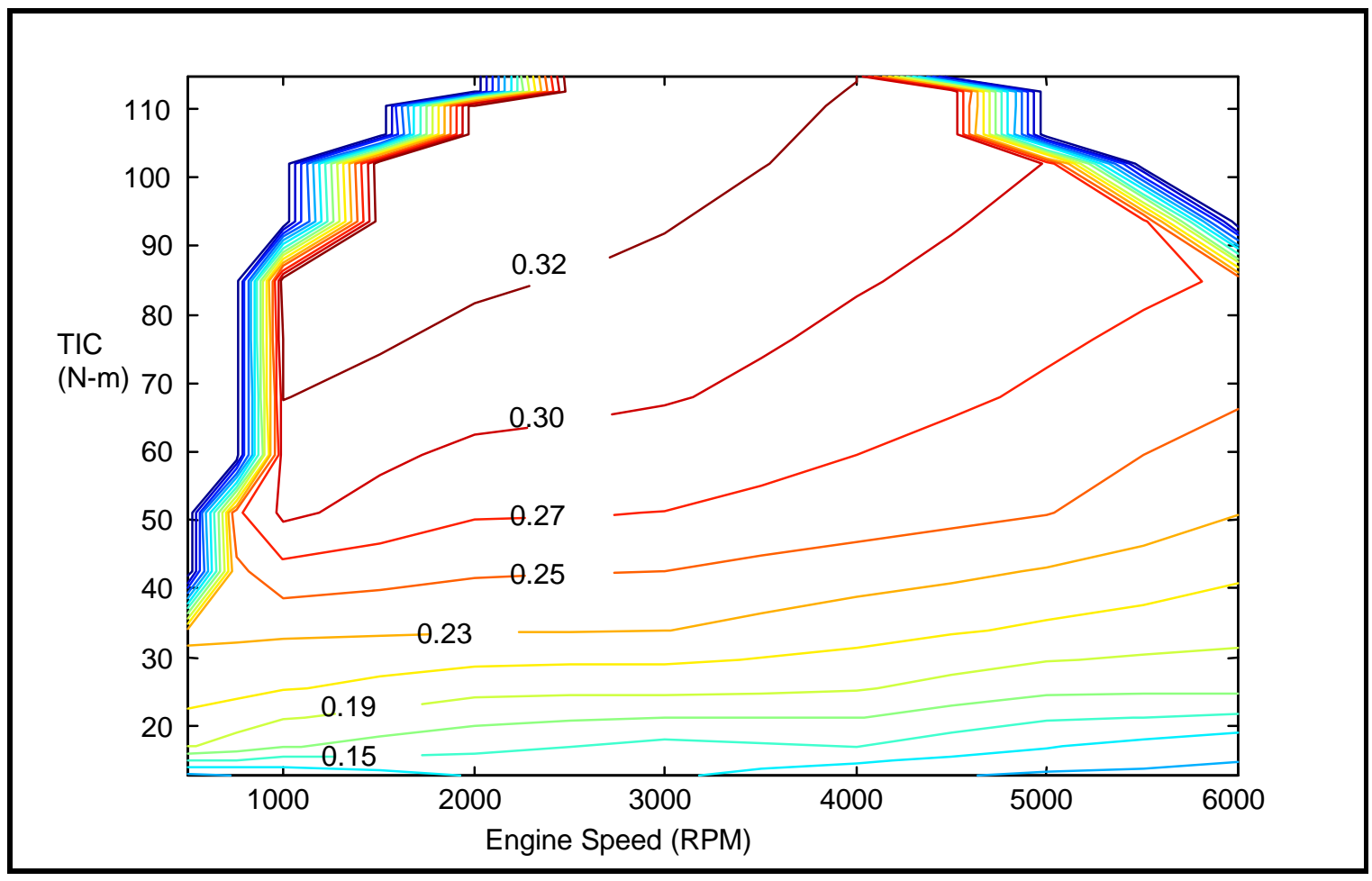

Figure 3.3.1.3: Thermal Efficiency Contour of a 1.6 liter Spark Ignited Natural Gas Engine for a Given Engine Torque and Speed

\subsubsection{Motor and Controller Efficiency Replication}

Motor and controller efficiencies are simulated with a look-up table much like that for the engine efficiency. The motor efficiency can not be accurately scaled to work with different sized motors as in the engine efficiency simulations. For this reason and because of lack of efficiency data only one motor controller combination is simulated. This becomes less important though since the efficiency of the motor changes little over its operating range. Figure 3.3.2.1. shows the efficiency of the Unique Mobility SR-218 motor and controller combination (at typical operating temperatures) as used in the simulations. [8] 


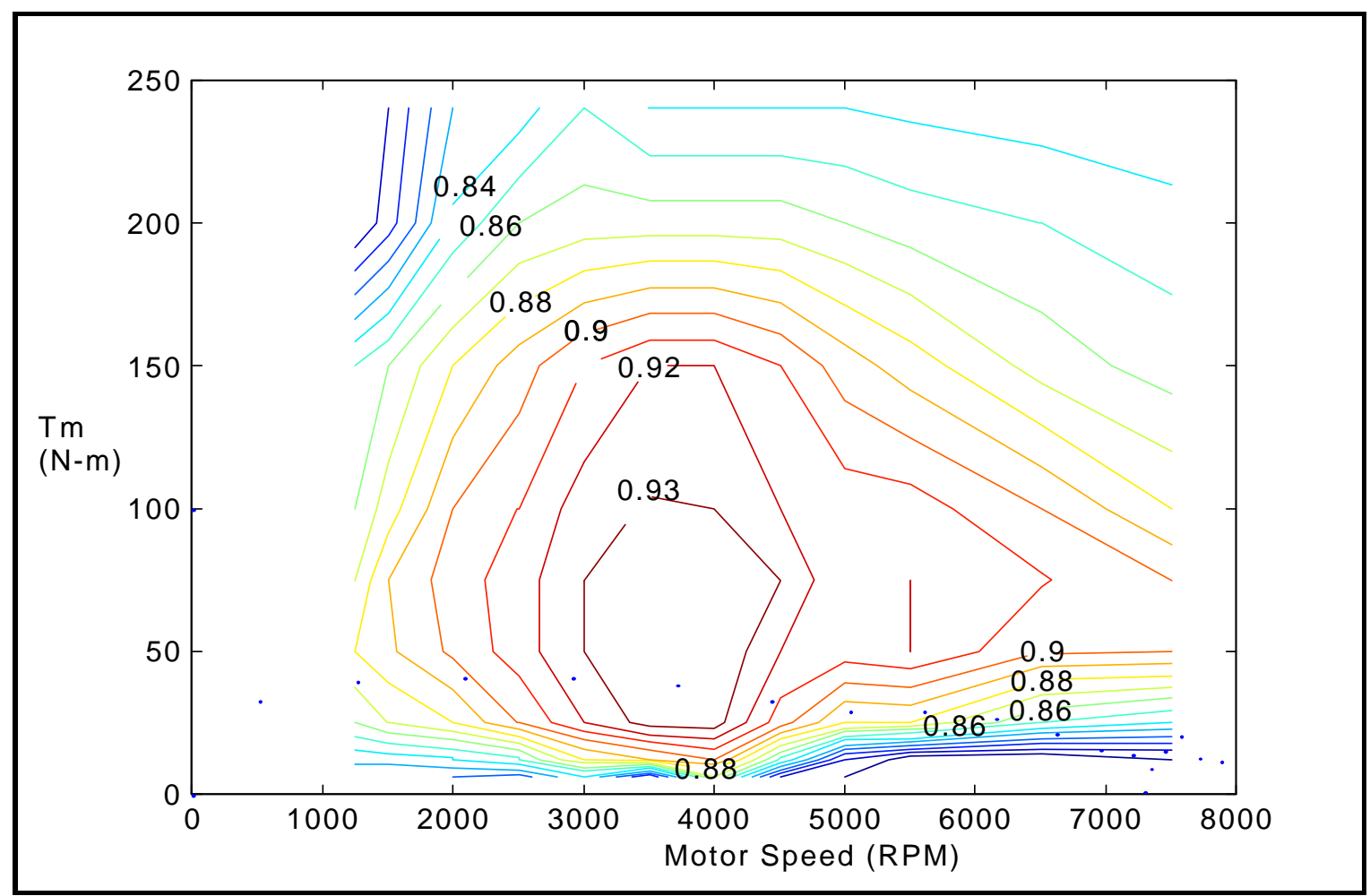

Figure 3.3.2.1: Efficiency Contour of Motor and Controller Combination for a Given Motor Torque and Speed

\subsubsection{Transmission Behavior Replication}

\subsubsection{Manual and Automatic Transmission}

The manual transmission's efficiency was possibly the simplest to simulate. This simulation assumes that efficiency is only a function of gear selection. Figure 3.3.3.1.1. shows a bar graph of the various gears and their assumed efficiencies. [4] The automatic transmission efficiency is not as simple, for it is dependent on several factors. A modern automatic transmission has a lock up feature that locks up the torque converter (preventing slip or mismatch in speed across the torque converter) to increase the overall transmission efficiency. This simulation assumes that the torque converter is unlocked in first gear only; all other gears are, therefore, locked and are far more efficient. The transmission efficiency is equated linearly with transmission input speed, but with 
different equations used for different gears. These efficiencies can be seen in Figure 3.3.3.1.2. This erroneously assumes that the transmission's efficiency is not related to input torque. The linear relation, though, was derived at a moderate torque, and the errors should average close to actual efficiencies for both high and low torques.

The most difficult aspect of simulating a manual or automatic transmission is the gear selection at any vehicle speed and load. During the development of this program it was seen that gear selection had a large influence over the efficiency of the vehicle, which reinforced the importance of accurately simulating gear selection. Both the automatic and manual transmissions use the same decision making process which is shown in Figure 3.3.3.1.3. Basically the transmission is shifted into a higher gear when $80 \%$ of the engine's torque limit is reached. The engine is shifted into a lower gear when a the engine is producing less than $20 \%$ of its torque capacity. This leaves a considerably large dead band to prevent the transmission from being shifted excessively. There are also considerations to prevent the engine from "lugging" at too low a speed, and to keep the engine from over-speeding. Figure 3.3.3.1.4. demonstrates the gear selection process with respect to engine operation. 


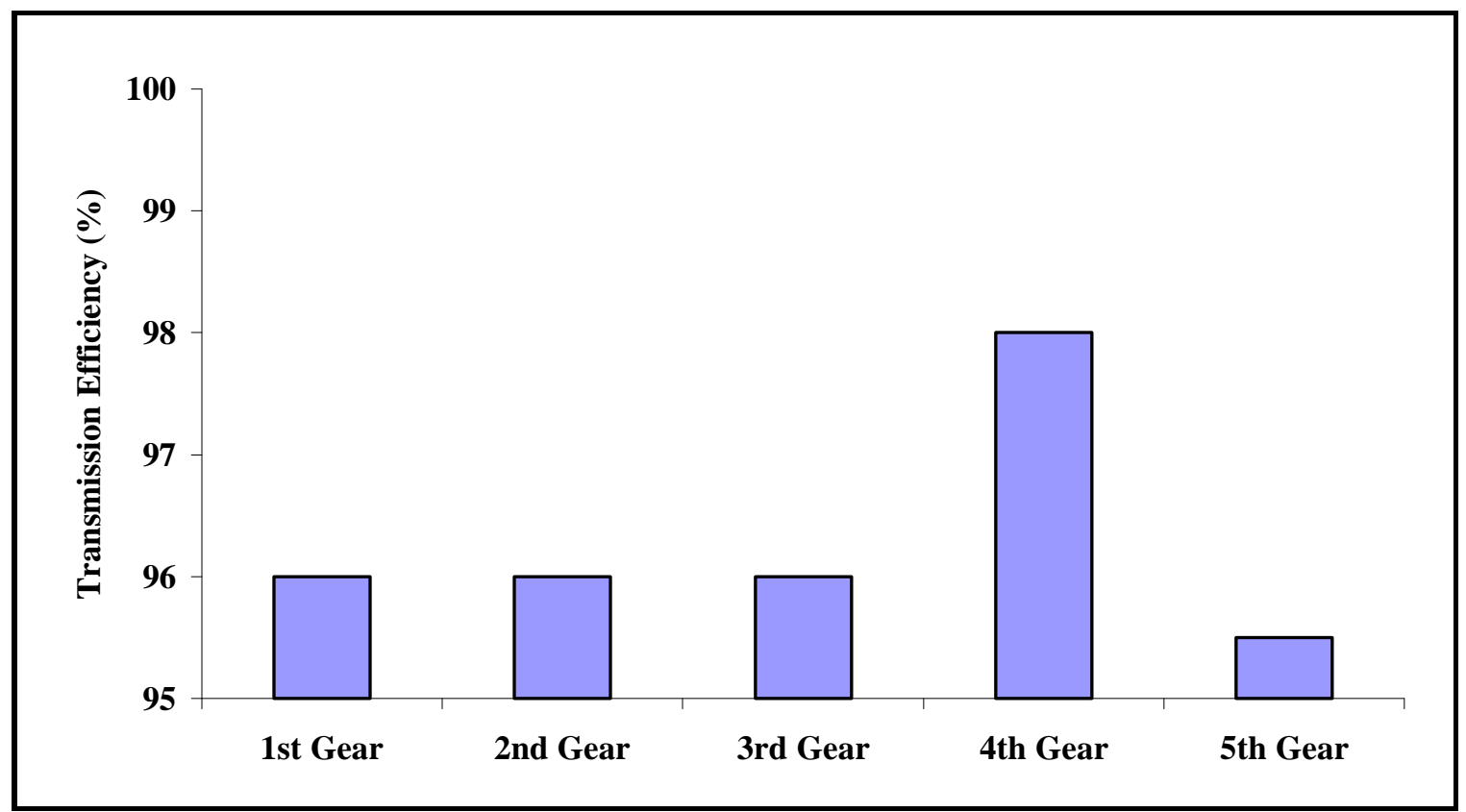

Figure 3.3.3.1.1: Manual Transmission Gear Efficiencies [4]

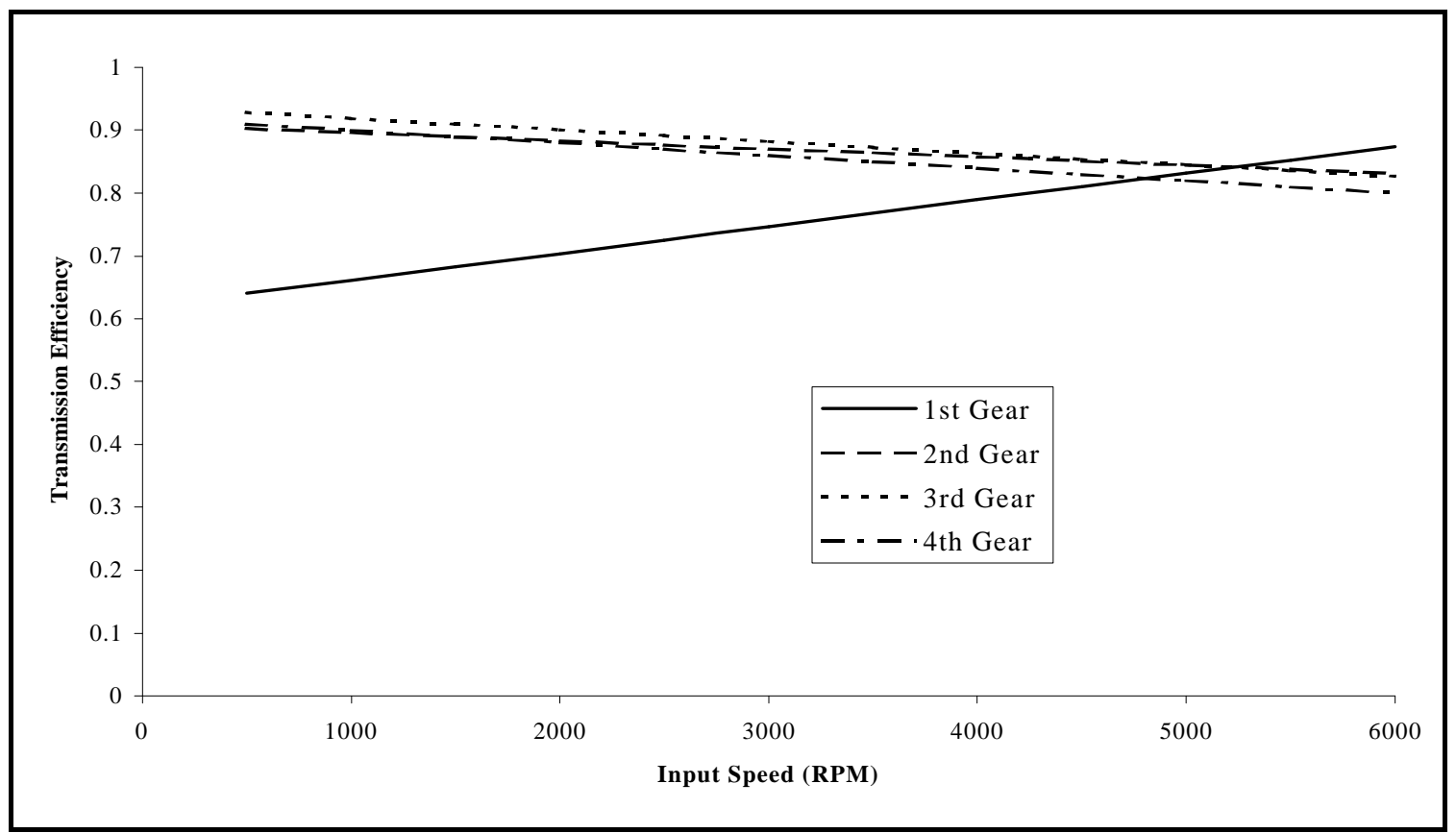

Figure 3.3.3.1.2: Automatic Transmission Gear Efficiencies versus Input Speed [5] 


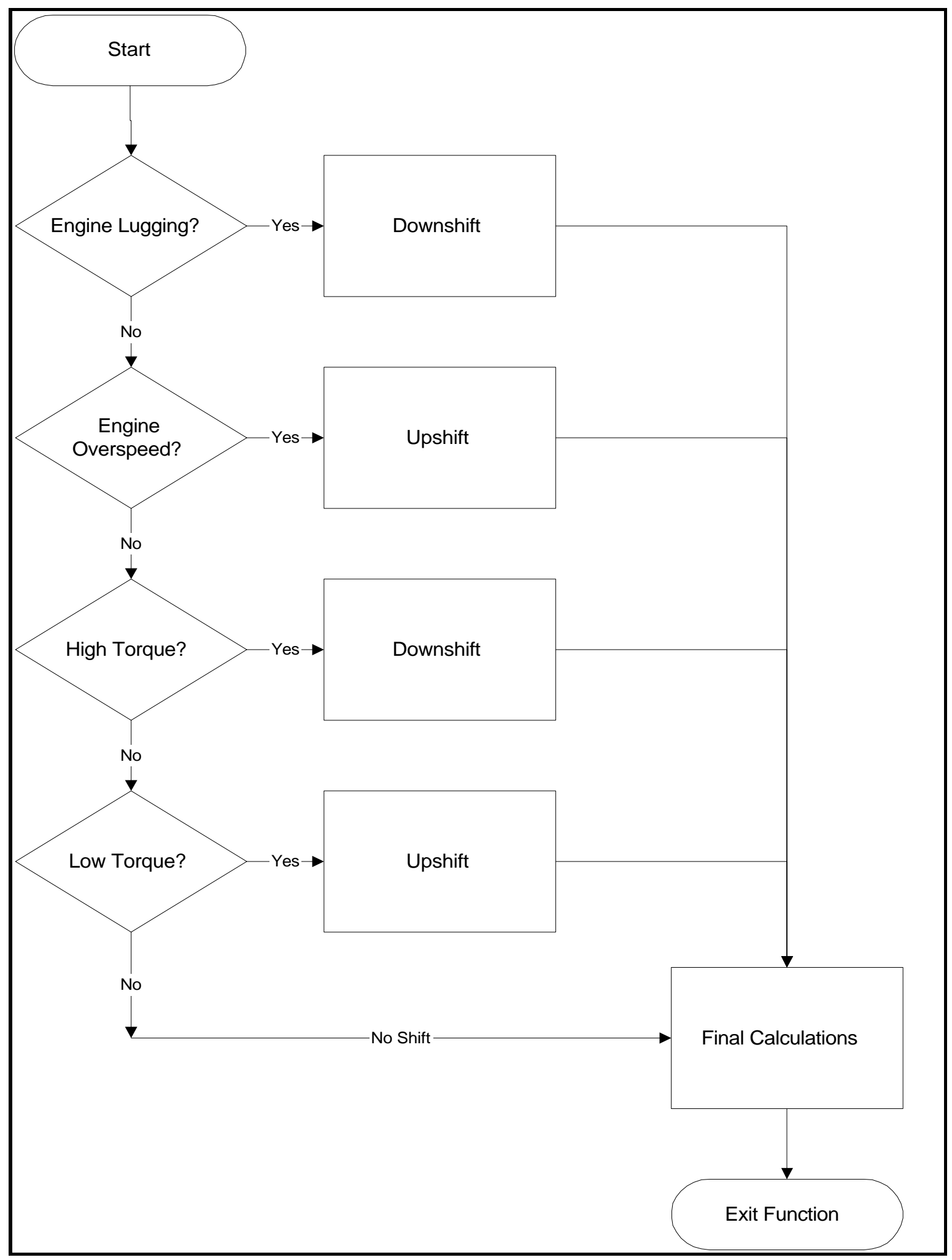

Figure 3.3.3.1.3: Gear Selection Process 


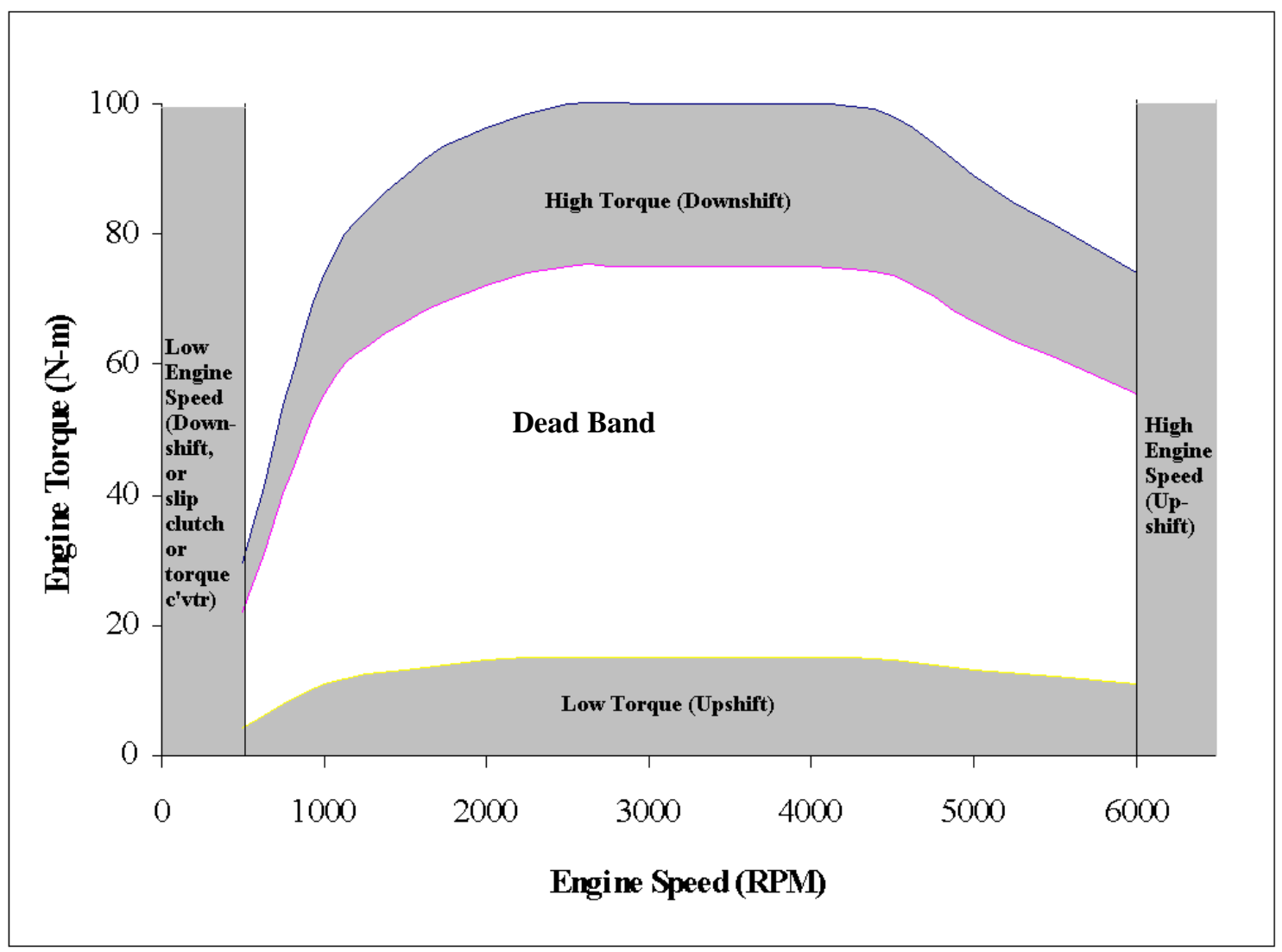

Figure 3.3.3.1.4: Gear Selection with Respect to Engine Operation

\subsubsection{Continuously Variable Transmission}

The Continuously Variable Transmission (CVT) is by far the most difficult of all the transmissions to simulate. The CVT was simulated as a function of three variables, belt ratio, input torque, and input speed. A three dimensional look-up matrix was created representing typical power losses of a first generation pusher belt type CVT. Figure 3.3.3.2.1. illustrates this matrix and Figure 3.3.3.2.2. contains a surface plot of the CVT efficiency as a function of torque and speed for a set belt ratio of $0.6: 1$, input : output. Normally the engine and CVT efficiency are plotted in combination, but for this simulation program since multiple components may be connected to the CVT its efficiency is kept separate. Notice at high speeds and low loads that the efficiency 
becomes negative. In this case the transmission actually requires more input torque than is provided to maintain that particular speed. For similar reasons the simulation becomes problematic. In the simulations the only known features of the transmission are the output speed, output torque, and belt ratio. The power lost in the transmission is dependent on input torque which is in turn dependent on the power lost in the transmission. This is solved iteratively within the program.

The CVT belt ratio is selected logically as illustrated in Figure 3.3.3.2.3. This is much like the gear selection process for automatic and manual transmissions except that there are no dead-bands, for it is not difficult to change ratio as in a conventional transmission. 


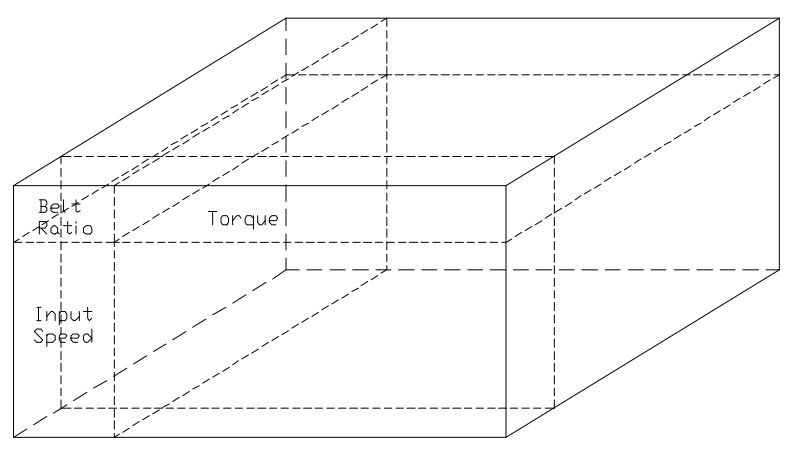

Figure 3.3.3.2.1: Three-Dimensional CVT Power Loss Matrix

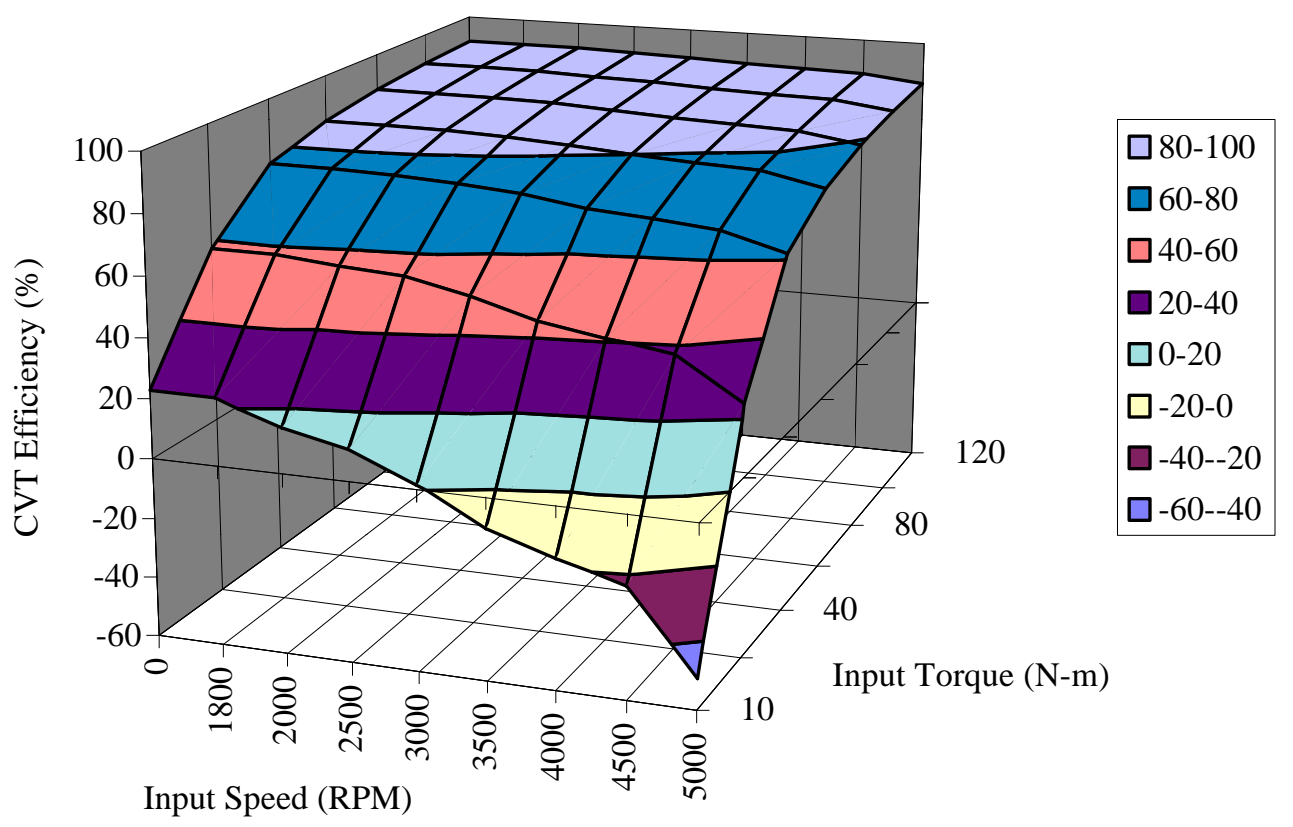

Figure 3.3.3.2.2: Surface Plot of CVT Efficiency for 0.6:1 Belt Ratio 


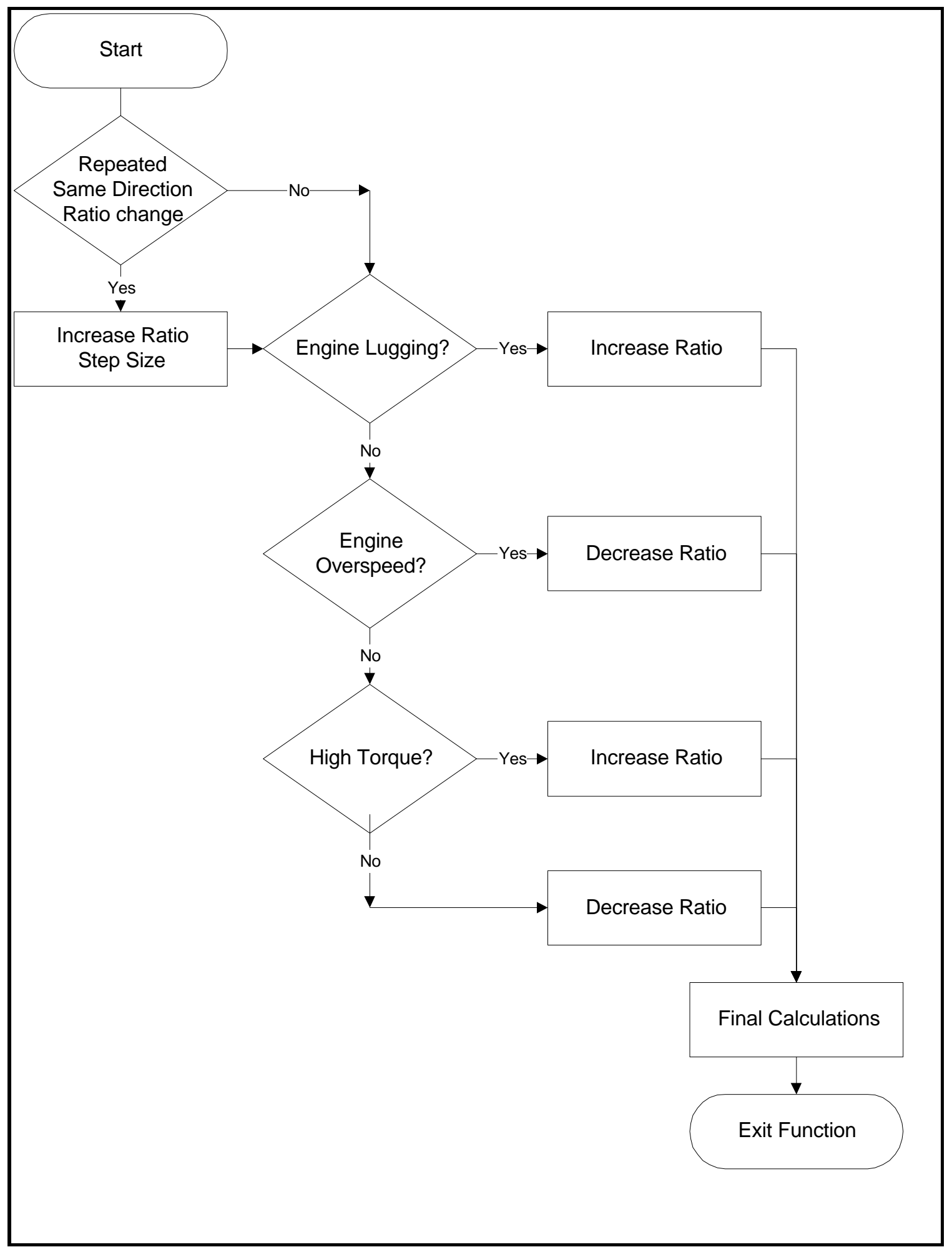

Figure 3.3.3.2.3: CVT Ratio Selection Flowchart 


\subsubsection{Planetary Gear Set}

Toyota's advanced HEV design and current research at West Virginia University has sparked interest in the use of planetary gear sets in HEVs. As outlined in section 3.1.2. a combination series and parallel hybrid electric vehicle was simulated. In this vehicle an engine, motor, and alternator are all connected via a planetary gear set. This allows full engine speed and load control by altering load and speed of the (much more efficient) alternator. Figure 1.2.3.1. demonstrates this connection. Difficulty in simulation arises with the second degree of freedom. This requires an additional variable input compared to traditional powertrains. This additional input was designated as being the engine speed. This means that both engine speed and load are controlled completely independently of actual vehicle speed and load, unless they are so chosen to be equal, and the engine is controlled as such.

The torque and speeds of the planetary gear set are equated based on Figure 3.3.3.3.1. The following equations use a force and moment arm analysis.

$$
F p c=\frac{T p c}{(p \cdot N s)+(p \cdot N p)}
$$

$\begin{array}{lll}\text { where } & \text { Fpc } & \text { force from planetary carrier } \\ \mathrm{Tpc} & = & \text { torque acting on planetary carrier } \\ \mathrm{p} & = & \text { diametral pitch of gear set } \\ \mathrm{Ns} & = & \text { number of teeth on sun gear } \\ \mathrm{Np} & = & \text { number of teeth on planetary gear }\end{array}$


$T s=\frac{-F p c \cdot p \cdot N s}{2}$

where $\quad$ Ts $=$ resulting torque on sun gear

After substituting and canceling the diametral pitch,

$T s=\frac{T p c \cdot N s}{2 \cdot(N s+N p)}$

Now solving for resultant torque on ring gear, $\mathrm{Tr}$,

$\boldsymbol{T r}=\frac{-\boldsymbol{F p c} \cdot(2 \cdot \boldsymbol{p} \cdot \boldsymbol{N p}+\boldsymbol{p} \cdot \boldsymbol{N s})}{2}$

After substituting and canceling the diametral pitch,

$\operatorname{Tr}=\frac{-T p c \cdot(2 \cdot N p+N s)}{2 \cdot(N s+N p)}$ 


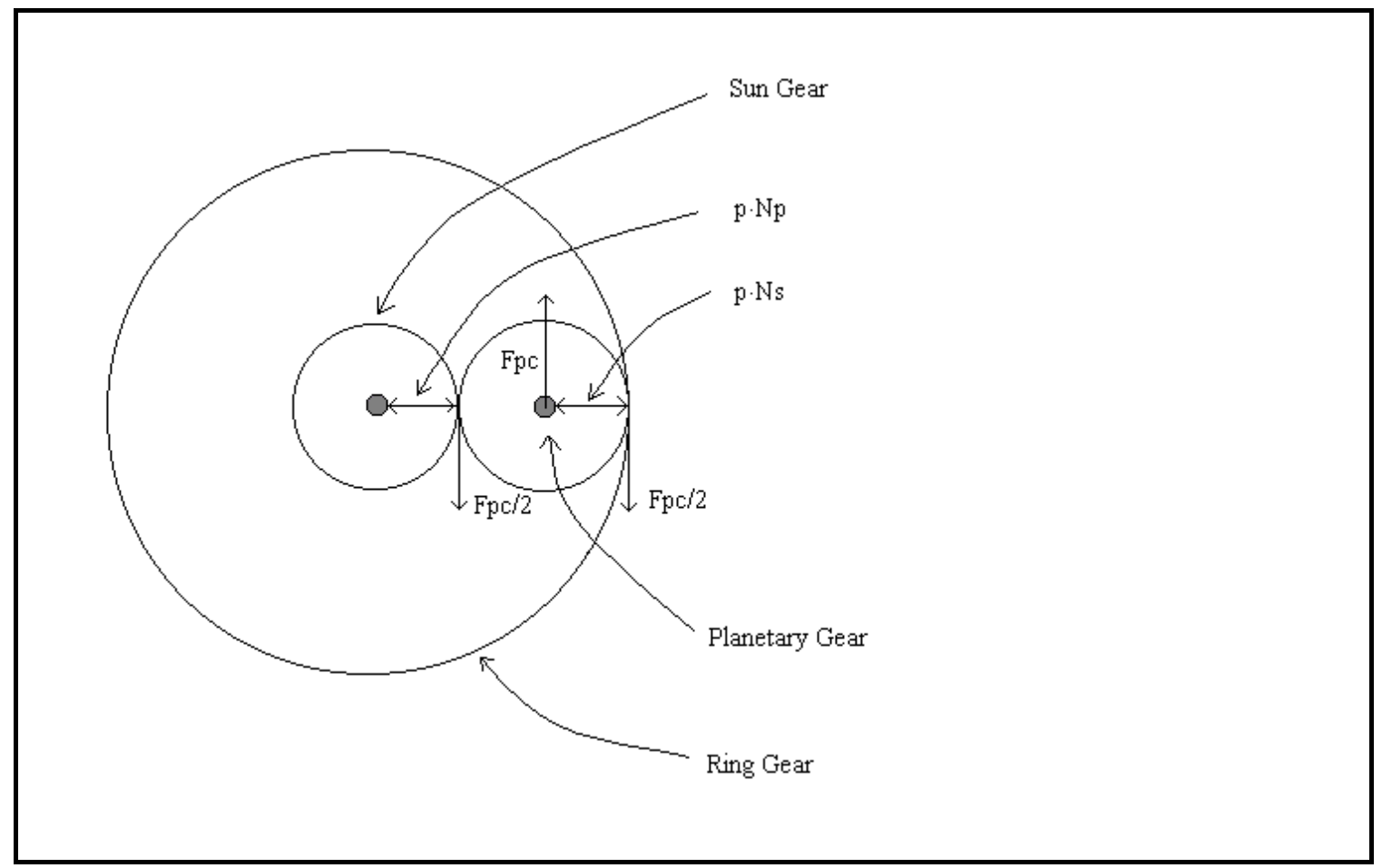

Figure 3.3.3.3.1: Planetary Gear Set Force Analysis

\subsubsection{Battery Simulation}

The batteries are basically modeled as two electrical components, one being a chemical voltage source, and the other being an internal resistance. This chemical voltage of the batteries is a function of SoC and is equated linearly from approximately $93 \%$ nominal battery voltage at $10 \%$ SoC to approximately $110 \%$ nominal battery voltage at $100 \%$ SoC as shown in Figure 3.3.4.1. This is intended to represent the natural chemical voltage of lead acid batteries. The internal resistance of the batteries is simulated as a logical function of both direction of current flow, and SoC temperature also plays an important role but is not considered in this simulation. Figure 3.3.4.2. demonstrates this selection process. This chemical voltage and internal resistance can be 
arranged in the electrical circuit shown in Figure 3.3.4.3. The power needed from the battery pack is known and the resultant current is then derived. From Kirchoff's voltage law stating that the algebraic sum of all voltages around a closed loop in an electric circuit is equal to zero, with substitutions, the battery pack voltage can be represented as, $V_{b}=V_{c}-V_{\Omega}$

where

$$
\begin{aligned}
& \mathrm{V}_{\mathrm{b}}=\text { battery pack voltage } \\
& \mathrm{V}_{\mathrm{c}}=\text { chemical voltage of batteries } \\
& \mathrm{V}_{\Omega}=\text { voltage drop across internal resistance of batteries and the resistance } \\
& \text { of connections }
\end{aligned}
$$

Ohm's law states that voltage is equal to resistance multiplied by current through the resistance. After substitution, $\mathrm{V}_{\Omega}$ can be found,

$V_{\Omega}=I B \cdot \Omega$

where

$$
\begin{aligned}
& \text { IB }=\text { current through battery pack. } \\
& \Omega=\text { electrical resistance of battery pack }
\end{aligned}
$$

Power can be defined by current multiplied by voltage. Evaluated at the ends of the circuit and rearranged to yield an equation for current through the circuit. 
$I B=\frac{P_{b a t t}}{V_{b}}$

where $\quad \mathrm{P}_{\text {batt }}=$ power out of battery pack

Substituting,

$V_{b}=V_{c}-I B \cdot \Omega$

Substituting,

$I B=\frac{P_{b a t t}}{V_{c}-I B \cdot \Omega}$

Solving for IB,

$I B=\frac{V_{c} \pm \sqrt{\left(-V_{c}\right)^{2}-4 \cdot \Omega \cdot P_{b a t t}}}{2 \cdot \Omega}$

Now that battery current is known, through back-substitution the battery pack voltage can be calculated. Power loss to the electrical resistance of the battery pack, $\mathrm{P}_{\mathrm{lb}}$, can be represented as, 


$$
P_{l b}=I B^{2} \cdot \Omega
$$

The total chemical power, $\mathrm{P}_{\mathrm{c}}$, is needed for later energy calculations.

$P_{c}=I B \cdot V_{c}$

The instantaneous efficiency of the batteries, $\eta_{\mathrm{b}}$, is defined as,

$\eta_{b}=\frac{P_{b a t t}}{P_{c}}$

The resultant efficiency of the batteries can be seen in Figure 3.3.4.4. Notice the sharp drop in efficiency once under discharge the batteries reach $50 \%$ efficiency. In the electric circuit, when the power dissipated across the internal resistance is equal to the power at the load, the batteries have reached maximum theoretical power output. Any current draw beyond this point only reduces the power out. A perfect example of this is a short circuit; if the load resistance were equal to zero, large currents would be seen yet the power output would remain at zero. Also notice the lower than expected charging efficiency for low SoC charging. This is a result of lower pack voltage requiring higher current to transfer the same power, and thus loosing more power to the internal resistance of the battery pack. 


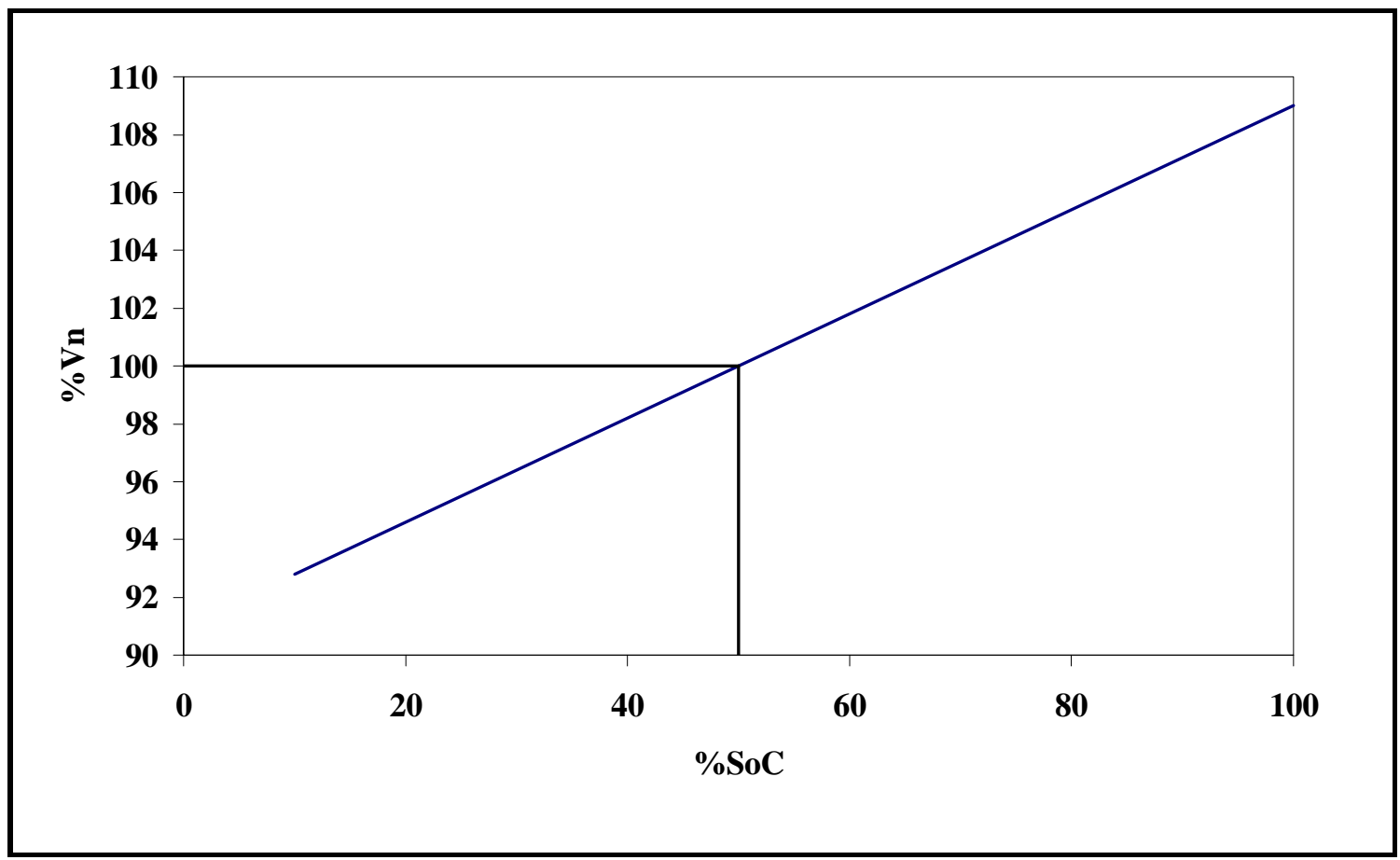

Figure 3.3.4.1: Nominal Battery Chemical Voltage as a Function of SoC

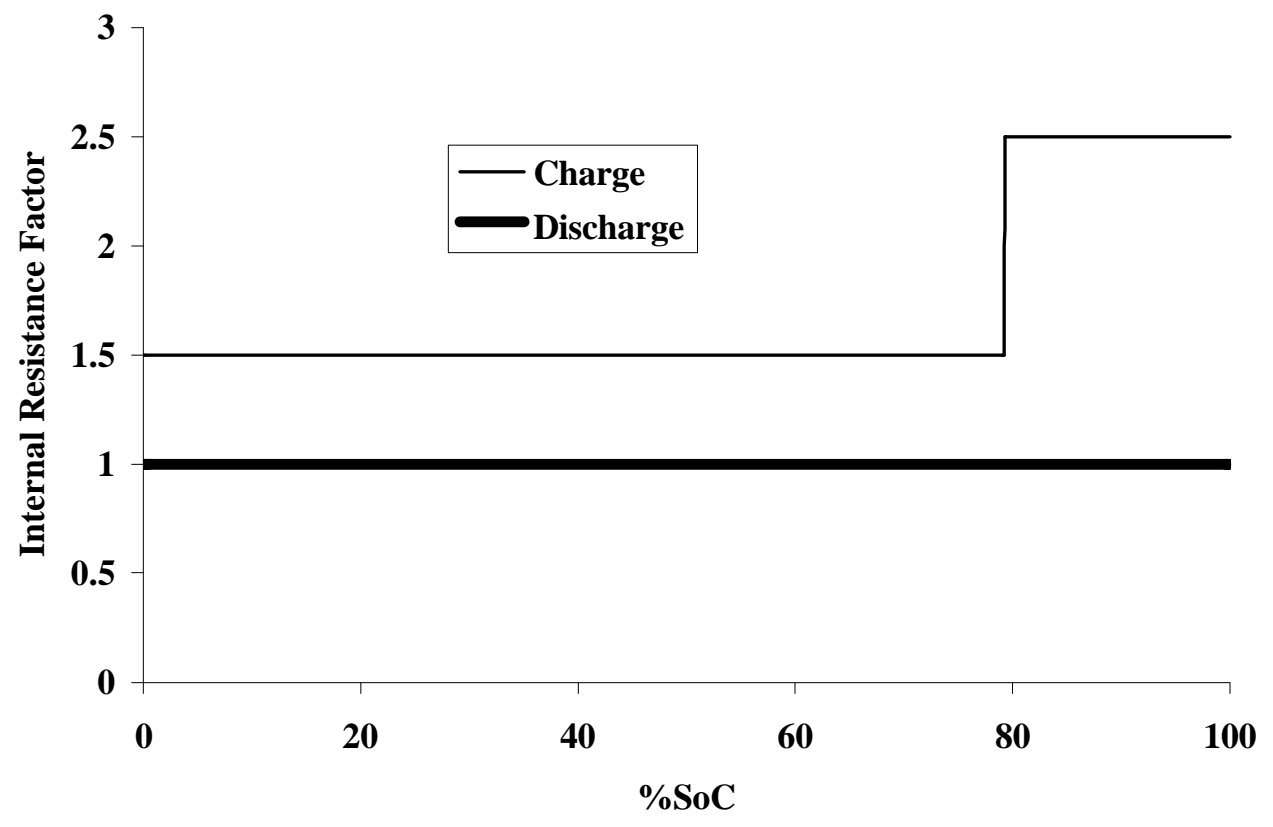

Figure 3.3.4.2: Internal Resistance Factor as a Function of SoC 


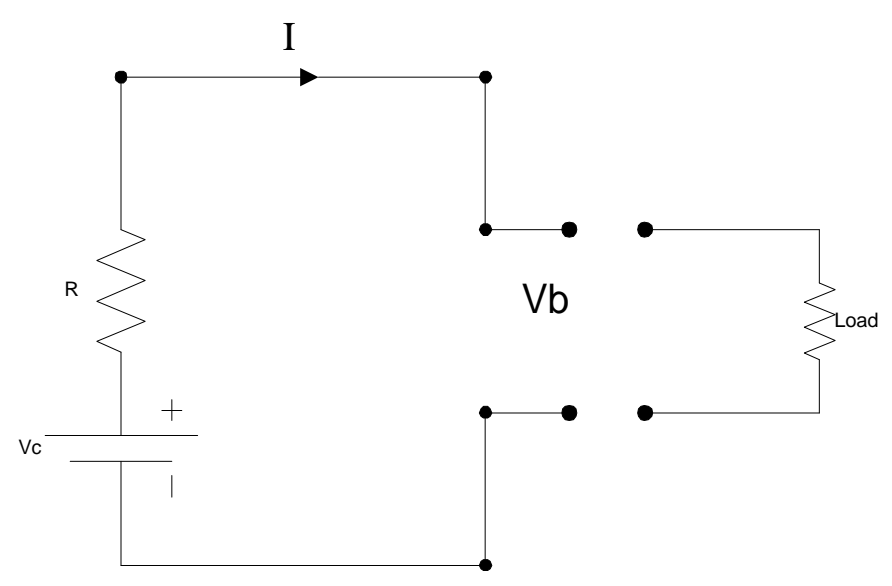

Figure 3.3.4.3: Battery Pack Equivalent Circuit

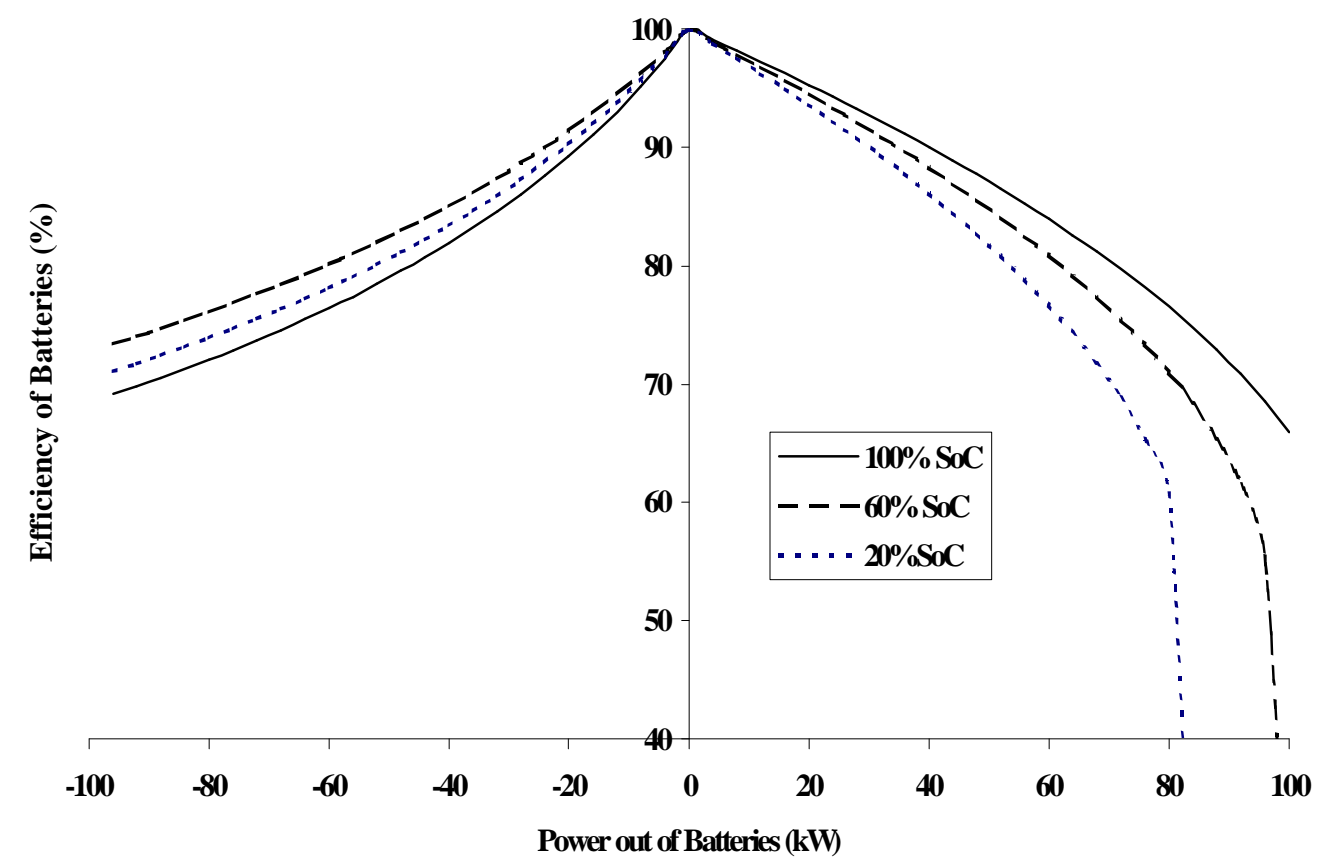

Figure 3.3.4.4: Battery Efficiency versus Power Out of a 324 volt Battery Pack 


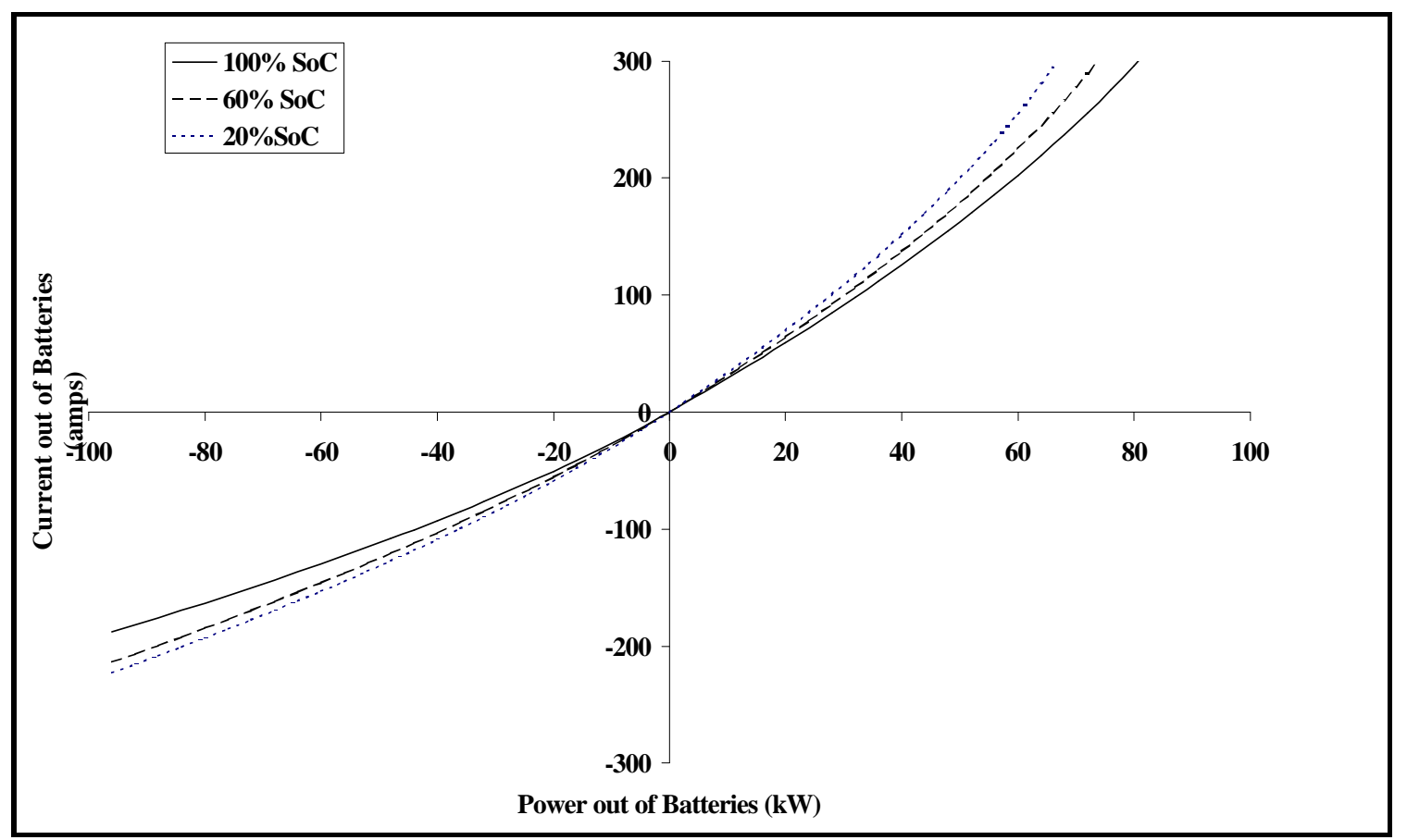

Figure 3.3.4.5: Current Out of Battery Pack versus Power Out of Pack

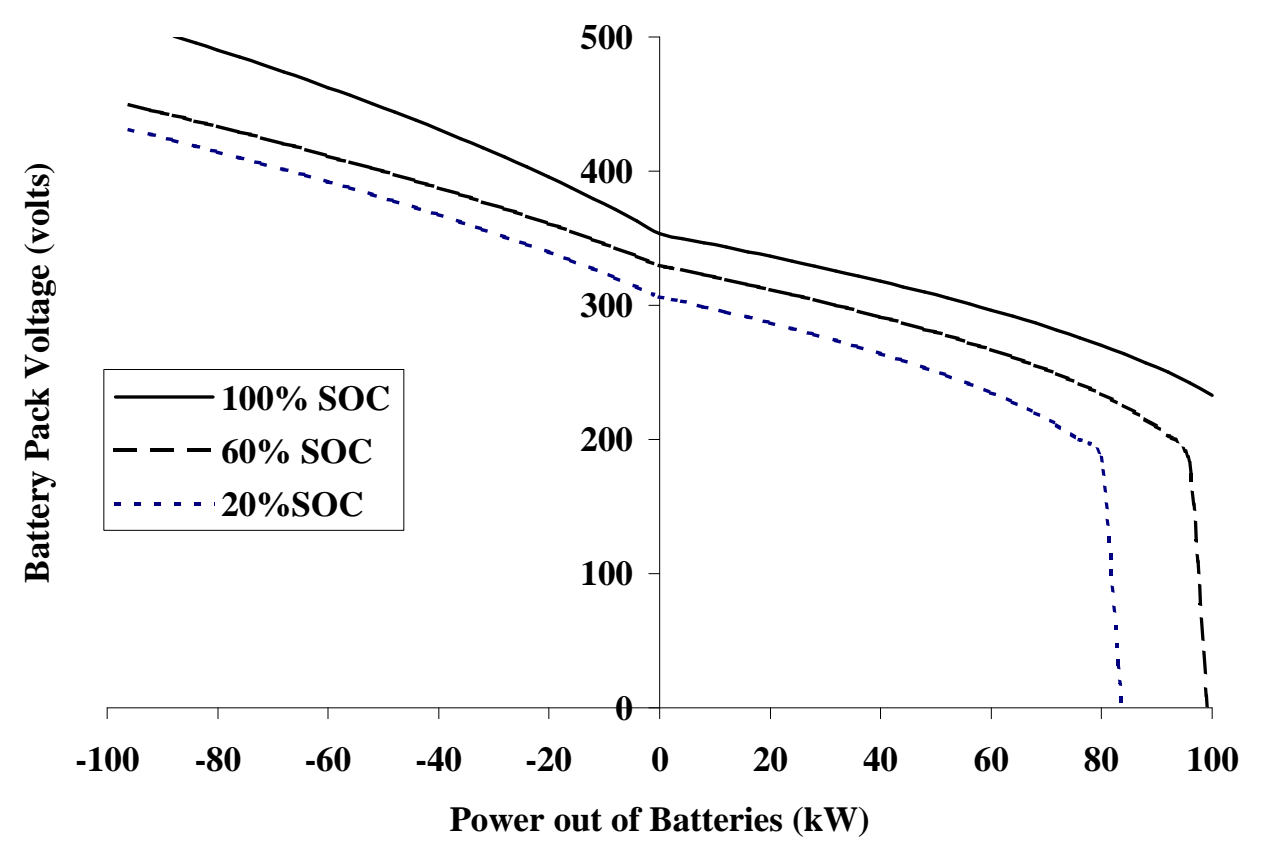

Figure 3.3.4.6: Battery Pack Voltage versus Power out of Pack 


\subsubsection{Energy and Efficiency Calculations}

At the end of the individual powertrain modules there are energy and efficiency calculations. All calculations to this point are in terms of the instantaneous power, $\mathrm{P}_{\mathrm{i}}$. A history of this power consumption is held in vectors. Since the time step for all of the vectors is one second, and the powers calculated are in watts, a simple summation of the vectors results in a number for net energy consumed or produced in watt-seconds $(\mathrm{J})$.

$E=P_{i} \cdot \Delta t$

For $\Delta \mathrm{t}=1.0$

$E_{s}=P_{s}$

where $\quad E_{\mathrm{s}}=$ energy for one time step

$\mathrm{P}_{\mathrm{s}}=$ power of time step

This calculates the energy at each step. The summation of the individual step yields a net energy, $E_{n}$.

$\sum E_{s}=\sum P_{s} \cdot \Delta t$

$E_{n}=\sum E_{s}$ 
All references to fuel consumption to this point are in terms of energy used. Using the energy density of gasoline $(44,000 \mathrm{KJ} / \mathrm{Kg})[1]$ and the volumetric density of gasoline, the energy required from the arbitrary fuel is equated to a volume in gallons of gasoline.

For hybrid electric vehicles there are two energy sources, one electric, the other fuel. If there is a net electric energy difference to or from the batteries this must be compensated for. Stating the exact net energy consumed produced by the batteries during a test is difficult since the energy calculations are an integration of current and time producing much error. When HEVs are tested on a dynamometer there is a SoC correction procedure to more accurately portray vehicle efficiency. Basically two similar tests are performed, one with net energy out of the batteries, the other with net energy into the batteries. The two test points are plotted on a graph as shown in Figure 3.3.5.1. Assuming a linear relation the zero axis intercept is calculated to provide actual vehicle efficiency (assuming zero net state of charge difference in the batteries). 


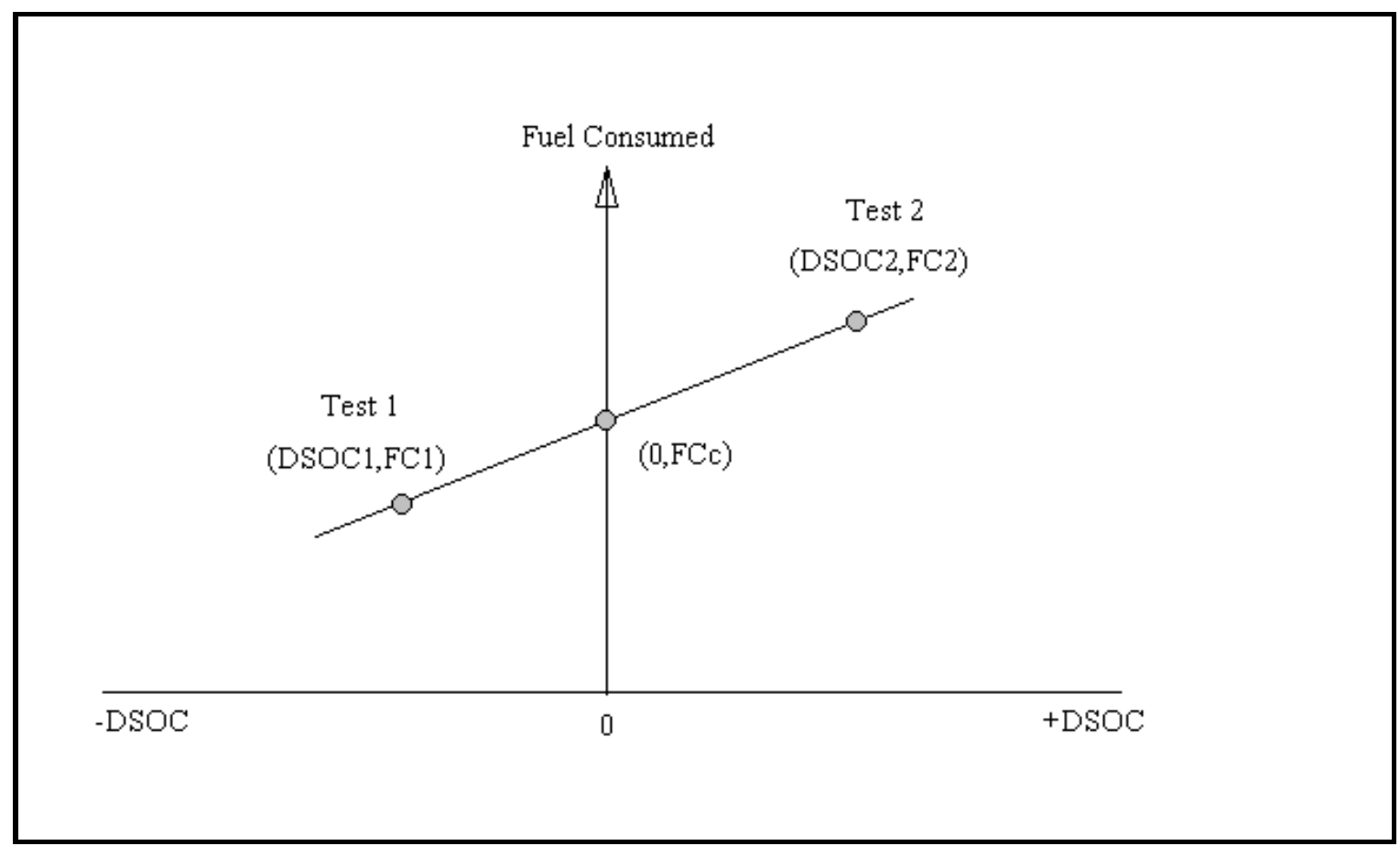

Figure 3.3.5.1: SoC Correction Procedure [9].

where

$\begin{array}{ll}\text { DSOC } & =\text { delta state of charge } \\ \text { FC } & =\text { fuel consumption } \\ \text { FCc } & =\quad \text { corrected fuel consumption }\end{array}$




\section{Results, Validation, and Discussion}

\subsection{Simulation and Comparison of Several Conventional Vehicles}

This study simulates conventional vehicles to validate the modular vehicle simulation program. Conventional vehicles were chosen based on their similarities of their engines to those modeled. The specific goal of this exercise was to validate the engine and transmission efficiency replication procedures. As mentioned earlier, the engine is the largest source of energy loss in any vehicle (conventional or hybrid), and therefore, the importance of accurately reproducing the engine's efficiency is greatest.

\section{Volkswagen Passat}

The 1996 Volkswagen Passat was simulated as an example of conventional vehicles using compression ignition engines. This particular vehicle was chosen since the base compression ignition engine simulated was that of the Volkswagen Passat. The actual efficiency traces mentioned in Section 1.2 were used to simulate the fuel efficiency calculated and measured by the EPA. Table 4.1.1 demonstrates the actual and simulated efficiency of the Volkswagen Passat. The fuel economy numbers tabulated below are in miles per gallon equivalent (mpge), being the gasoline equivalent of the fuel consumed.

\begin{tabular}{|l|l|l|l|}
\hline & Actual (mpge) & Simulated (mpge) & Difference (\%) \\
\hline FUDS & 33.2 & 34.7 & +4.3 \\
\hline HWFET & 40.4 & 44.7 & +9.6 \\
\hline US06 & Not Available & 35.7 & - \\
\hline
\end{tabular}

Table 4.1.1: Actual and Simulated Fuel Economy for 1996 Volkswagen Passat [10] 
No test data is available for the US06 since it has not been instated yet as a normal fuel economy test procedure and it will not be required until the model year 2000. No actual test data was found for any vehicle on the US06 for comparison. Some error in the given simulated values is due to a lack of exact values for cross sectional area and coefficient of drag for the Volkswagen Passat. Constant velocity fuel economy simulations were performed and can be seen in Table 4.1.2. Table 4.1.3. displays the actual parameters entered into the program for the Passat.

\begin{tabular}{|l|l|}
\hline Steady Velocity Simulated (mph) & Resultant Fuel Economy (mpge) \\
\hline $\mathbf{4 5}$ & 85.5 \\
\hline $\mathbf{7 0}$ & 48.6 \\
\hline
\end{tabular}

Table 4.1.2: Constant Velocity Fuel Consumption Simulation for 1996 Volkswagen Passat

\begin{tabular}{|l|l|}
\hline Vehicle Parameter & Value used in simulation \\
\hline Mass (kg) & 1474 \\
\hline Aerodynamic Drag Coefficient ( ) & 0.34 \\
\hline Cross-sectional Area $\left(\mathrm{m}^{2}\right)$ & 1.9 \\
\hline Coefficient of Rolling Resistance ( ) & 0.0065 \\
\hline
\end{tabular}

Table 4.1.3: Vehicle Parameter Values for Simulation of 1996 Volkswagen Passat

Figure 4.1.1. demonstrates the actual engine operating points during the HWFET. This plot can be used to demonstrate the benefits of hybridizing. There are many points of operation during which the engine is running very inefficiently, by running at too low 
a torque and or too high a speed. Hybridizing the vehicle can eliminate these points of poor efficient operation shifting the majority of the engine operating points into the high efficiency $(40 \%)$ zone of operation. Some points of operation actually fall outside the engines capability. This is due to the shifting logic not correcting until the next iteration. This does induce minimal error due to the low occurrence.

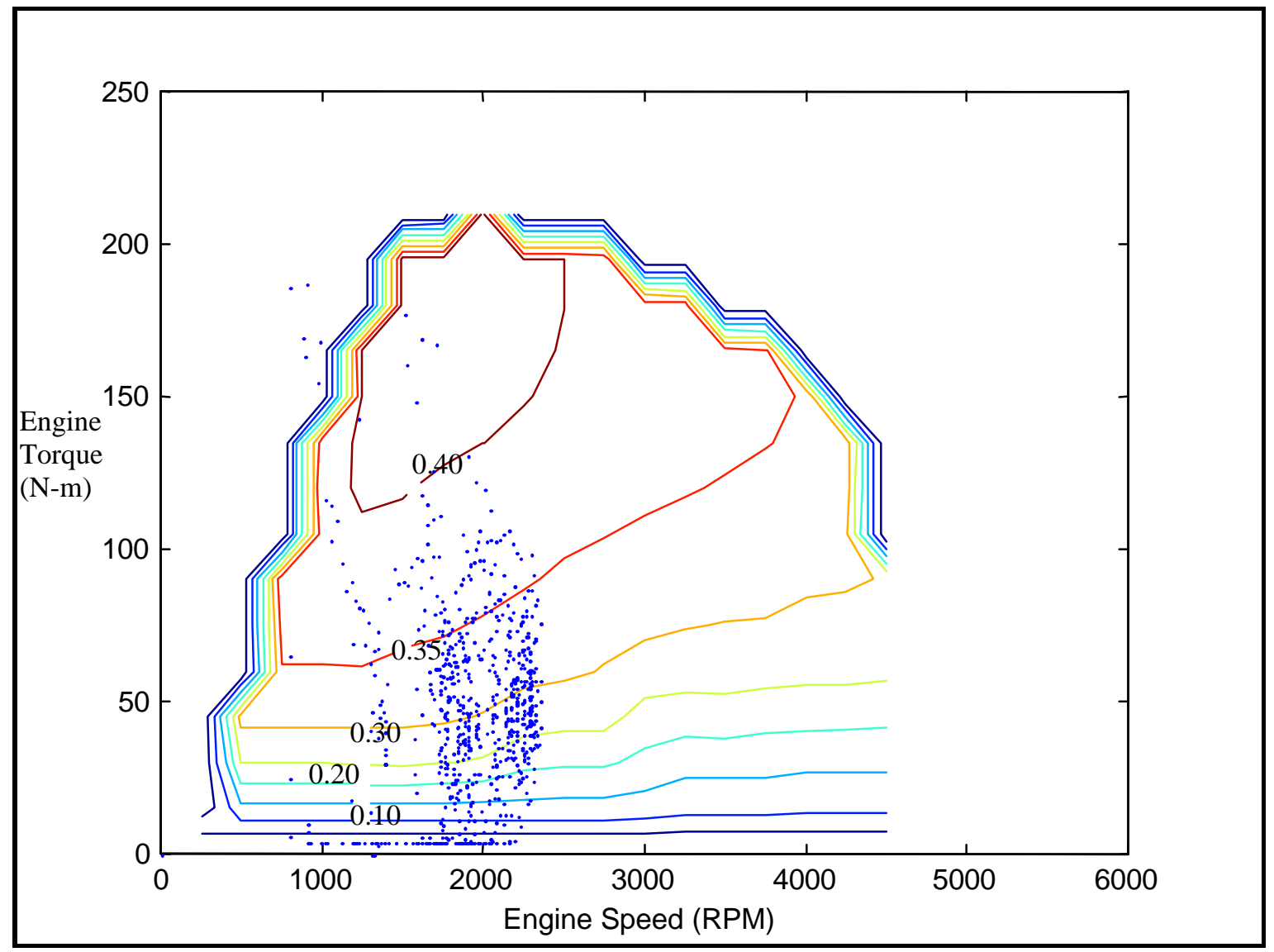

Figure 4.1.1: 1996 Volkswagen Passat Engine Operation for the HWFET with Engine Efficiency Contour

\section{Ford P2000}

The Ford P2000 concept vehicle recently announced by Ford Motor Company, was simulated to validate the re-scaling of engine displacement for compression ignition 
engines. The Ford P2000 uses a 1.2 L diesel while the engine data available is for a $1.9 \mathrm{~L}$ diesel. The Ford P2000 has a conventional powertrain with an ultra-light aluminum body yielding a total vehicle weight of $907 \mathrm{~kg}$. The high efficiency of the compression ignition engine and the low vehicle weight is Ford's near term approach to meeting PNGV goals. The simulation results are shown in Table 4.1.4. and Table 4.1.5. with the parameters used in the program shown in Table 4.1.6. Ford has announced that the vehicle is capable of $66 \mathrm{mpg}$ and this simulation shows that this value is a reasonable assumption for the HWFET.

\begin{tabular}{|l|l|l|l|}
\hline & Actual (mpge) & Simulated (mpge) & Difference (\%) \\
\hline FUDS & Not Available & 45.4 & - \\
\hline HWFET & 66 & 65.4 & $0.9 \%$ \\
\hline US06 & Not Available & 49.9 & - \\
\hline
\end{tabular}

Table 4.1.4: Actual and Simulated Fuel Economy for the Ford P2000 [11]

\begin{tabular}{|l|l|}
\hline Steady Velocity Simulated (mph) & Resultant Fuel Economy (mpge) \\
\hline $\mathbf{4 5}$ & 93.0 \\
\hline $\mathbf{7 0}$ & 60.3 \\
\hline
\end{tabular}

Table 4.1.5: Constant Velocity Fuel Consumption Simulation for Ford P2000

\begin{tabular}{|l|l|}
\hline Vehicle Parameter & Value used in simulation \\
\hline Mass (kg) & 907 \\
\hline Aerodynamic Drag Coefficient ( ) & 0.29 \\
\hline Cross-sectional Area $\left(\mathrm{m}^{2}\right)$ & 1.9 \\
\hline Coefficient of Rolling Resistance ( ) & 0.0055 \\
\hline
\end{tabular}

Table 4.1.6: Vehicle Parameter Values for Simulation of Ford P2000 


\section{Saturn Coupe}

A 1996 Saturn Coupe was simulated in this study to validate the spark-ignited gasoline engine efficiency and the re-scaling calculations for different sized spark ignited engines. As mentioned in Section 3.3.1. the only actual spark ignited gasoline engine data available was that for a 1.6 L. The Saturn has a $1.9 \mathrm{~L}$ engine, and therefore the available data had to be re-scaled. Table 4.1.7. tabulates both simulated and actual test data for the Saturn SL Coupe, with the simulation parameters shown in Table 4.1.8.

\begin{tabular}{|l|l|l|l|}
\hline & Actual (mpge) & Simulated (mpge) & Difference (\%) \\
\hline FUDS & 28 & 31.4 & +10.8 \\
\hline HWFET & 37 & 37.9 & +2.4 \\
\hline US06 & Not Available & 31.5 & \\
\hline
\end{tabular}

Table 4.1.7: Actual and Simulated Fuel Economy for 1996 Saturn Coupe [10]

\begin{tabular}{|l|l|}
\hline Vehicle Parameter & Value used in simulation \\
\hline Mass (kg) & 1300 \\
\hline Aerodynamic Drag Coefficient ( ) & 0.29 \\
\hline Cross-sectional Area $\left(\mathrm{m}^{2}\right)$ & 1.9 \\
\hline Coefficient of Rolling Resistance ( ) & 0.0075 \\
\hline
\end{tabular}

Table 4.1.8: Vehicle Parameter Values for Simulation of 1996 Saturn Coupe 


\section{Chevrolet Lumina}

A 1996 Chevrolet Lumina was simulated to test the extent to which the engine efficiency data could be re-scaled and used in the program. As a reminder, the available spark ignited gasoline engine data was for a four cylinder. The Chevrolet Lumina has a 3.4 L V6 engine. This simulation also validates parameter information for the Lumina to help simulate the 1996-97 WVU FutureCar in a later section of this study. Table 4.1.9. displays simulated and actual test results for the Lumina with simulation parameters shown in Table 4.1.10.

\begin{tabular}{|l|l|l|l|}
\hline & Actual (mpge) & Simulated (mpge) & Difference (\%) \\
\hline FUDS & 21 & 23.1 & $+9.1 \%$ \\
\hline HWFET & 35 & 31.5 & $-10 \%$ \\
\hline US06 & Not Available & 26.0 & - \\
\hline
\end{tabular}

Table 4.1.9: Actual and Simulated Fuel Economy for 1996 Chevrolet Lumina [10]

\begin{tabular}{|l|l|}
\hline Vehicle Parameter & Value used in simulation \\
\hline Mass (kg) & 1500 \\
\hline Aerodynamic Drag Coefficient ( ) & 0.3 \\
\hline Cross-sectional Area $\left(\mathrm{m}^{2}\right)$ & 2.05 \\
\hline Coefficient of Rolling Resistance ( ) & 0.0075 \\
\hline
\end{tabular}

Table 4.1.10: Vehicle Parameter Values for Simulation of 1996 Chevrolet Lumina

The engine operation points for the Lumina, which are shown in Figure 4.1.2. demonstrate the opportunity for increased powertrain efficiency through hybridization. Hybridizing can eliminate the extremely low efficiency operation points. More 
specifically series hybridization will be most beneficial at low torque requirements and a parallel at higher torque requirements.

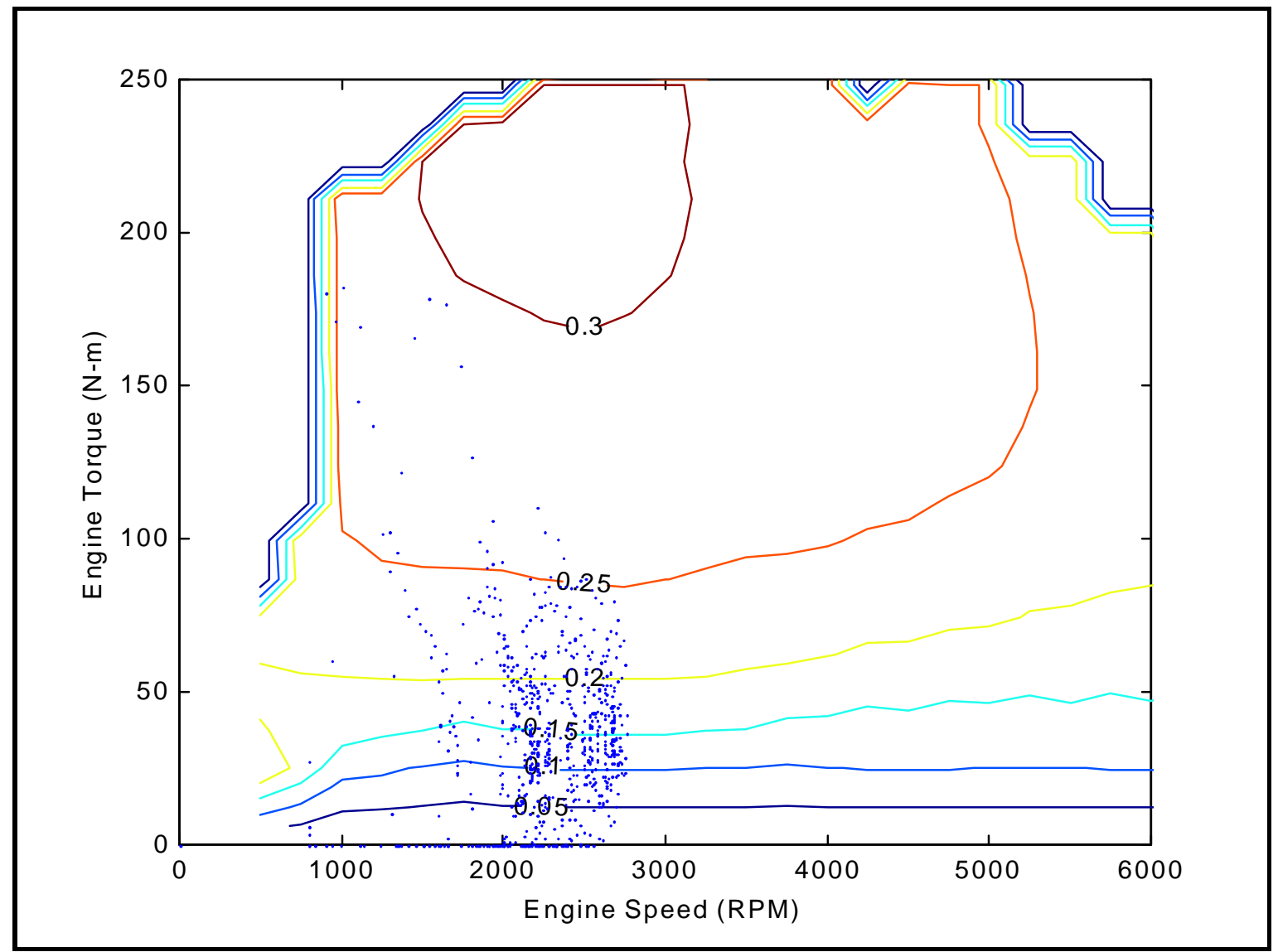

Figure 4.1.2: Conventional 1996 Chevrolet Lumina Highway Engine Operation with Engine Efficiency Contours

\section{Mercury Sable}

The 1994 Mercury Sable is simulated to validate parameter information for use in simulating the 1998 WVU FutureCar in a later section of this study. The Sable is equipped with a 3.1 L V6 engine. Actual and simulated results are shown in Table 4.1.11. with the simulation parameters shown in Table 4.1.12. 


\begin{tabular}{|l|l|l|l|}
\hline & Actual (mpge) & Simulated (mpge) & Difference (\%) \\
\hline FUDS & 20 & 19.0 & -5.0 \\
\hline HWFET & 29 & 27.1 & -6.6 \\
\hline US06 & Not Available & 18.7 & - \\
\hline
\end{tabular}

Table 4.1.11: Actual and Simulated Fuel Economy for 1994 Mercury Sable [10]

\begin{tabular}{|l|l|}
\hline Vehicle Parameter & Value used in simulation \\
\hline Mass (kg) & 1633 \\
\hline Aerodynamic Drag Coefficient ( ) & 0.32 \\
\hline Cross-sectional Area $\left(\mathrm{m}^{2}\right)$ & 2.05 \\
\hline Coefficient of Rolling Resistance ( ) & 0.0075 \\
\hline
\end{tabular}

Table 4.1.12: Vehicle Parameter Values for Simulation of 1994 Mercury Sable

In addition, the Mercury Sable Aluminum Intensive Vehicle (AIV) was simulated because it was the actual base vehicle used for the 1998 WVU FutureCar. The steelbodied Mercury Sable vehicle parameters were used in simulating the AIV with the exception of the weight. The AIV was simulated with a weight of 1534kg. Table 4.1.13. displays the simulation results for the AIV Sable. These results can only be compared to the steel-bodied Sable since there were no actual fuel economy test results available.

\begin{tabular}{|l|l|}
\hline & Simulated (mpge) \\
\hline FUDS & 19.5 \\
\hline HWFET & 27.6 \\
\hline US06 & 21.3 \\
\hline
\end{tabular}

Table 4.1.13: Simulated Fuel Economy for the 1994 Mercury Sable AIV 


\subsection{Simulation and Comparison of Series Vehicles}

There have been few series HEVs tested that could be used for the validation of this program. The 1997 WVU FutureCar was successfully tested at the National Vehicle Emissions and Fuel Laboratory at Ann Arbor, Michigan in June 1997. Table 4.2.1. contains a comparison of the simulated and actual fuel economy data. The electrical efficiency was simulated by running the test solely as an EV. The simulation results are shown in Table 4.2.2. Constant velocity fuel efficiency was calculated to compare with over the road fuel efficiency numbers seen. At the end of the competition in 1997, the WVU FutureCar performed in a road rally driving over 300 miles from Detroit, Michigan, to Warren, Pennsylvania. Significant sections of this rally were sustained high speeds of around 60 to $75 \mathrm{mph}$. Poor fuel efficiency numbers were seen, similar to the simulation. An approximate 33 mpge was calculated for this event. Table 4.2.3. displays the simulation results. This poor efficiency is explained by the energy conversion losses associated with series HEVs as described in Section 1.2.1. At these speeds the ICE is continuously operating near were it would be anyway (as a conventional vehicle) except the energy has to be converted from mechanical to electrical back to mechanical undergoing unnecessary losses.

\begin{tabular}{|l|l|l|l|}
\hline & Actual (mpge) & Simulated (mpge) & Difference (\%) \\
\hline FUDS & 52.6 & 52.0 & $-1.1 \%$ \\
\hline HWFET & 40.9 & 40.8 & $0.2 \%$ \\
\hline US06 & Not Available & 31.9 & - \\
\hline
\end{tabular}

Table 4.2.1: Actual and Simulated Fuel Economy for 1997 WVU FutureCar 


\begin{tabular}{|l|l|l|l|}
\hline & Actual (Whrs/mi.) & $\begin{array}{l}\text { Simulated } \\
\text { (Whrs/mi.) }\end{array}$ & Difference (\%) \\
\hline FUDS & 188 & 168 & $-10.6 \%$ \\
\hline HWFET & 149 & 167 & +10.8 \\
\hline US06 & Not Available & 262 & - \\
\hline
\end{tabular}

Table 4.2.2: Actual and Simulated Electrical Efficiency for 1997 WVU FutureCar

\begin{tabular}{|l|l|}
\hline Steady Velocity Simulated (mph) & Resultant Fuel Economy (mpge) \\
\hline $\mathbf{4 5}$ & 62.9 \\
\hline $\mathbf{7 5}$ & 39.3 \\
\hline
\end{tabular}

Table 4.2.3: Constant Velocity Fuel Consumption Simulation for 1997 WVU FutureCar

\begin{tabular}{|l|l|}
\hline Vehicle Parameter & Value used in simulation \\
\hline Mass (kg) & 1800 \\
\hline Aerodynamic Drag Coefficient ( ) & 0.30 \\
\hline Cross-sectional Area $\left(\mathrm{m}^{2}\right)$ & 2.05 \\
\hline Coefficient of Rolling Resistance ( ) & 0.005 \\
\hline
\end{tabular}

Table 4.2.4: Vehicle Parameter Values for Simulation of 1997 WVU FutureCar

Figure 4.2.1. demonstrates the thermostatic type control of the engine operation.

The control is based on SoC as mentioned in Section 3.1.2. Notice the net SoC difference at the end of the trace demonstrating the need for SoC correction, otherwise the fuel efficiency observed would include a net gain in charge of the batteries that could 
be later extracted from the pack propelling the vehicle farther for the same amount of fuel.

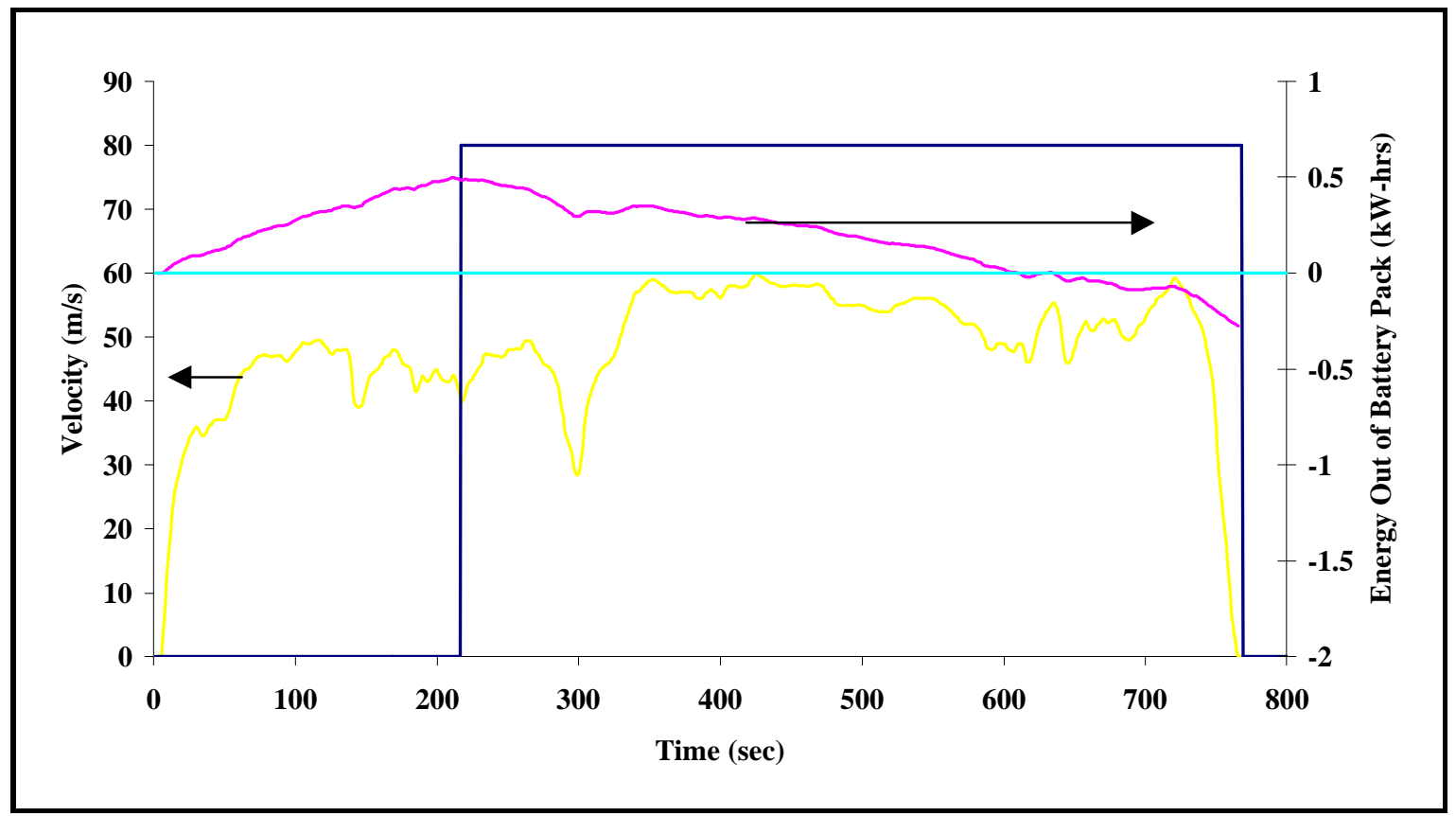

Figure 4.2.1: Net Energy Flow and Engine Operation for 1997 FutureCar on the HWFET (simulation)

Figure 4.2.2. demonstrates engine torque, speed and efficiency operation points. This highlights the significant increase in efficiency gained by hybridization. Maintaining a constant power out while the engine speed changes causes the slanted line created by the operation points. This engine speed variation is caused by the natural (somewhat linear) speed versus voltage characteristic of the alternator. As the battery voltage varies with load so does the engine speed (slightly).

Figure 4.2.3. demonstrates the motor operation points. Notice the small efficiency gradients lessening the importance of optimal motor speed operation. It is desired however, to operate the motor at speeds less than 4000 RPM at light loads. 


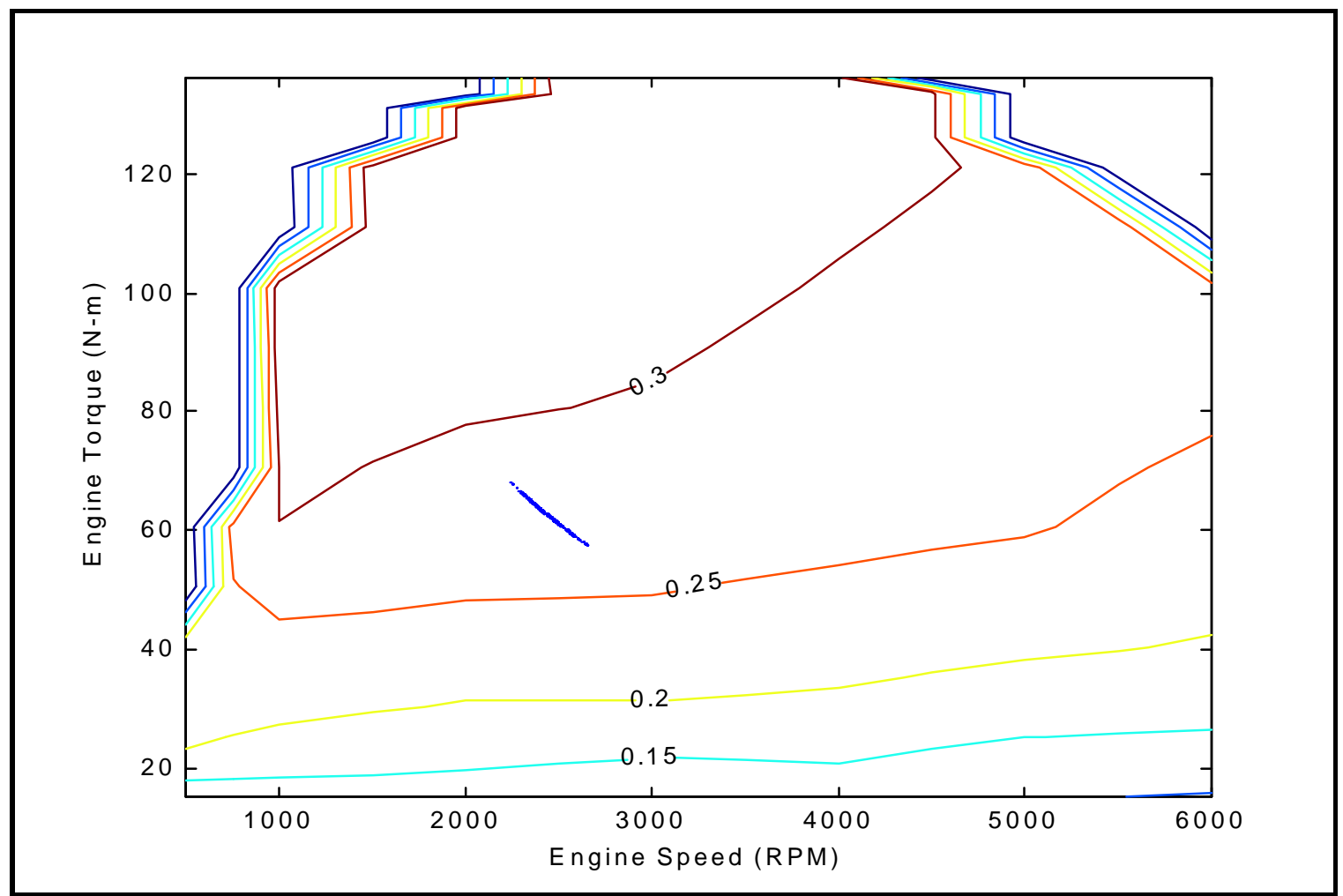

Figure 4.2.2: 1997 WVU FutureCar Engine Operation for the HWFET with Engine Efficiency Contour

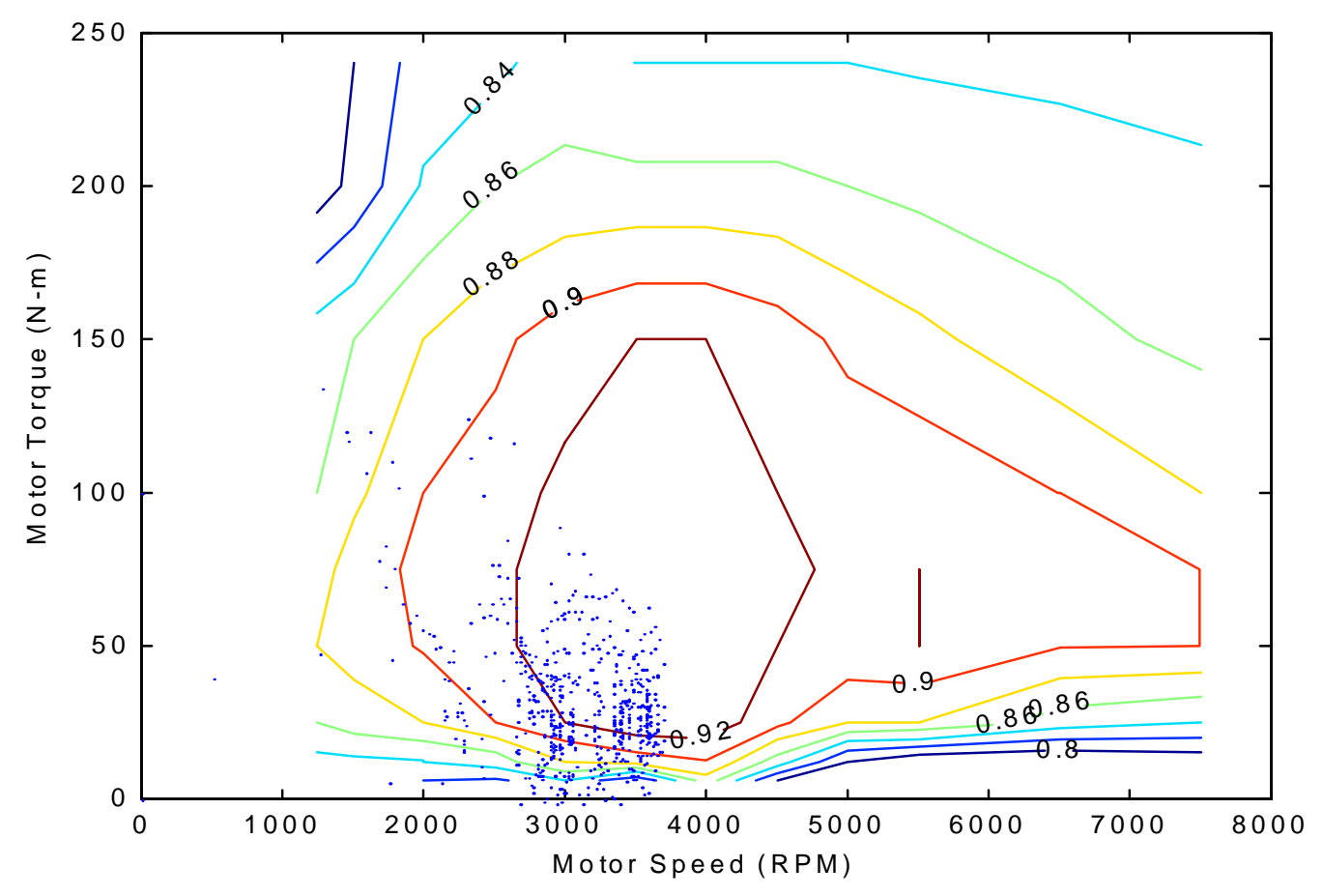

Figure 4.2.3: 1997 WVU FutureCar Motor Operation for the HWFET with Motor 


\section{Efficiency Contour \\ 4.3. Simulation and Comparison of Parallel Vehicles}

There are few parallel HEVs tested with available data for validation of this

program. The 1998 WVU FutureCar has yet to be tested as a parallel. Table 4.3.1.

contains simulated fuel economy data. The low fuel economy result for the US06 is a result of the low electrical efficiency shown in Table 4.3.2. which is caused by the high power requirements associated with the trace. These power peaks exceed the capability of the battery pack creating an extremely high output current. This needs to be corrected for an accurate US06 simulation of the 1998 WVU FutureCar. Table 4.3.3. shows the parameters used in the simulation.

\begin{tabular}{|l|l|l|l|}
\hline & Actual (mpge) & Simulated (mpge) & Difference (\%) \\
\hline FUDS & Not Available & 49.0 & -- \\
\hline HWFET & Not Available & 55.5 & -- \\
\hline US06 & Not Available & 32.2 & -- \\
\hline
\end{tabular}

Table 4.3.1: Actual and Simulated Fuel Economy for 1998 WVU FutureCar

\begin{tabular}{|l|l|l|l|}
\hline & Actual (Whrs/mi.) & Simulated & Difference (\%) \\
& & (Whrs/mi.) & \\
\hline FUDS & -- & 188 & \\
\hline HWFET & -- & 187 & \\
\hline US06 & Not Available & 394 & \\
\hline
\end{tabular}

Table 4.3.2: Energy Efficiency of 1998 WVU FutureCar 


\begin{tabular}{|l|l|}
\hline Vehicle Parameter & Value used in simulation \\
\hline Mass (kg) & 1584 \\
\hline Aerodynamic Drag Coefficient ( ) & 0.31 \\
\hline Cross-sectional Area (m ${ }^{2}$ ) & 2.05 \\
\hline Coefficient of Rolling Resistance ( ) & 0.0065 \\
\hline
\end{tabular}

Table 4.3.3: Vehicle Parameter Values for Simulation of 1998 WVU FutureCar

Figure 4.3.1. demonstrates the results obtained using a similar thermostat type control similar to that of the 1997 WVU FutureCar albeit in parallel operation. The engine operation points shown in Figure 4.3.2. are noticeably at higher efficiency and therefore the vehicle is more efficient overall than most conventional vehicles.

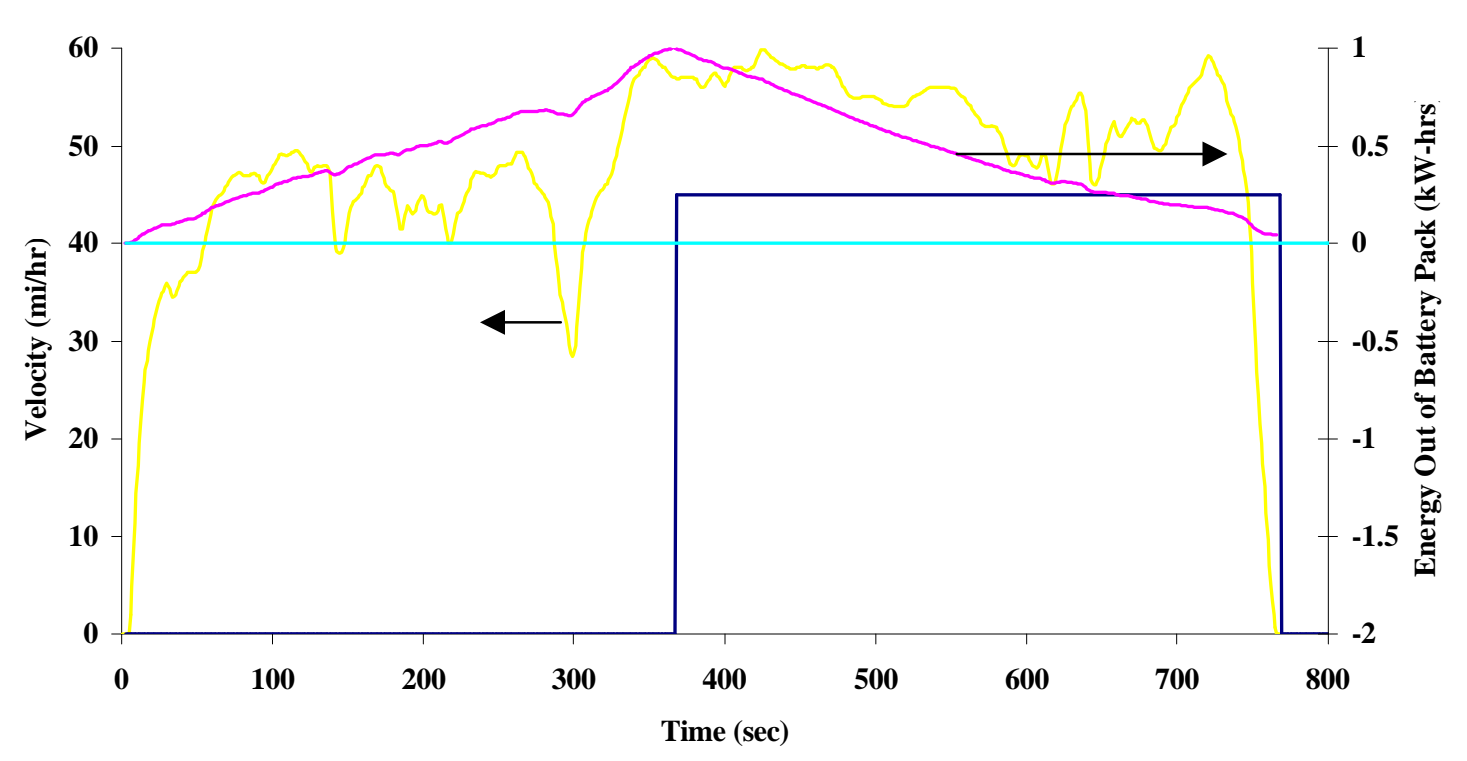

Figure 4.3.1: Net Energy Flow for the 1998 FutureCar on the Highway Fuel Efficiency Test (simulation) 


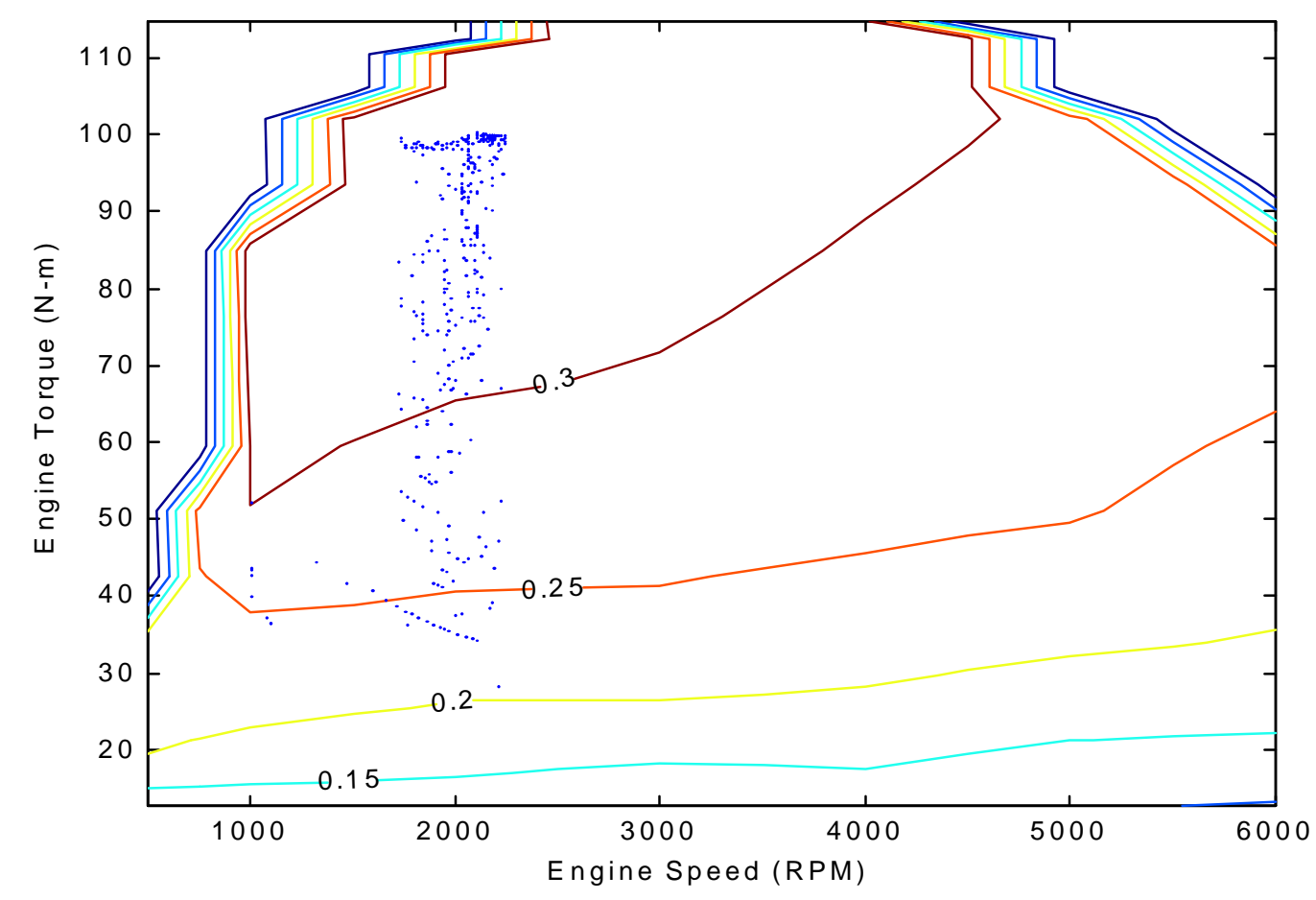

Figure 4.3.2: Engine Operation of 1998 WVU FutureCar for HWFET with Engine Efficiency Contour

\subsection{Simulation and Comparison of Combination HEVs}

The simulations of the Toyota Prius demonstrate the extent to which this modular program can be used to simulate complex HEV powertrain designs. The design of the Toyota Prius is unique and therefore is the only available combination series and parallel HEV for comparison. Table 4.4.1. displays actual and simulated fuel economy test results for the Toyota Prius. Very little information is available for actual fuel economy test results. Since this is not a production vehicle in the United States, the test results are from the manufacturer, and not the EPA. Constant velocity simulations were performed and are displayed in Table 4.4.2. Table 4.4.3. displays the coefficients used to achieve these results. 


\begin{tabular}{|l|l|l|l|}
\hline & $\begin{array}{l}\text { Actual Claimed } \\
\text { (mpge) }\end{array}$ & Simulated (mpge) & Difference (\%) \\
\hline FUDS & Not Available & 56.4 & - \\
\hline HWFET & Not Available & 63.5 & - \\
\hline US06 & Not Available & 55.4 & - \\
\hline $\begin{array}{l}\text { Japan 10-15 Mode } \\
\text { Test Cycle }\end{array}$ & 65.4 & 79.8 & $+18.0 \%$ \\
\hline
\end{tabular}

Table 4.4.1: Actual and Simulated Fuel Economy for the Toyota Prius

\begin{tabular}{|l|l|}
\hline Steady Velocity Simulated (mph) & Resultant Fuel Economy (mpge) \\
\hline $\mathbf{4 5}$ & 77.2 \\
\hline $\mathbf{7 0}$ & 51.3 \\
\hline
\end{tabular}

Table 4.4.2: Constant Velocity Fuel Consumption Simulation for the Toyota Prius [12]

\begin{tabular}{|l|l|}
\hline Vehicle Parameter & Value used in simulation \\
\hline Mass (kg) & 1200 \\
\hline Aerodynamic Drag Coefficient ( ) & 0.3 \\
\hline Cross-sectional Area $\left(\mathrm{m}^{2}\right)$ & 1.9 \\
\hline Coefficient of Rolling Resistance ( ) & 0.0055 \\
\hline
\end{tabular}

Table 4.4.3: Vehicle Parameter Values for Simulation of Toyota Prius

Figure 4.4.1. demonstrates the complete engine operation control. As described in Section 3.1.2. changes in the alternator operating speed varies the engine operation speed yielding complete control over the engine. 


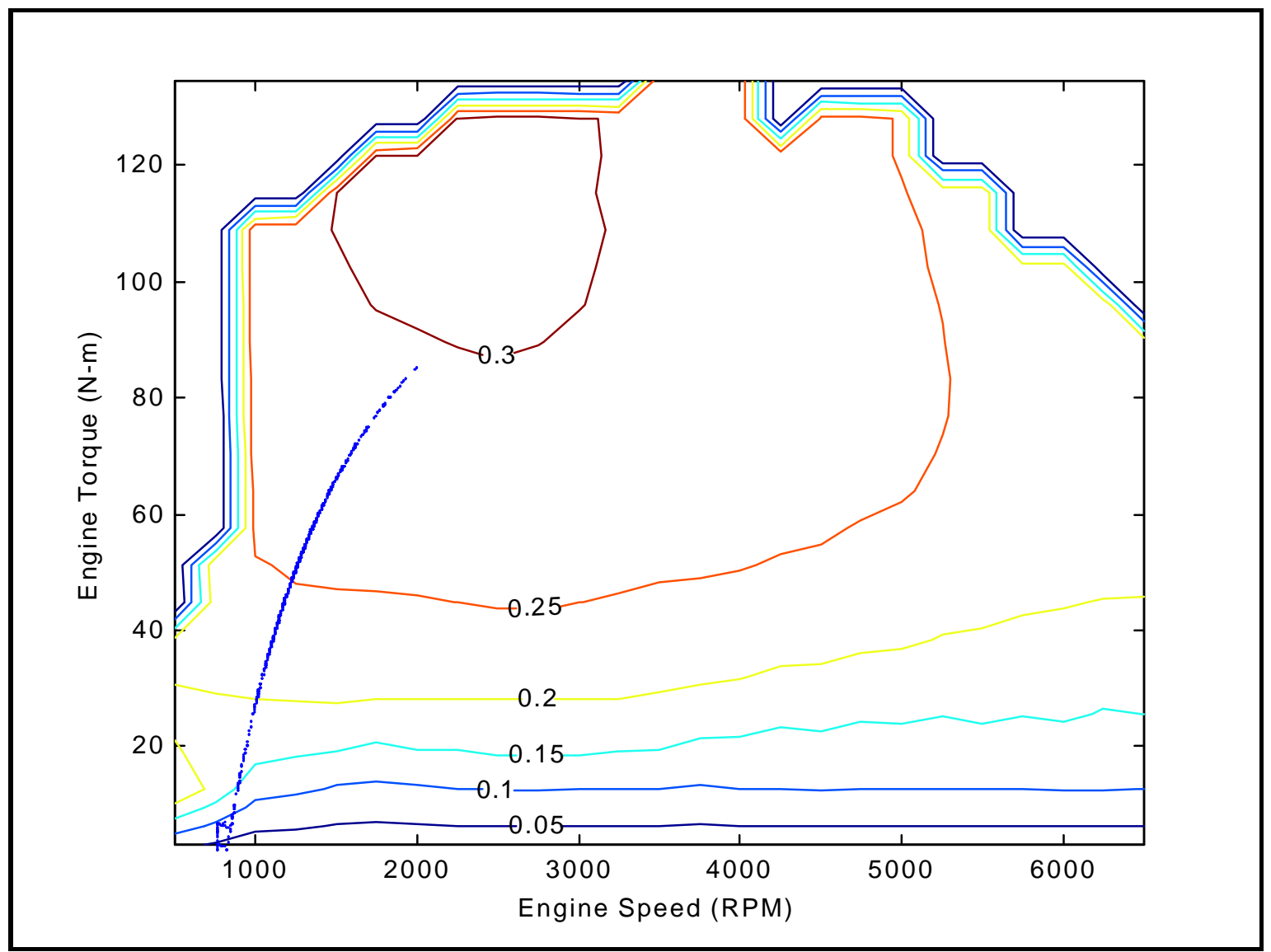

\section{Figure 4.4.1: Engine Operation for Toyota Prius on HWFET with Engine Efficiency Contour}

Figure 4.4.2 demonstrates the actual component power operation points. Notice that the alternator can vary the engine speed with relatively small power absorption. Figure 4.4.3. plots the component speed operation point. This demonstrates the alternator's ability to undergo great transients to ensure proper engine operating speeds. This plot demonstrates the problems of simulating Toyota's control. Nothing is known about the actual vehicle control strategy or any of the gear ratios used. Changing the control strategy and or gear ratios can actually turn the alternator into a motor for a third power source. This was not demonstrated in this simulation. 
There is a possibility for significant error in this simulation due to the advanced engine control required in the actual Prius. The engine in this simulation was simply rescaled as previously described. The Prius's ICE is probably the most advanced engine on the market today. It employs Miller cycling with an extremely high expansion ratio of 14.7:1 and advanced variable valve control. There is no detailed efficiency data available for this engine. 


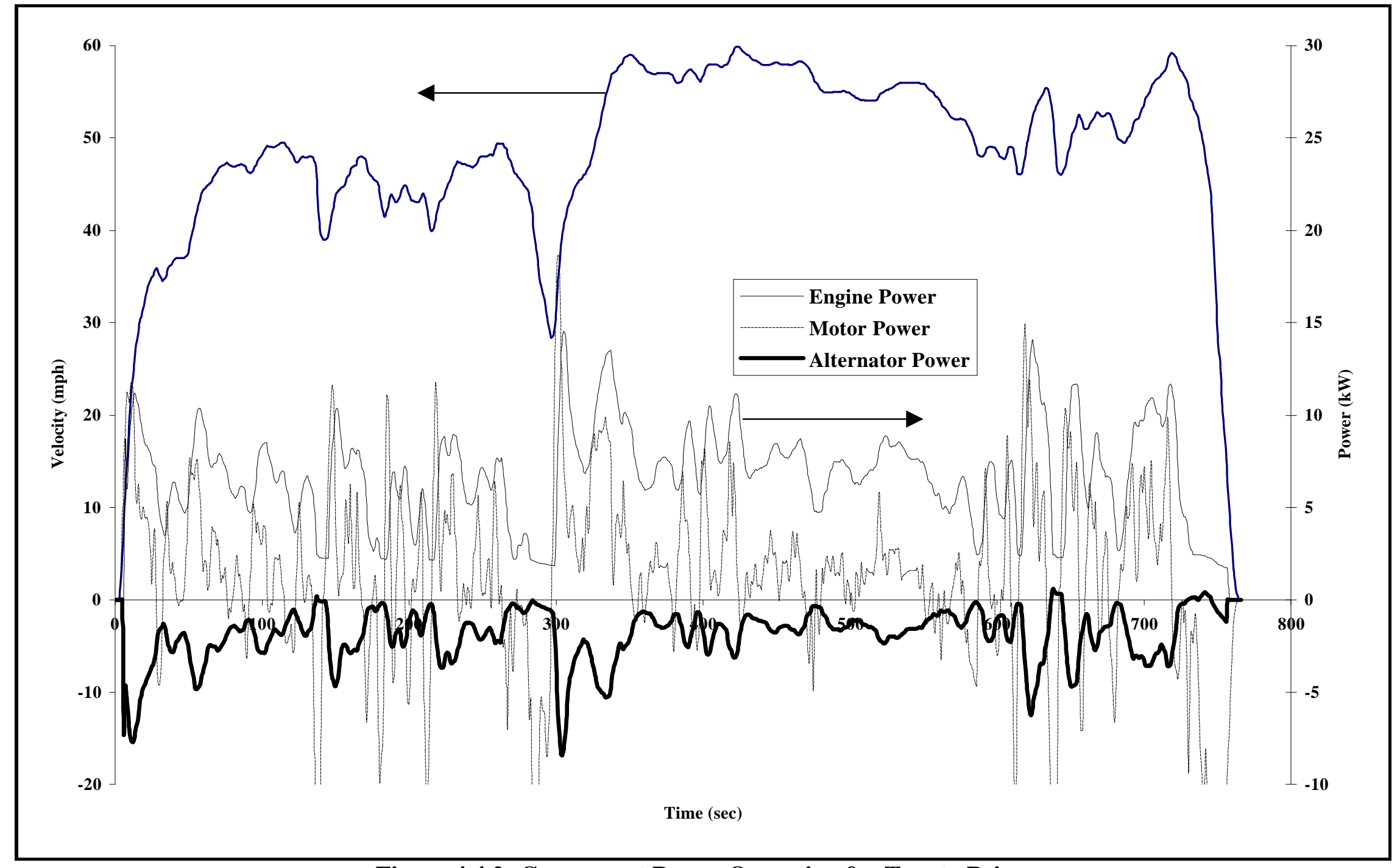

Figure 4.4.2: Component Power Operation for Toyota Prius 


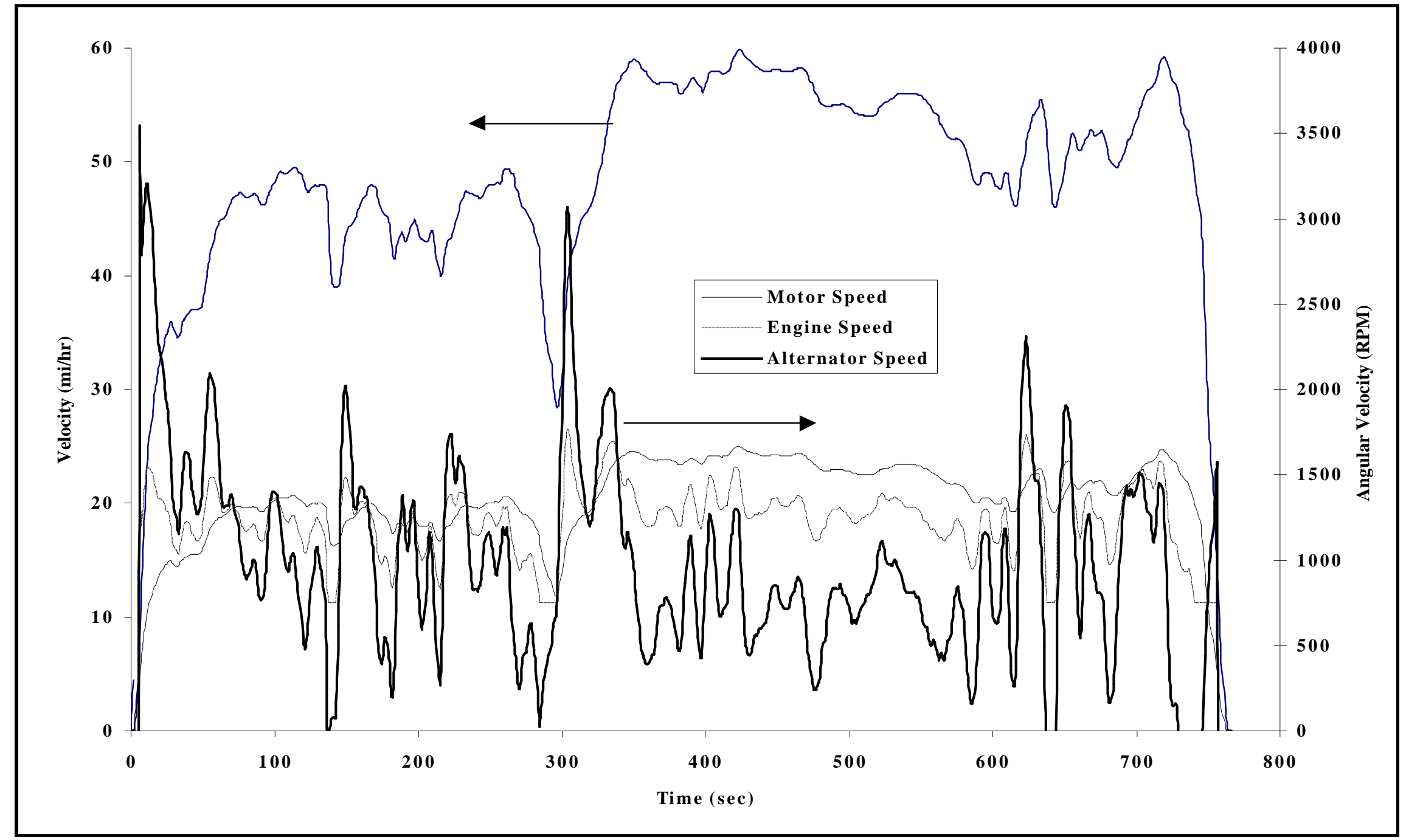

Figure 4.4.3: Component Operation for Toyota Prius 


\section{Future Work}

\subsection{Energy Storage Simulation}

\subsubsection{Improved Battery Simulation}

In this program only lead acid batteries were simulated, and the model used was over-simplified. This is due to the fact that little information is readily available on battery behavior. Testing is often performed on batteries, but the data published is often not applicable to the numerical simulation of battery behavior. Most published battery data is in terms of voltage versus time for a constant current discharge. This is not relevant for an HEV that has high cyclic loading. Electrochemical batteries are actually very difficult to simulate accurately; assumptions such as those made in this simulation program can be used except that more information is needed on battery internal resistance and open circuit voltage. This can simply be obtained through pulse charging and discharging tests, assuming that the batteries have no capacitive or inductive nature.

Similar information is needed for different battery types. HEVs require different battery characteristics than EVs. EVs typically require a with high energy density (energy per unit mass) while charge sustaining HEVs require a battery that has high power density. In both vehicle cases, battery pack weight is a large concern, though in an electric vehicle since the electric energy stored determines the range, in design, the total energy is maximized for a given acceptable weight. In charge sustaining HEVs since the fuel stored primarily determines the range, there is little concern about the electrical energy storage capability of the battery pack. This provides the opportunity for major weight reduction in the battery pack over EVs, but a new concern arises when considering the maximum power output capability that a battery pack can exert. Newer 
electric and HEVs are typically using Nickel Metal Hydride (NiMH) batteries for their high energy density and power density. These batteries have very different internal resistance versus $\mathrm{SoC}$ characteristics than lead acid batteries. Once again very there is very little information published on NiMH batteries. There has been a lot of focus lately on newer, more advanced batteries like lithium ion, sodium, and zinc air batteries. All of these batteries have potential and should be considered when designing HEVs. Typically though, the more advanced the battery the less information that is available.

\subsubsection{Advanced Energy Storage Systems Simulation}

In recent years several advanced storage systems have been considered for use in hybrid electric vehicles. Some of these systems are flywheels and ultracapacitors. This simulation program has no provisions for these storage devices to be simulated; although, being modular with little research a simulation could be easily made for these devices and inserted as an option in the main program.

\section{Flywheels}

These devices are simple in nature; but, once again, there are little available data on actual existing devices. The flywheel is simply simulated as a mass with considerable centrifugal inertia attached to a motor/alternator; efficiencies could be placed in a look-up table much like this simulation program does for the traction motor. The flywheel would also have a spin down inefficiency associated with the fact that the flywheel would slow and lose inertial energy on its own due to bearing and windage losses. 


\section{Ultracapacitors}

Ultracapacitors are possibly the easiest to simulate. They are simply simulated as capacitors with a very small internal resistance and a leakage current. This data, though, is not readily available.

\subsection{Improved Cycle Simulation}

This simulation program simulates the vehicles as though they perfectly follow the speed versus time trace for the applicable emissions or fuel efficiency test. When the vehicles are actually tested, they are driven by a driver who watches the vehicle speed trace on a screen. If the vehicle were to "fall off the trace", the driver has to make a correction. This correction usually is a sharp acceleration or deceleration, and most likely, this requires the vehicle to accelerate at a greater rate than any actual acceleration seen on the trace.

It is very difficult to simulate the actual characteristics of a real driver. Any attempt would likely increase the accuracy of this simulation program. This correction would most easily be done by a pre-processing program that would simply input the exact trace and output a trace, which has been altered by an integrator and differentiator, that would more closely reflect an actual vehicle trace of speed versus time.

\subsection{Emissions Predictions}

This simulation program could be modified to predict the real-time emissions for a vehicle. The engine speed and load versus time trace, taken after the vehicle trace has been simulated, could be such as that developed at West Virginia University, and 
inputted into a neural network based virtual sensing program. This virtual sensing program is basically a neural network set up to predict emissions from a particular engine and is trained on a dynamometer while the engine is transiently loaded. This program has proven to predict the emissions of an engine within $12 \%$ accuracy on an instantaneous basis and within 5\% on an integrated test basis. [12] 


\section{Conclusions}

A simulation program such as the one developed in this study allows a comprehensive look at the benefits of almost any powertrain component. Simulating several conventional vehicles where the fuel economy was well documented validated this program. Though some contending technologies in future HEV design such as flywheels, fuel cells ultracapacitors, and more advanced battery technology were not modeled, the modular based program is easily modified to include these technologies, by simple modifications to the program, and by changing or replacing modules.

The design of a vehicle intended to meet PNGV goals is an iterative process of correctly sizing and configuring powertrain components. For any one configuration of powertrain components there is a single set of optimal component sizes, lending to a program which can test many concepts without requiring any to be built. There are many component technologies available to help reach these goals, but most come at a great expense. It is of considerable importance in the design to know if the expense is worth the benefit provided.

The program developed in this study predicts efficiency and performance for conventional vehicles, HEVs, and EVs with minimal error. Components in this program with relatively large energy loss such as the internal combustion engine, batteries, electric motor, electric motor controller, and transmission, have been modeled in detail to assure accuracy. As the greatest source of energy loss the engine was modeled in the most detail. Each component modeled was validated by comparing the results obtained with existing vehicles. The compression ignition engine was validated with the simulation of the Volkswagen Passat. The various spark ignited internal combustion engines were 
validated by the simulation of several vehicles, including the Saturn coupe, the Chevrolet Lumina, and the Mercury Sable. The series powertrain was validated by the simulation of the 1997 WVU FutureCar.

With the addition of a model of advanced components, namely flywheels, ultracapacitors, and more advanced batteries, this program can provide a broad perspective of present and future HEV design. All of the above mentioned components are simple to model, only requiring characteristic data. Once this data are available the program can be modified simply by adding a module for the new component. Emissions prediction would also be a great improvement to this simulation program. Emissions can be predicted with great accurately with the use of a neural network based virtual sensing technology which has been proven at West Virginia University.[12] Together with emissions predictions, this simulation program will be an extremely powerful tool in the design of a vehicle to meet PNGV goals. 


\section{References}

1. Taylor, Wayne, Feasible Design Strategies for Near-Term Hybrid Electric Vehicles, MSME Thesis, West Virginia University, August 1997

2. Senger, Randall Donn, Validation of ADVISOR as a Simulation Tool for a Series Hybrid Electric vehicle using the Virginia Tech FutureCar Lumina, Thesis, Virginia Polytechnical Institute, 1997

3. Zeleznik, Frank J., and Bonnie J. McBride, "Modeling The Internal Combustion Engine", NASA Reference Publication No. 1094, Lewis Research Center, Cleveland OH, 1985

4. Greenbaum, Joseph J., Michel A. Kuger, and Barry E. Westmoreland, "Manual Transmission Efficiency Trends and Characteristics," SAE Paper No. 942274, 1994

5. Park, Dong Hoon, Do Gi Lim, and Hee Bock Cho, "Theoretical Investigation on Automatic Transmission Efficiency," SAE Paper No. 960426, 1996

6. Unnewehr, L.E., "Electrical Component Modeling and Sizing for EV Simulation", SAE Paper No. 780215, 1978

7. Heywood, J. B., Internal Combustion Engine Fundamentals, McGraw-Hill, New York, NY, 1988

8. Communication from Unique Mobility, Inc., Golden, Colorodo, Subject: SR218H motor specifications

9. 1998 FutureCar Challenge Rules and Regulations, Mike Duoba, ANL, February 10, 1997

10. Information from electronic archive: www.epa.gov

11. Ford Motor Company 1998

12. Atkinson, Christopher M., Theresa Long, and E. L. Hanzevack, "Virtual Sensing and Emissions Prediction System for On-board Diagnostics and Engine Control", SAE Paper No. 980516,1998 


\section{Bibliography}

Bagot, Nick, Editor, "Electric and Hybrid Vehicle Technology '97", UK \&International Press, 1997

Kreyszig, Erwin, “Advanced Engineering Mathematics”, John Wiley \& Sons, New York, New York, 1993

Reinholz, Mabie, "Mechanisms and Dynamics of Machinery", John Wiley \& Sons, New York, New York, 1987

Smith, Ralph J., and Richard C. Dorf, "Circuits Devices and Systems”, John Wiley \& Sons, New York, New York, 1992

Unique Mobility INC., "Installation Manual for CALIBER EV 53 SR218H Brushless DC Motor CA40-300L Inverter EVPH332 Digital Controller”, Ver. 1.05

Unique Mobility INC., "User's Manual for CALIBER EV 53 SR218H Brushless DC Motor CA40-300L Inverter EVPH332 Digital Controller", Ver. 1.05 


\section{Appendix A}

\section{Main Program Module}

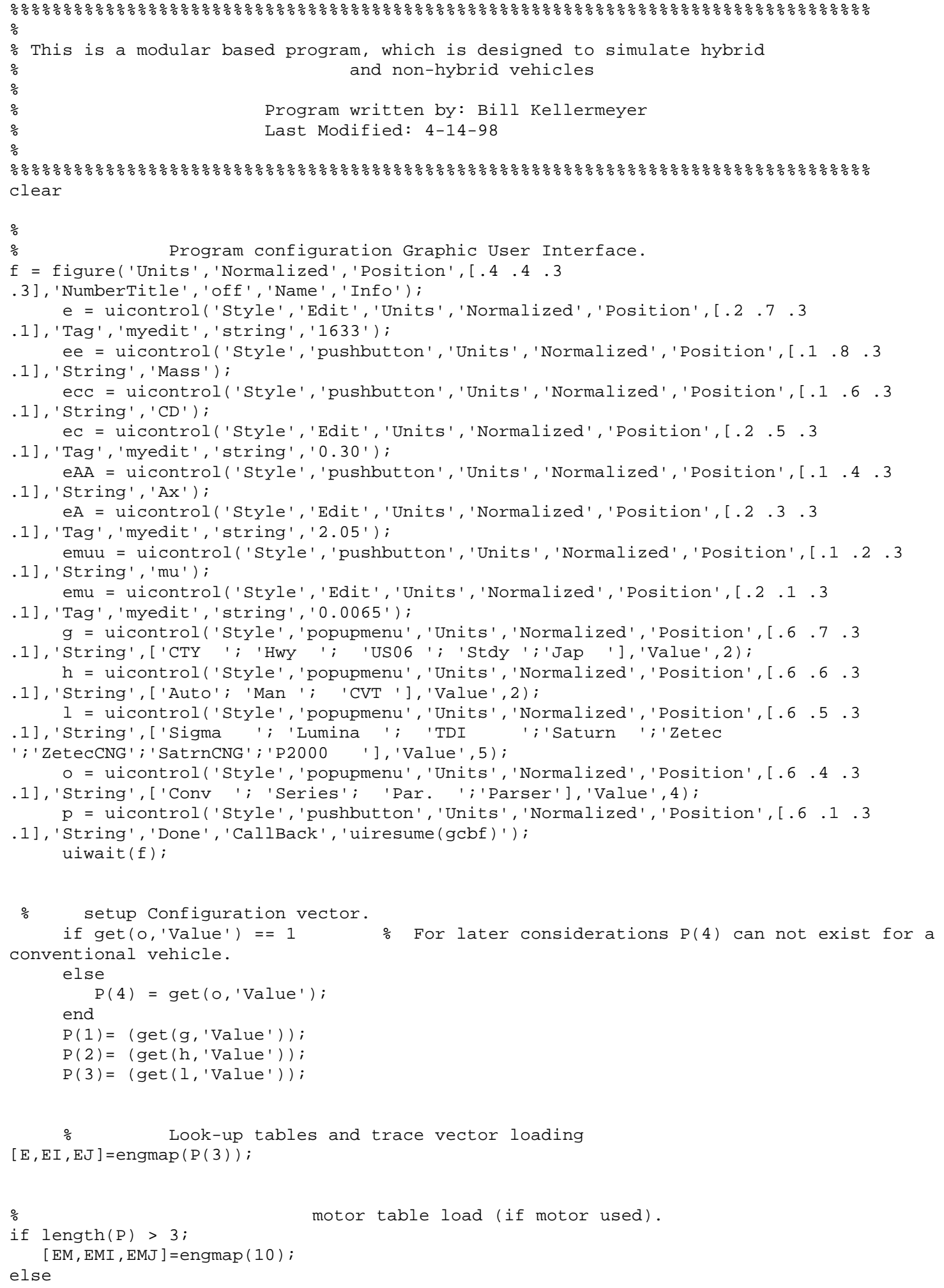




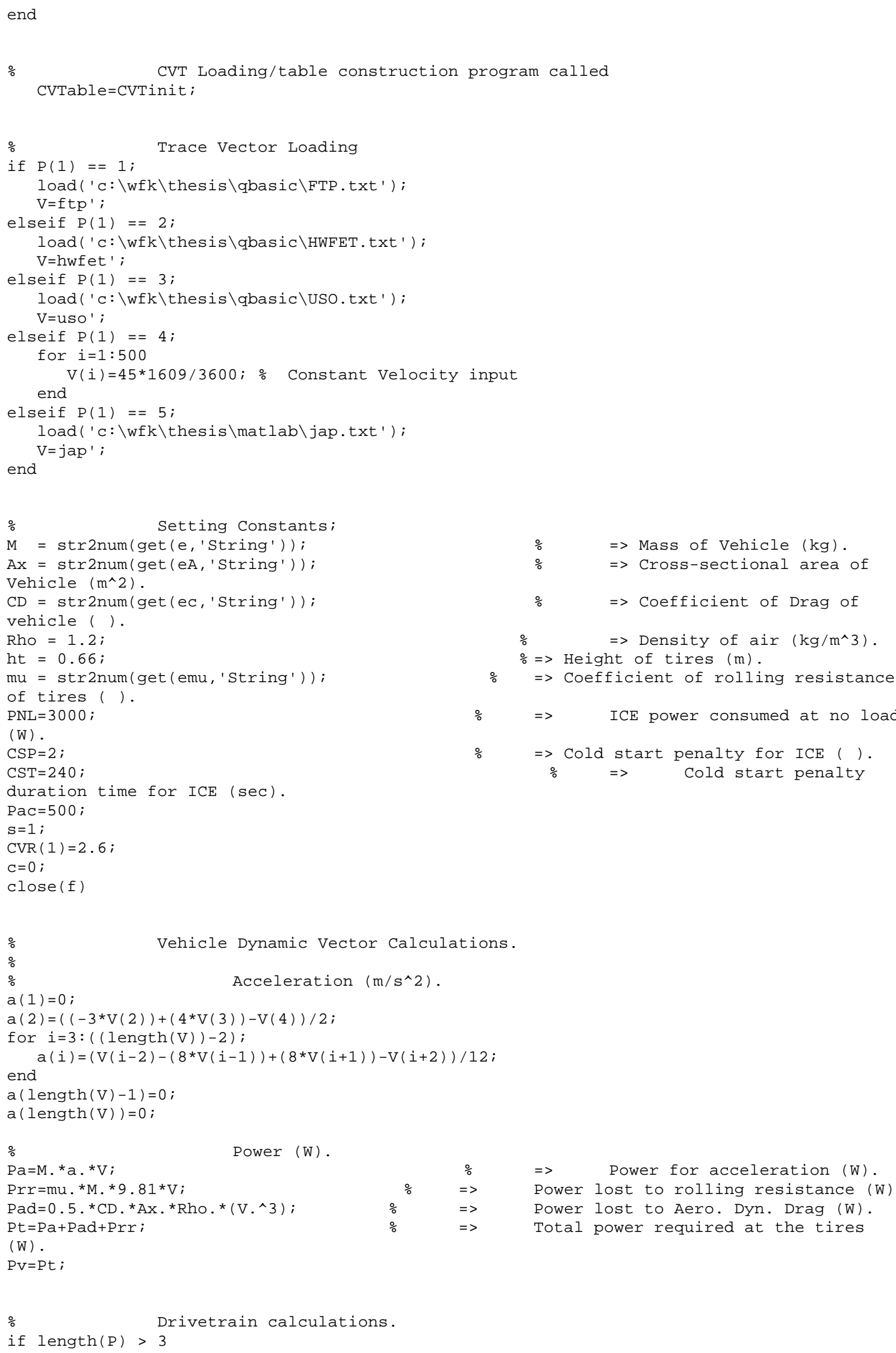




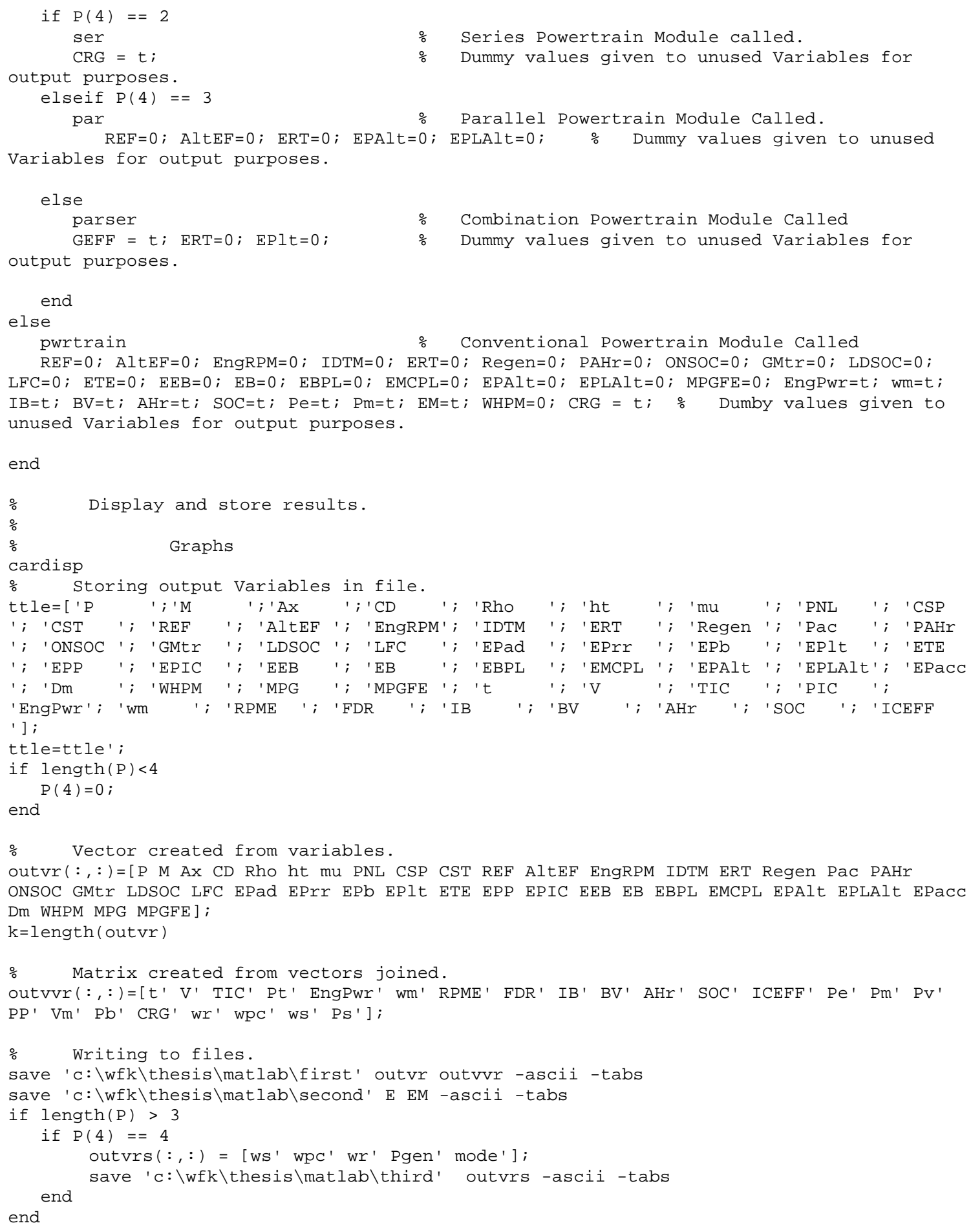




\section{Appendix B}

\section{Conventional Powertrain Simulation Module}

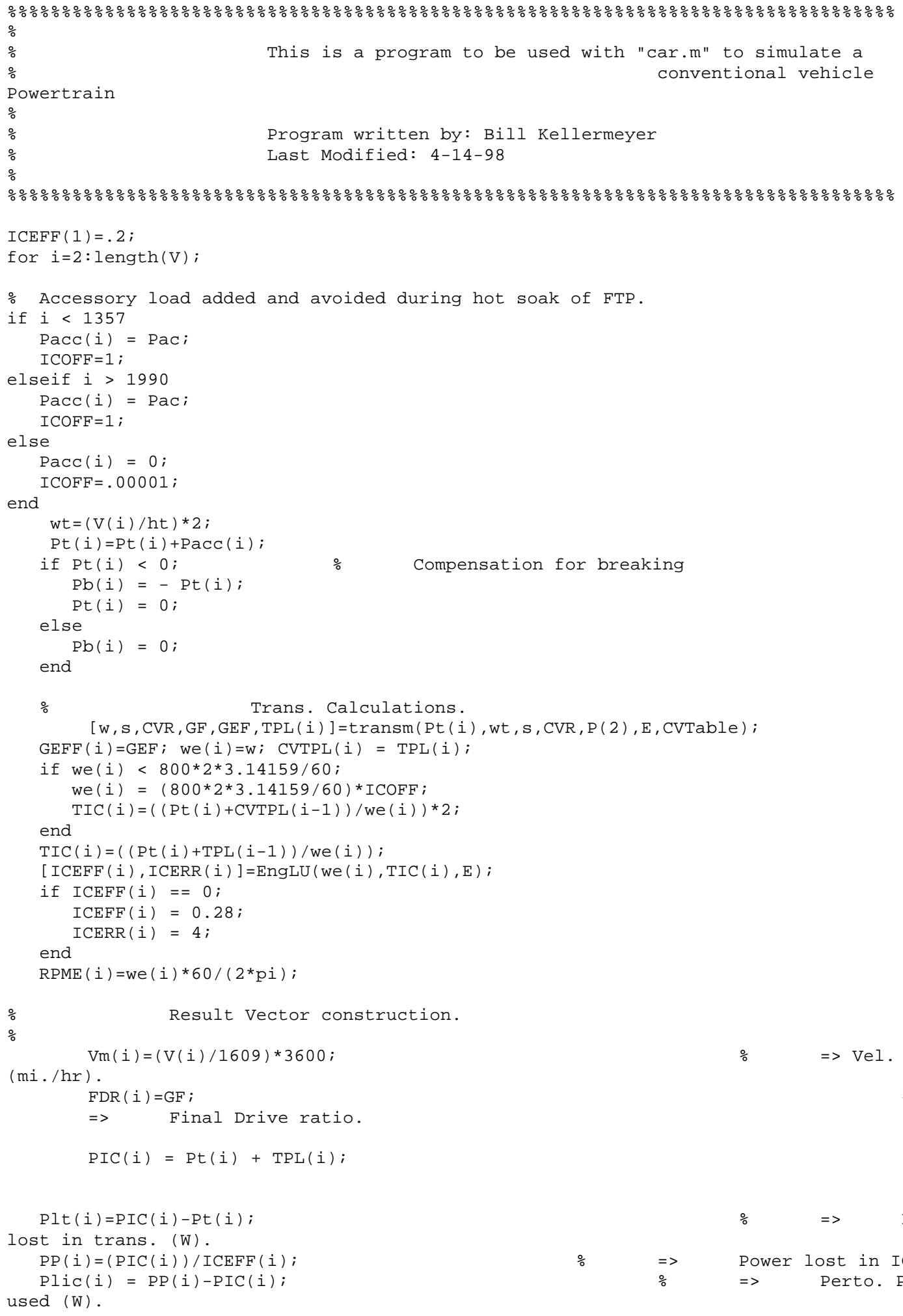


$t(i)=i$;

$=>$ Time vector (sec).

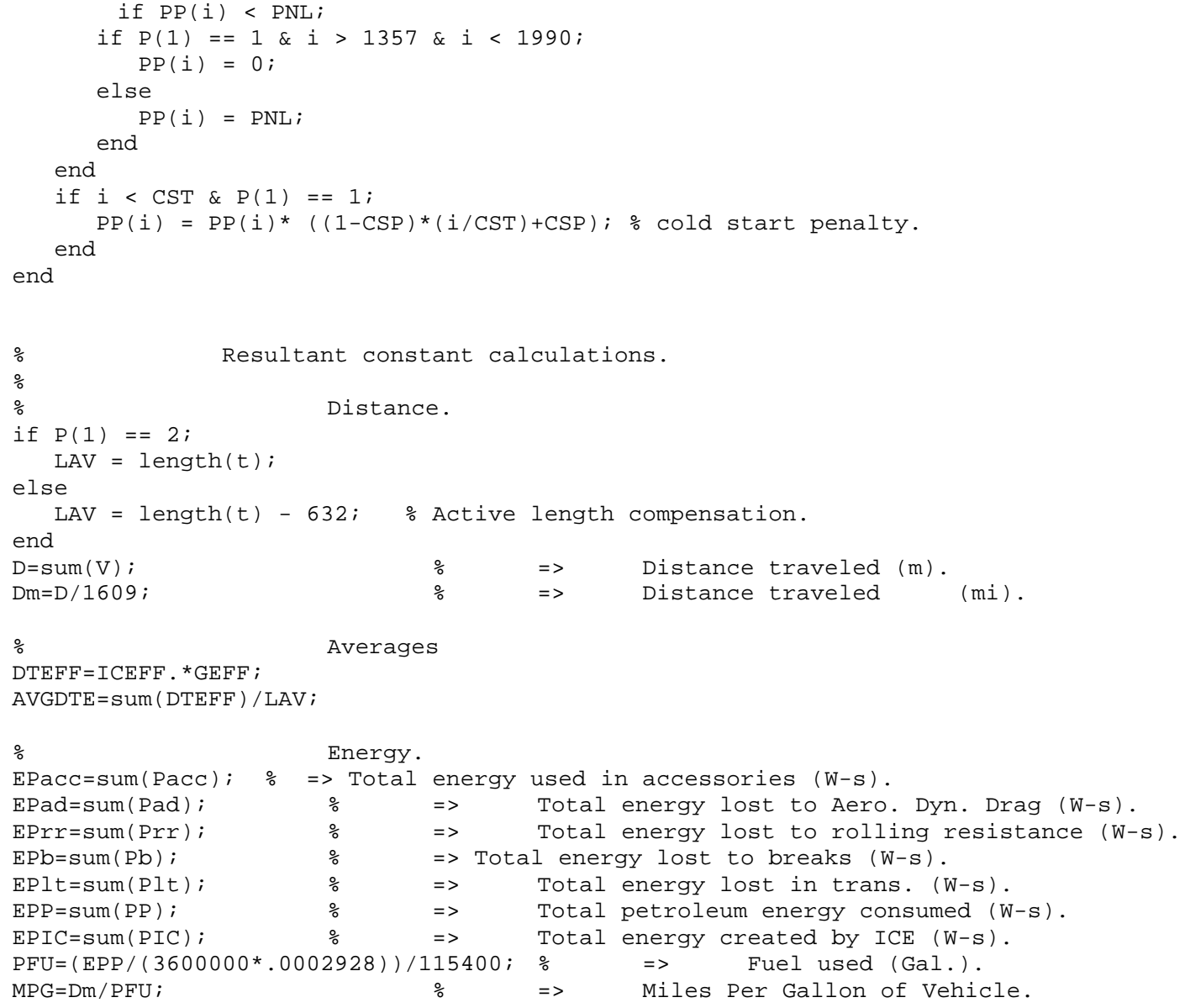




\section{Appendix C}

\section{Series Powertrain Simulation Module}

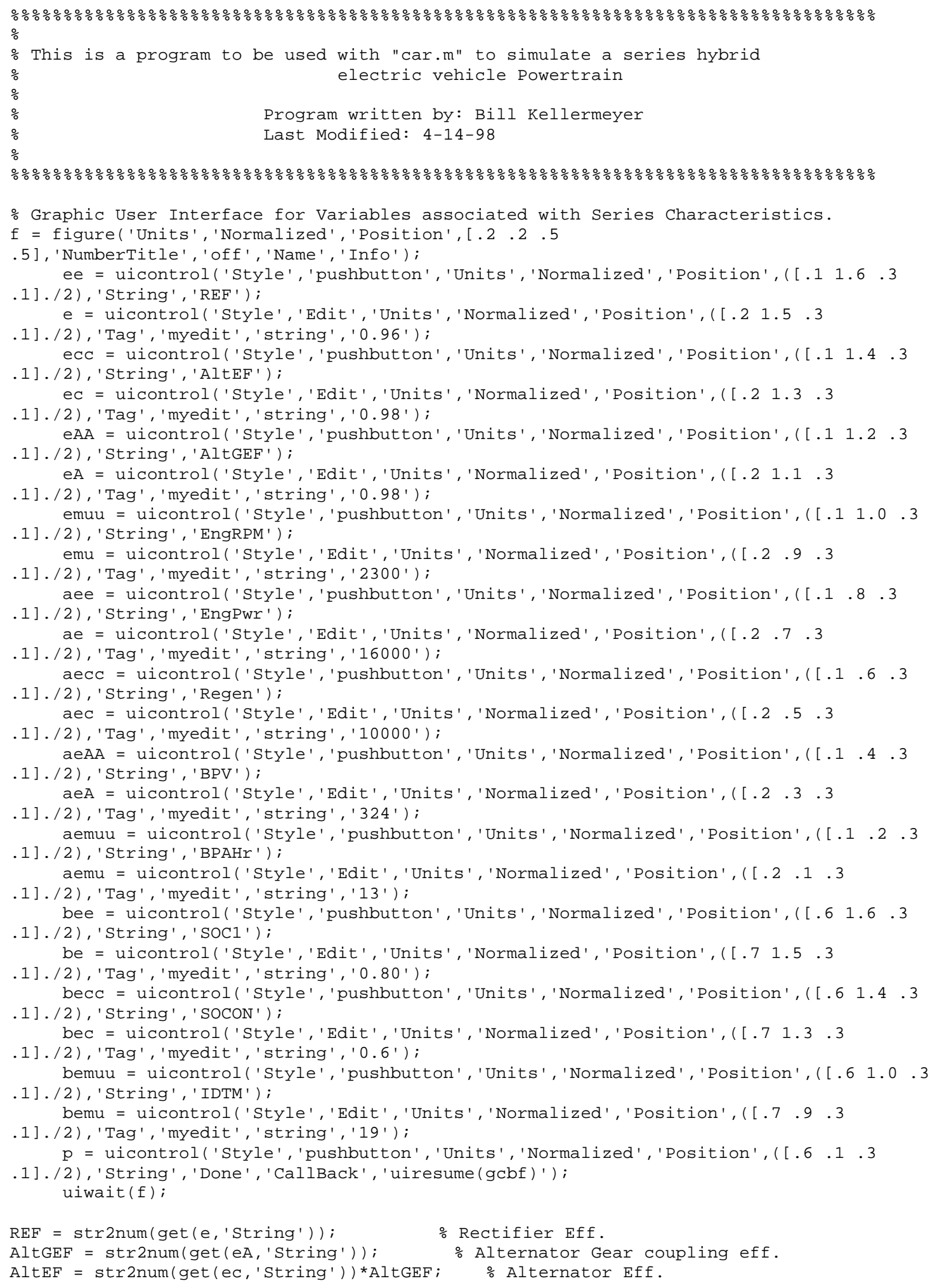




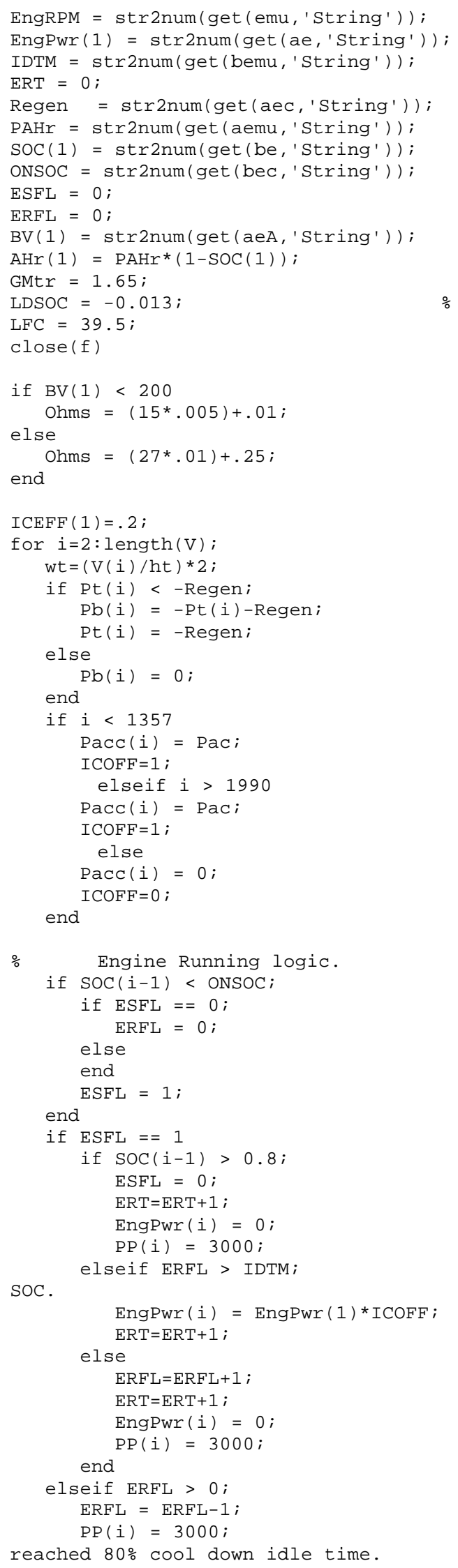

: Engine shut down on UDDS.

: Engine off compensation (UDDS only).

\% Engine shut down on UDDS.

\% Ensure fresh start.

o Start/maintain engine running.

High State of Charge shut-down.

Engine on and revved but batt's. not too $80 \%$

\% Engine on, no rev, and Batt's not too $80 \%$

Engine on Batt's 


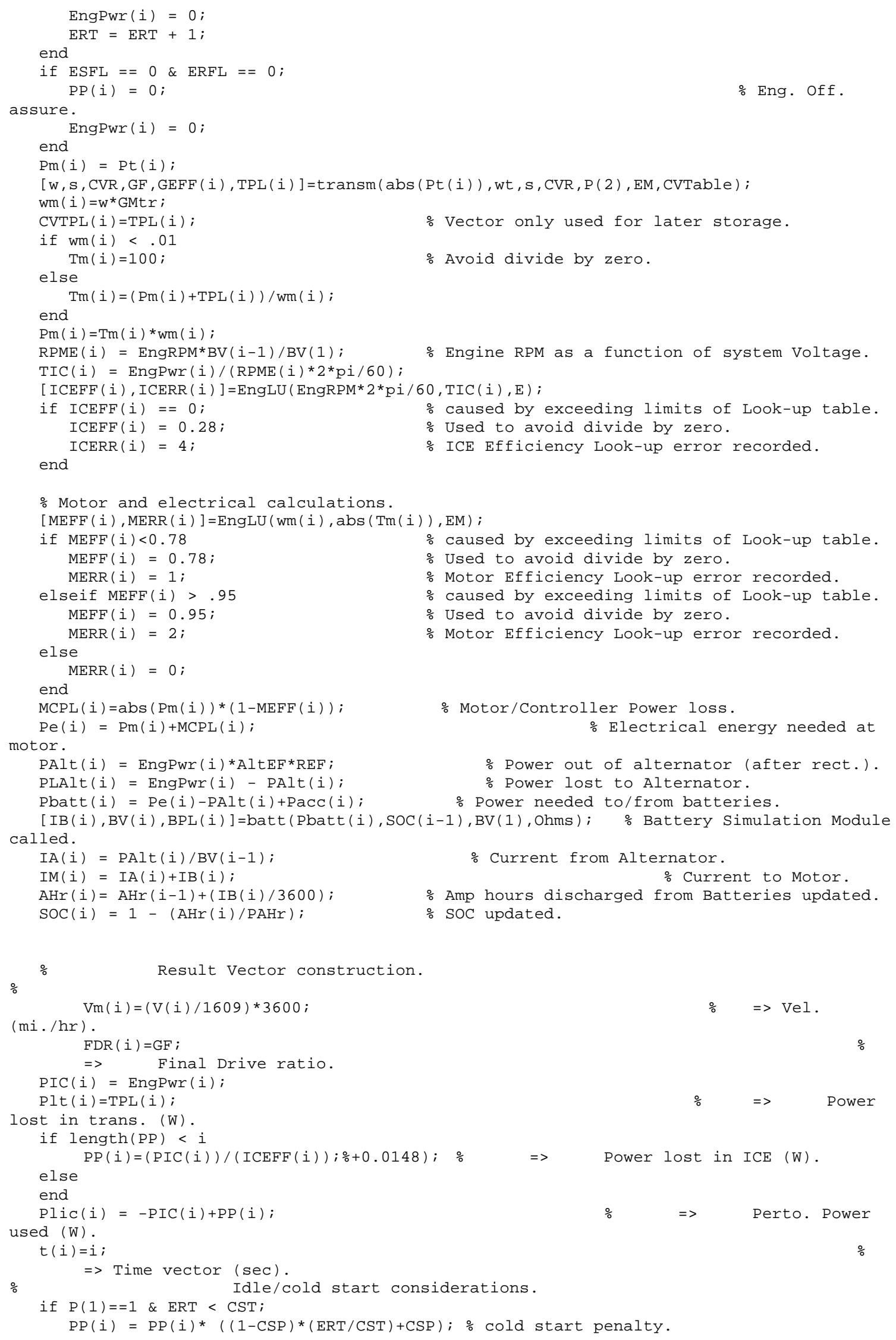




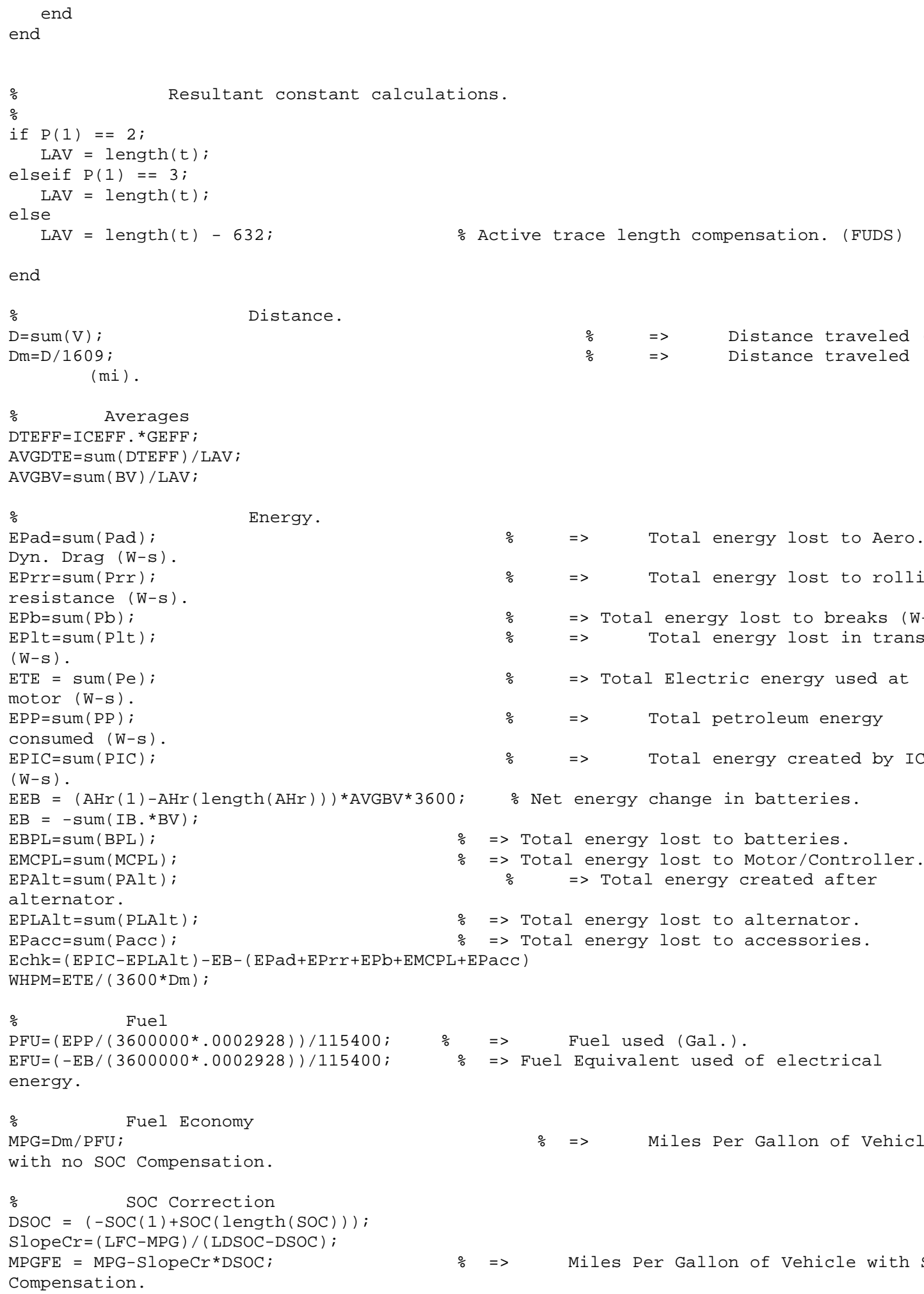




\title{
Appendix D
}

\section{Parallel Powertrain Simulation Module}

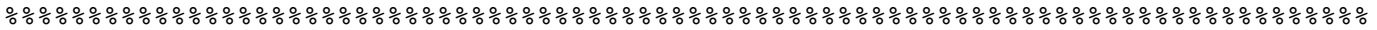 \\ $\circ$ \\ \% This is a program to be used with "car.m" to simulate a parallel hybrid \\ electric vehicle Powertrain \\ Program written by: Bill Kellermeyer \\ Last Modified: 4-14-98

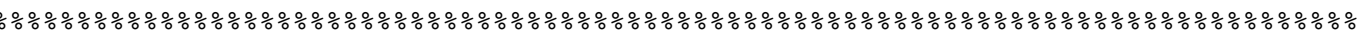 \\ - Graphic User Interface for Variables associated with Parallel Characteristics. \\ $\mathrm{f}=$ figure('Units', 'Normalized', 'Position', [.2 .2 .5 \\ .5], 'NumberTitle', 'off', 'Name', 'Info'); \\ aee $=$ uicontrol('Style', 'pushbutton', 'Units', 'Normalized', 'Position', ([.1 .8 .3 \\ .1]./2), 'String', 'EngPwr'); \\ ae = uicontrol('Style',' Edit',' Units', 'Normalized', 'Position', ([.2 .7.3 \\ .1]./2),'Tag', 'myedit', 'string','16000'); \\ aecc = uicontrol ('Style', 'pushbutton', 'Units', 'Normalized', 'Position', ([.1 .6 .3 \\ .1]. (2), 'String', 'Regen'); \\ aec = uicontrol('Style','Edit','Units','Normalized','Position', ([.2 .5 .3 \\ .1]./2), 'Tag', 'myedit', 'string', '35000'); \\ aeAA = uicontrol('Style',' 'pushbutton','Units','Normalized','Position', ([.1 .4 .3 \\ .1]./2), 'String', 'BPV'); \\ aeA = uicontrol('Style',' 'Edit',' 'Units', 'Normalized', 'Position', ([.2 .3.3 \\ .1]./2),' Tag', 'myedit', 'string', '324'); \\ aemuu = uicontrol('Style','pushbutton', 'Units', 'Normalized', 'Position', ([.1 .2 .3 \\ .1] . /2), 'String', 'BPAHr'); \\ aemu = uicontrol('Style','Edit','Units','Normalized','Position', ([.2 .1 .3 \\ .1]./2), 'Tag', 'myedit', 'string', '13'); \\ bee = uicontrol ('Style', 'pushbutton', 'Units', 'Normalized', 'Position', ([.6 1.6 .3 \\ .1]./2), 'String', 'soc1'); \\ be = uicontrol ('Style',' Edit','Units', 'Normalized', 'Position', ([.7 1.5 .3 \\ .1] . /2), 'Tag', 'myedit', 'string', '0.7'); \\ becc = uicontrol('Style','pushbutton','Units','Normalized', 'Position', ([.6 1.4.3 \\ .1] . /2), 'String', 'SOCON'); \\ bec = uicontrol('Style','Edit','Units','Normalized','Position', ([.7 1.3 .3 \\ .1] . (2),' 'Tag', 'myedit', 'string', '0.6'); \\ cebb = uicontrol('Style','pushbutton','Units','Normalized','Position', ([.6 1.2 .3 \\ .1]./2), 'String', 'GMtr'); \\ ceb = uicontrol('Style','Edit','Units','Normalized', 'Position', ([.7 1.1 .3 \\ .1]./2), 'Tag', 'myedit', 'string', '1.65'); \\ bemuu = uicontrol('Style','pushbutton','Units', 'Normalized','Position', ([.6 1.0 .3 \\ .1]. (2), 'String', 'IDTM'); \\ bemu = uicontrol ('Style','Edit','Units', 'Normalized', 'Position', ([.7 .9 .3 \\ .1]./2), 'Tag', 'myedit', 'string', '19'); \\ $\mathrm{p}=$ uicontrol('Style', 'pushbutton','Units', 'Normalized','Position', ([.6 .1 .3 \\ .1]./2), 'String', 'Done', 'CallBack', 'uiresume (gcbf)') ; \\ uiwait (f); \\ \% Setting constant Values \\ EngRPM $=1000$; \\ EngPwr (1) = str2num (get (ae, 'String')) \\ Regen $=\operatorname{str} 2$ num (get $($ aec, 'String')) \\ IDTM $=\operatorname{str} 2$ num (get (bemu, 'String')) \\ $\mathrm{PaC}=500$; \\ $\mathrm{PAHr}=\operatorname{str} 2$ num $($ get $($ aemu, 'String') ); \\ SOC $(1)=\operatorname{str} 2$ num (get (be, 'string')) \\ ONSOC $=$ str2num(get (bec, 'String')); \\ $\mathrm{ESFL}=0$; \\ $\mathrm{ERFL}=0$ \\ $\mathrm{ERT}=0$;

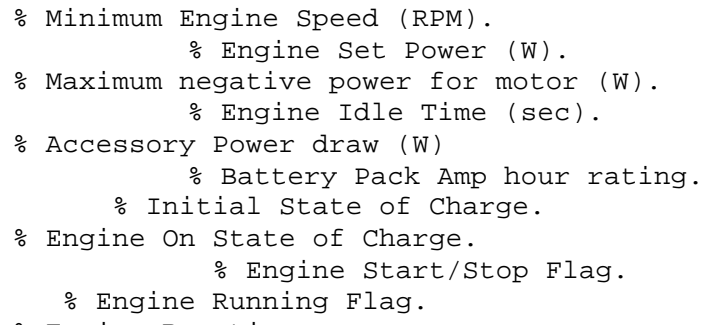




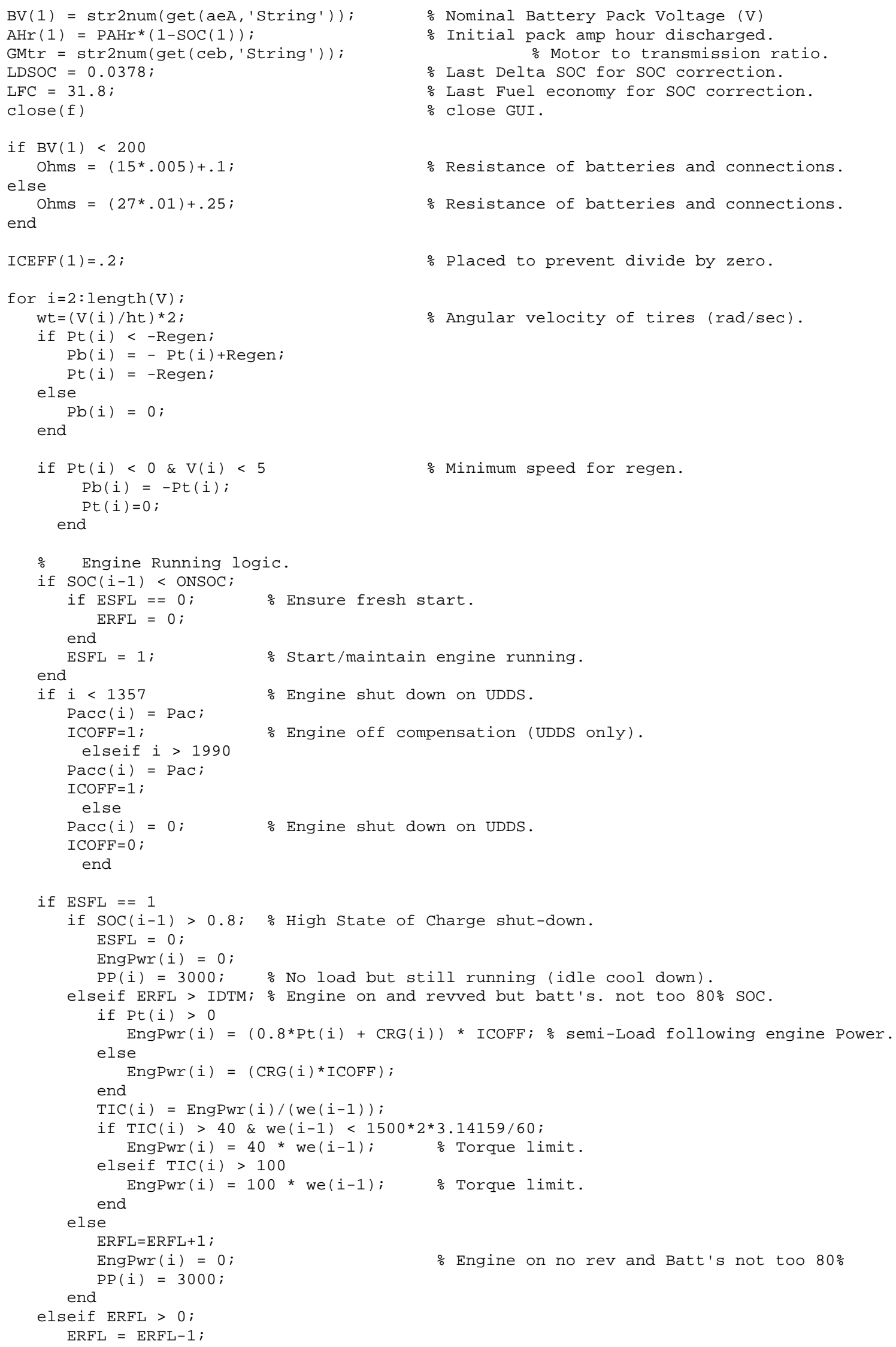

\% Nominal Battery Pack Voltage (V)

\% Initial pack amp hour discharged. o Motor to transmission ratio. 


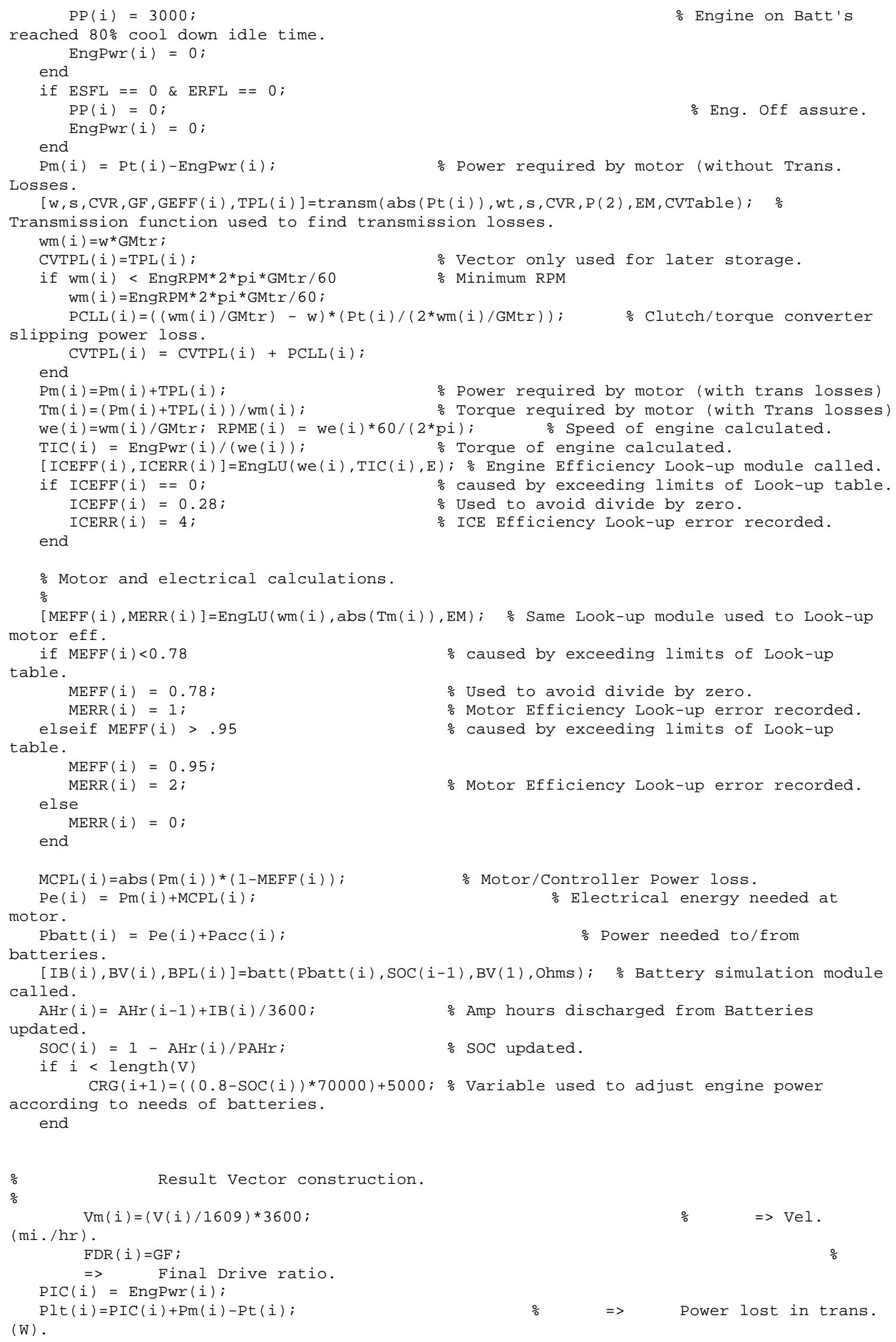




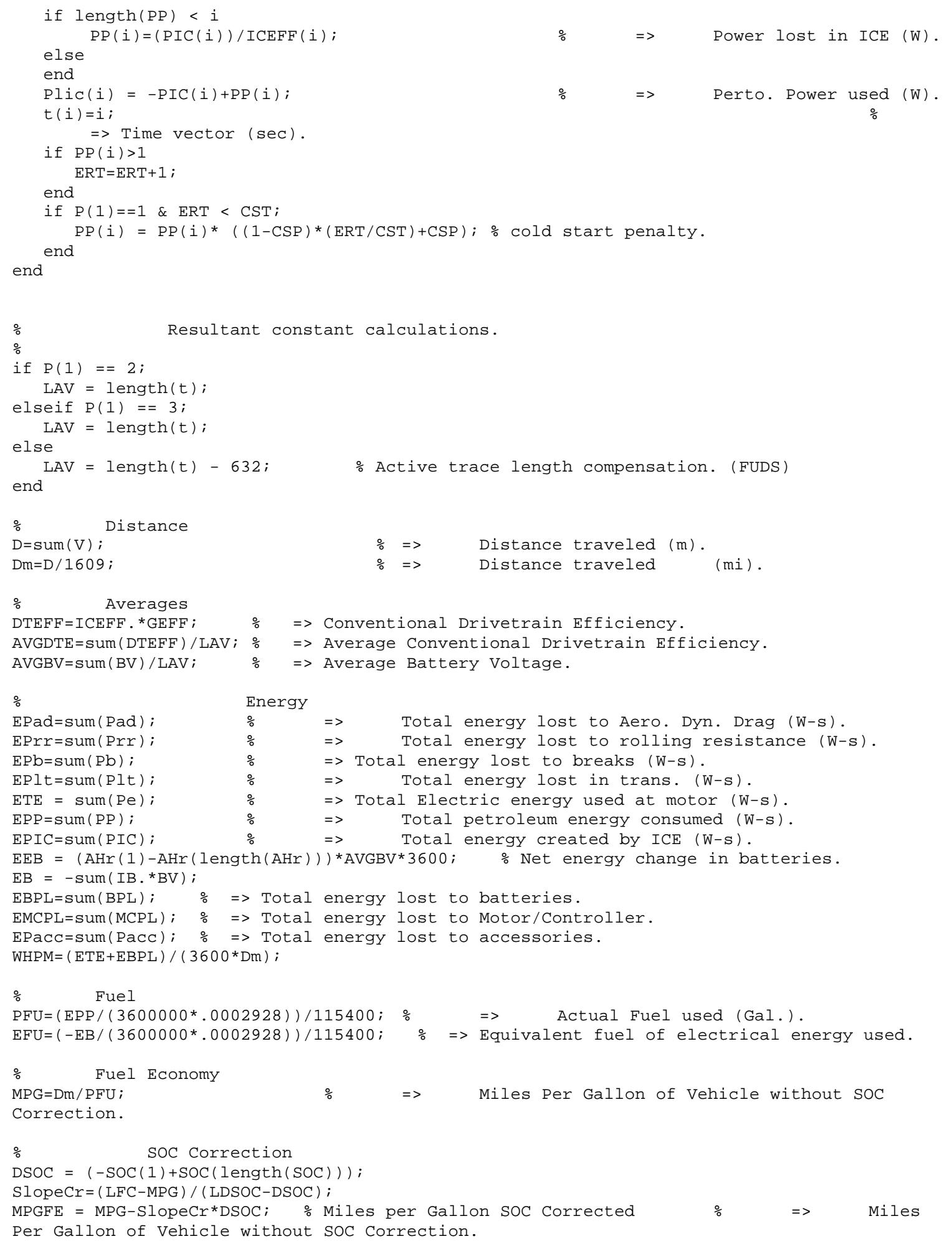




\title{
Appendix E
}

\section{Toyota Prius Powertrain Simulation Module}

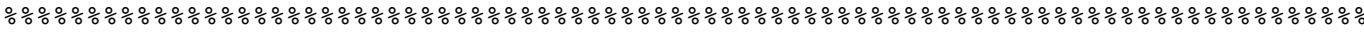 \\ - This is a program to be used with "car.m" so simulate a combination \\ parallel/series hybrid electric Vehicle powertrain \\ Program written by: Bill Kellermeyer \\ Last Modified: 4-14-98
}

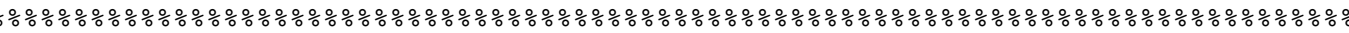

\% Graphic User Interface for Variables associated with Parallel/Series Characteristics

$\mathrm{f}=$ figure('Units', 'Normalized', 'Position', [.2 .2 .5

.5], 'NumberTitle', 'off', 'Name', 'Info');

ee = uicontrol('Style','pushbutton','Units','Normalized', 'Position', ([.1 1.6 .3

1] . /2), 'String', 'REF');

e = uicontrol('Style', 'Edit','Units', 'Normalized', 'Position', ([.2 1.5 .3

.1]./2),''Tag', 'myedit', 'string', '0.96');

ecc = uicontrol('Style', 'pushbutton', 'Units','Normalized', 'Position', ([.1 1.4 .3

.1]. /2), 'String', 'AltEF');

ec = uicontrol('Style','Edit','Units','Normalized','Position', ([.2 1.3.3

.1]./2),' 'Tag', 'myedit', 'string', '0.90');

eAA = uicontrol('Style','pushbutton','Units','Normalized','Position', ([.1 1.2 .3

.1]./2), 'String', 'AltGEF');

eA = uicontrol('Style','Edit','Units', 'Normalized', 'Position', ([.2 1.1 .3

.1]./2), 'Tag', 'myedit', 'string', '0.98');

emuu = uicontrol('Style','pushbutton','Units', 'Normalized', 'Position', ([.1 1.0.3

.1]./2), 'String', 'EngRPM');

emu = uicontrol('Style',' 'Edit',' 'Units', 'Normalized', 'Position', ([.2 .9 .3

.1]./2), 'Tag', 'myedit', 'string', '2300'); aee = uicontrol ('Style',' pushbutton','Units','Normalized','Position', ([.1 .8 .3

.1]./2), 'String', 'EngPwr'); $\mathrm{ae}=$ uicontrol('Style',' 'Edit',' 'Units', 'Normalized', 'Position', ([.2 .7 .3

1]./2),' 'Tag', 'myedit', 'string','16000'); aecc = uicontrol('Style',' 'pushbutton', 'Units', 'Normalized', 'Position', ([.1 .6 .3

1]./2), 'String', 'Regen'). aec = uicontrol('Style','Edit','Units', 'Normalized', 'Position', ([.2 .5 .3

.1]./2), 'Tag', 'myedit', 'string', '35000'); aeAA = uicontrol('Style', 'pushbutton', 'Units', 'Normalized', 'Position', ([.1 .4 .3

.1] . /2), 'String', 'BPV'); aeA = uicontrol('Style', 'Edit',' 'Units', 'Normalized', 'Position', ([.2 .3.3

.1]./2),' Tag', 'myedit', 'string', '324'); aemuu = uicontrol('Style','pushbutton','Units','Normalized','Position', ([.1 .2 .3

.1]./2), 'String', 'BPAHr');

aemu = uicontrol('Style','Edit','Units','Normalized','Position', ([.2 .1 .3

.1]./2), 'Tag', 'myedit', 'string', '13');

bee = uicontrol('Style','pushbutton',' 'Units','Normalized', 'Position', ([.6 1.6 .3

.1]./2), 'String', 'soC1');

be = uicontrol ('Style', 'Edit', 'Units', 'Normalized', 'Position', ( .71 .5 .3

.1]./2),'Tag', 'myedit','string','0.7'); becc = uicontrol('Style','pushbutton','Units','Normalized','Position', ([.6 1.4 .3

.1] . /2), 'String', 'SOCON'); bec = uicontrol('Style','Edit','Units','Normalized', 'Position', ([.7 1.3 .3

.1]./2),' 'Tag', 'myedit', 'string', '0.6'); cebb = uicontrol('Style',' 'pushbutton',' Units','Normalized', 'Position', ([.6 1.2 .3

.1]./2), 'String', 'GMtr') ceb = uicontrol ('Style','Edit','Units', 'Normalized', 'Position', ([.7 1.1 .3

.1]./2),' 'Tag', 'myedit', 'string', '2.15'); bemuu = uicontrol('Style', 'pushbutton', 'Units', 'Normalized', 'Position', ([.6 1.0.3

1]./2), 'String', 'IDTM').

bemu = uicontrol('Style','Edit', 'Units', 'Normalized', 'Position', ([.7 .9 .3

.1]./2),' 'Tag', 'myedit', 'string', '19');

cee = uicontrol('Style','pushbutton','Units','Normalized', 'Position', ([.6 0.8 .3

.1]./2), 'String', 'Np'). 


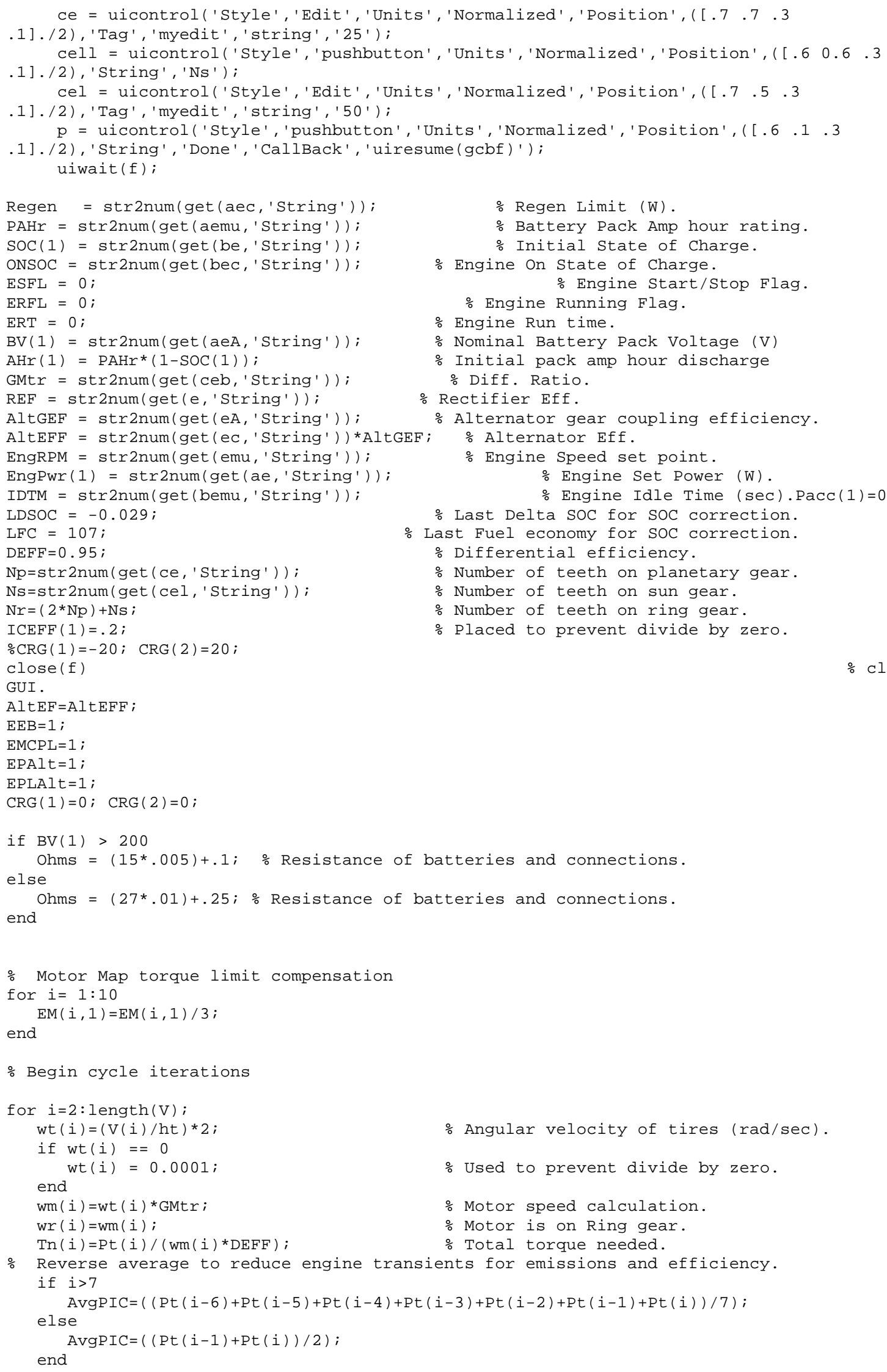

\% Reverse average to reduce engine transients for emissions and efficiency. if $i>7$ 


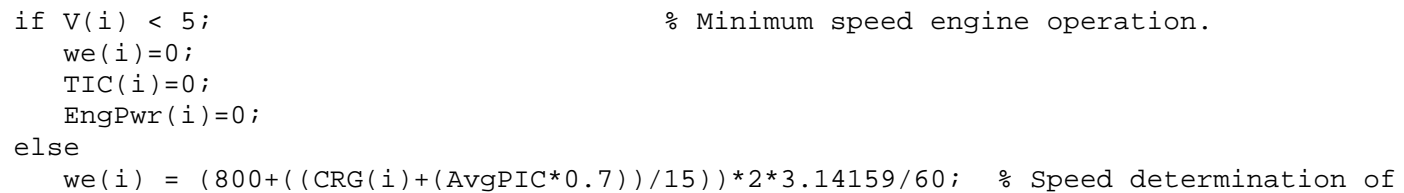

\% Motor Efficiency Look-up error 


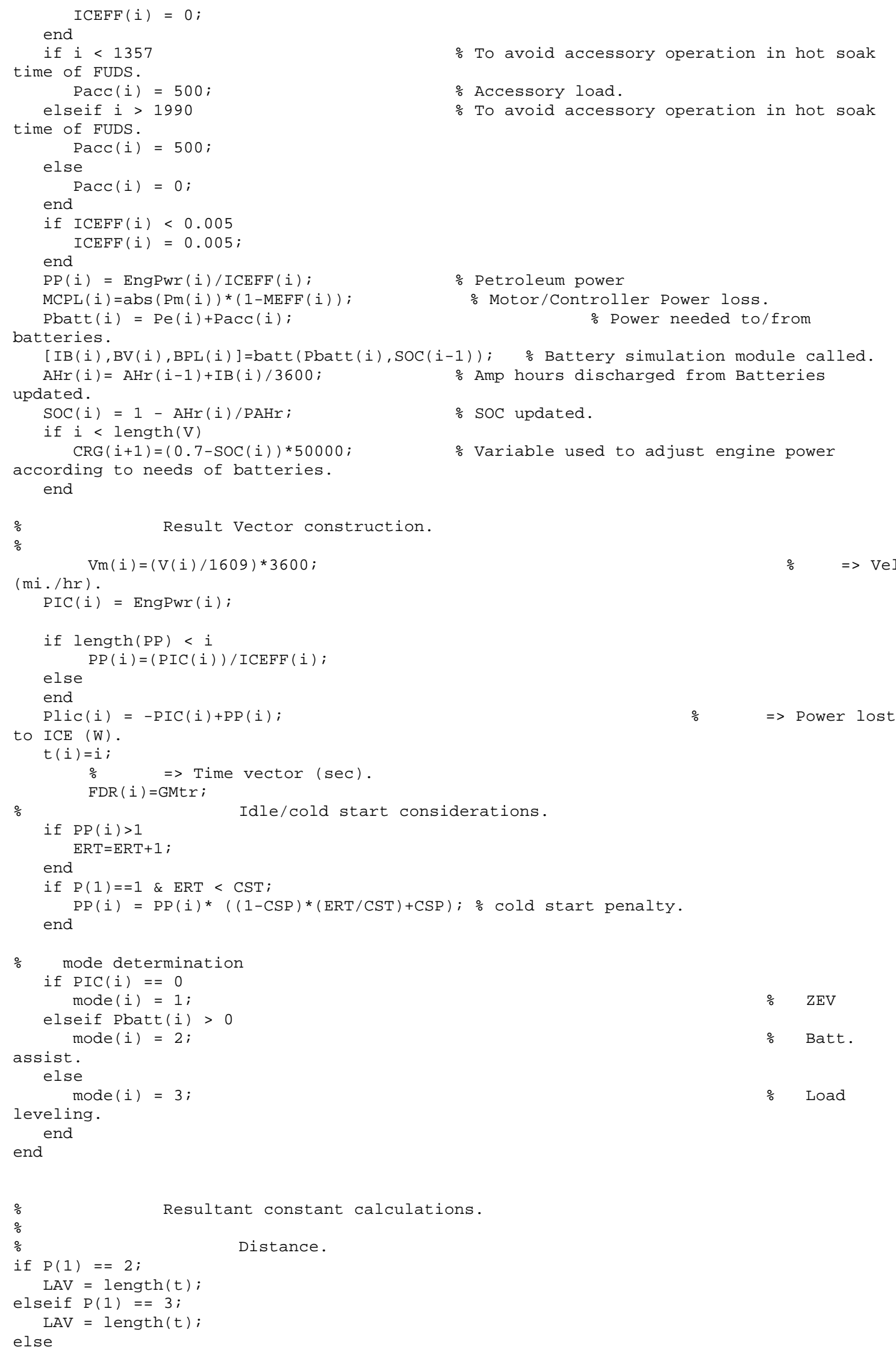




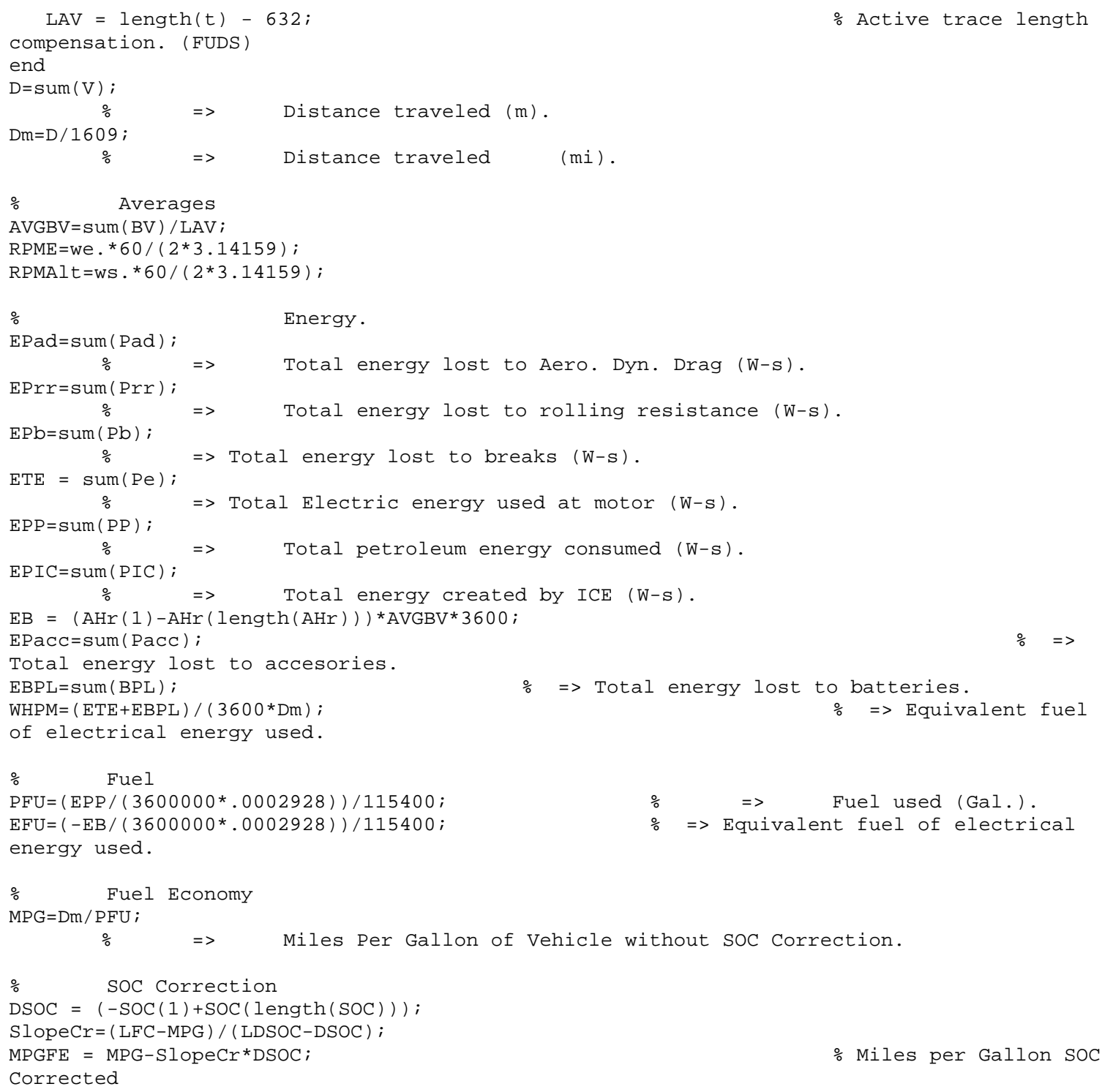




\section{Appendix F}

\section{Engine Efficiency Map Look-Up Module}

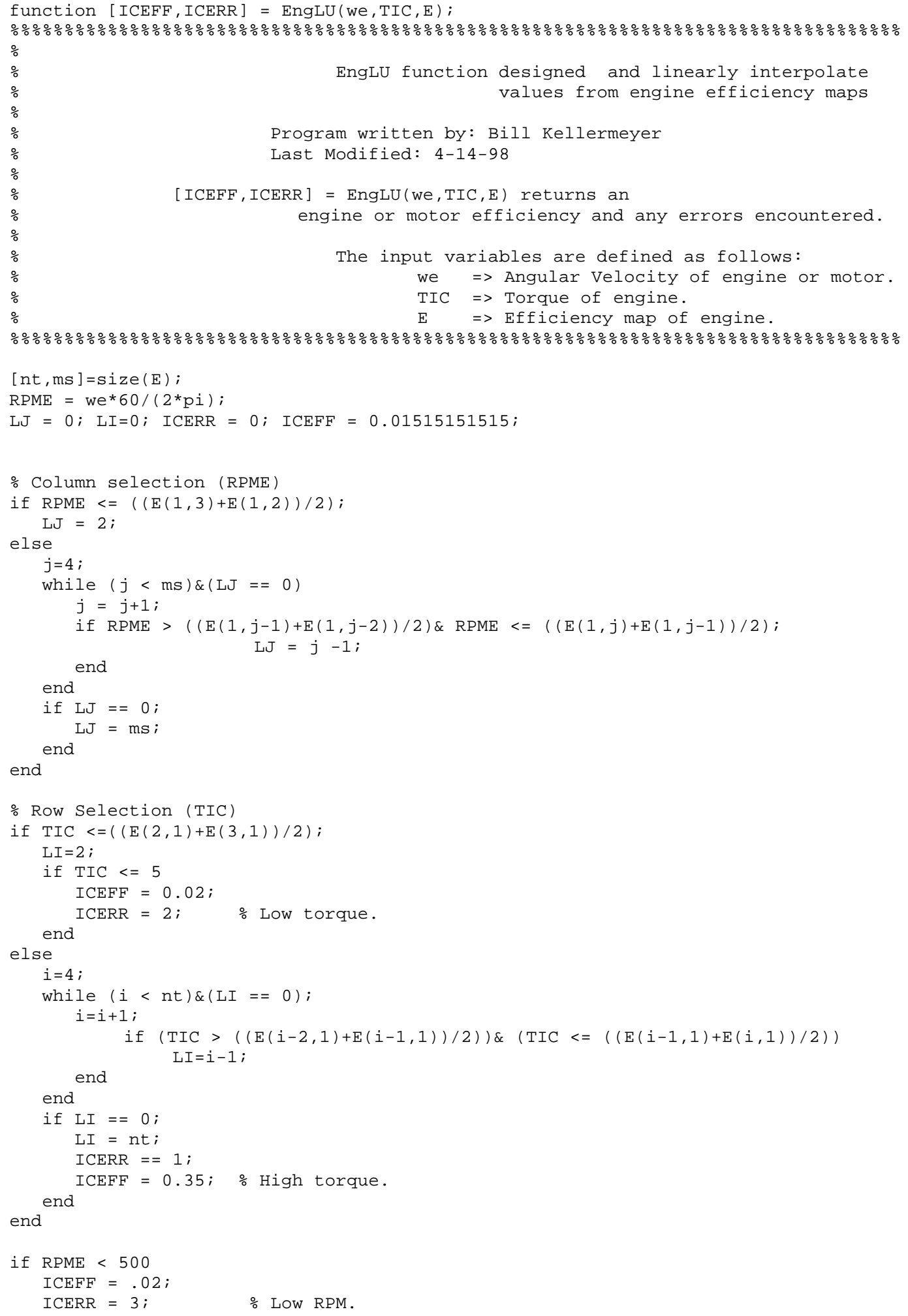


end

if $\operatorname{ICEFF}==0.01515151515$;

$\mathrm{ICEFF}=\mathrm{E}(\mathrm{LI}, \mathrm{LJ})$;

if $\mathrm{E}(7,7)>1$

$\mathrm{ICEFF}=\mathrm{ICEFF} / 100$;

end;

end

if $\max (E(:, 1))>200$

ICEFF $\quad=\quad \operatorname{ICEFF} * 1.1 ;$ \% Compensation for larger engines.

end 


\section{Appendix G}

\section{Transmission Efficiency Replication Module}

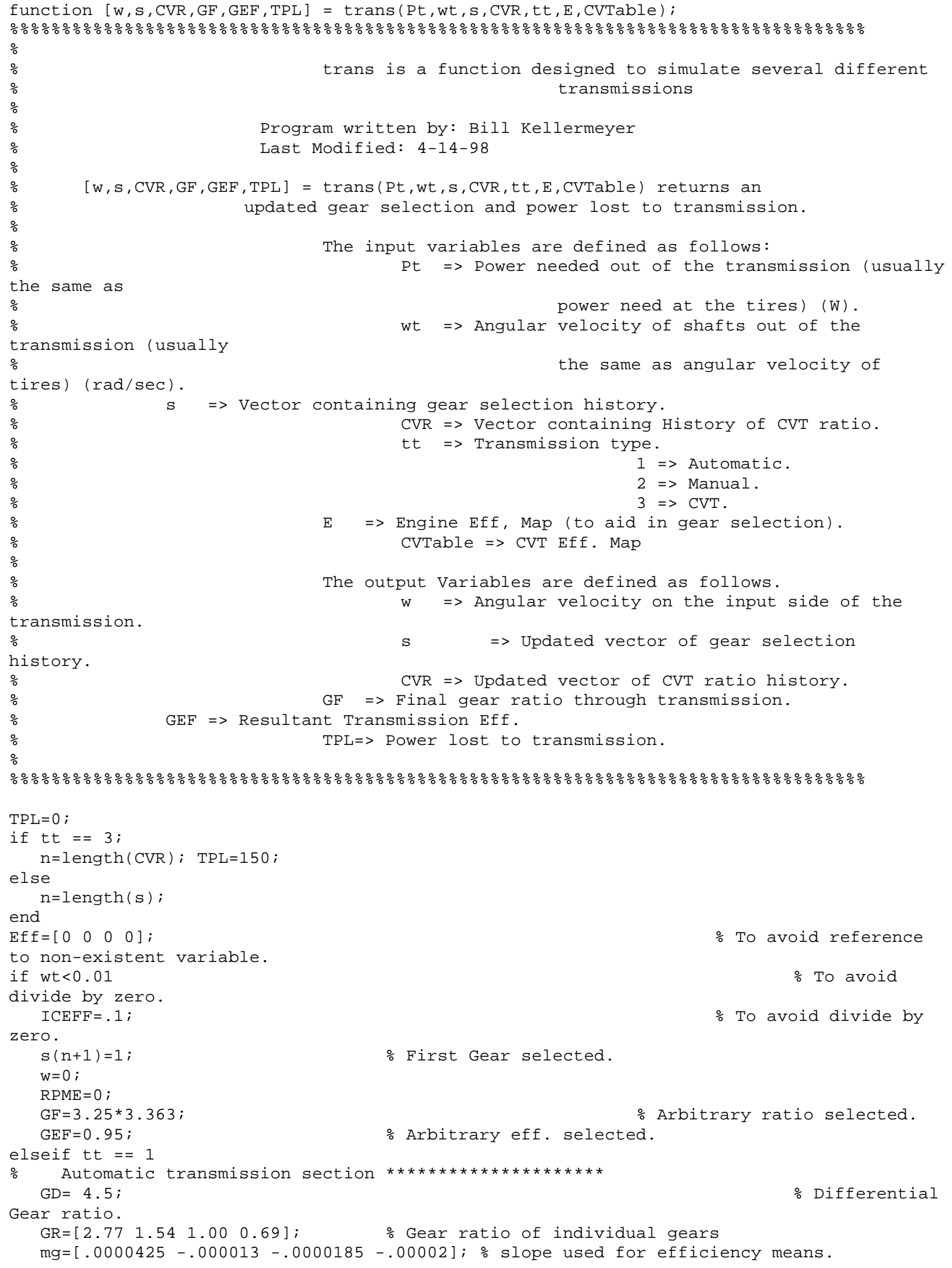




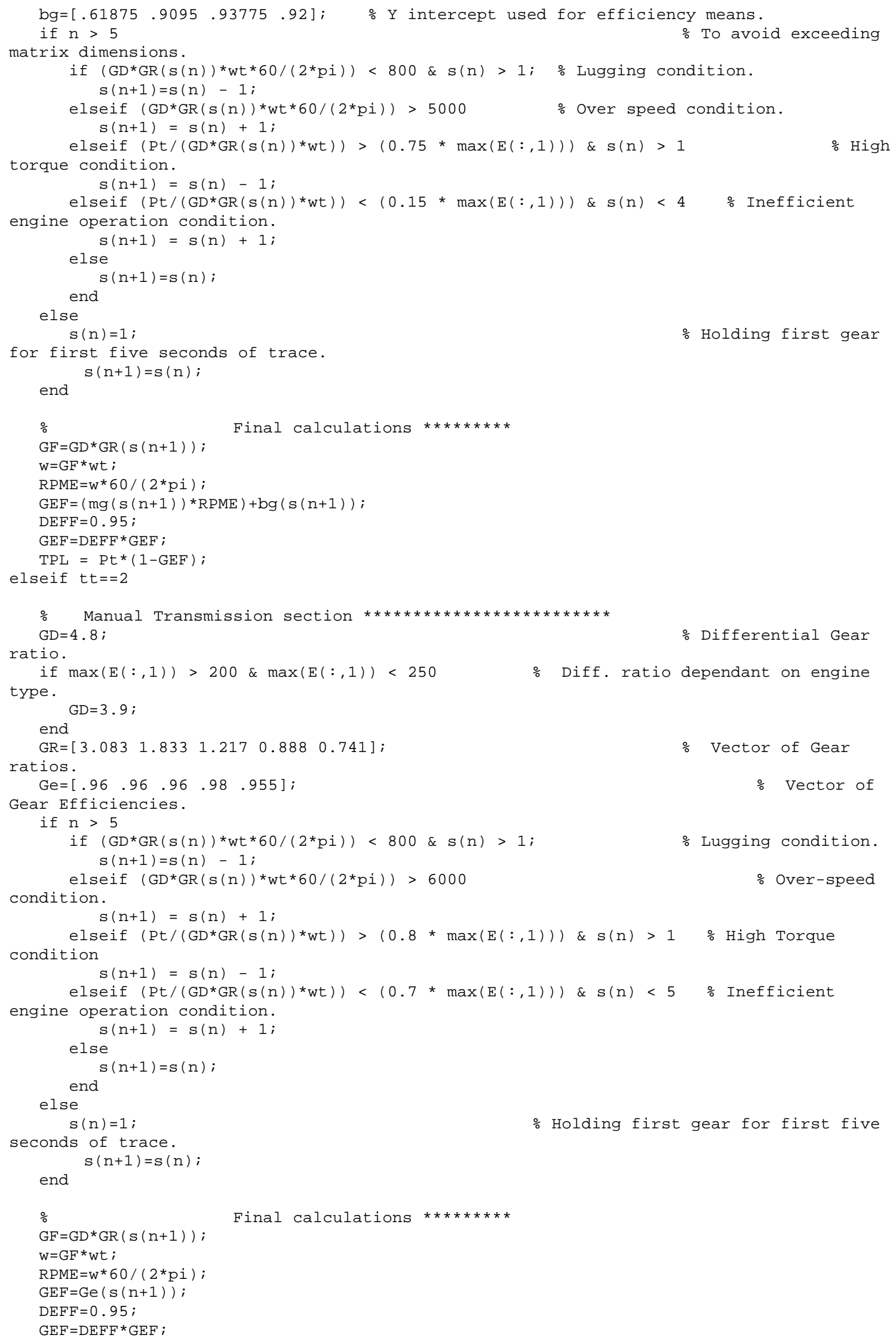




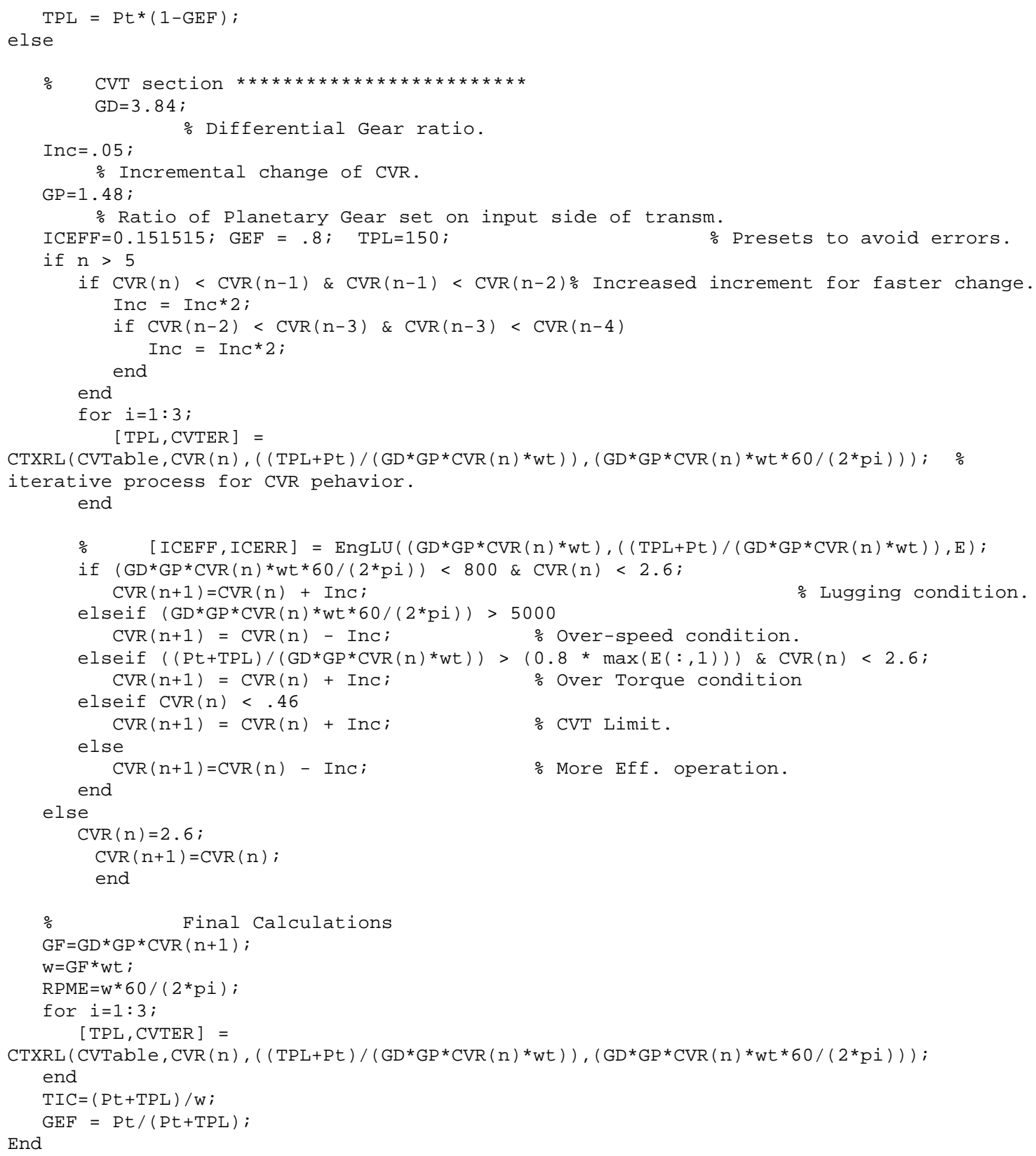




\section{Appendix H}

\section{Continuously Variable Transmission Three Dimensional Efficiency Look-up Module}

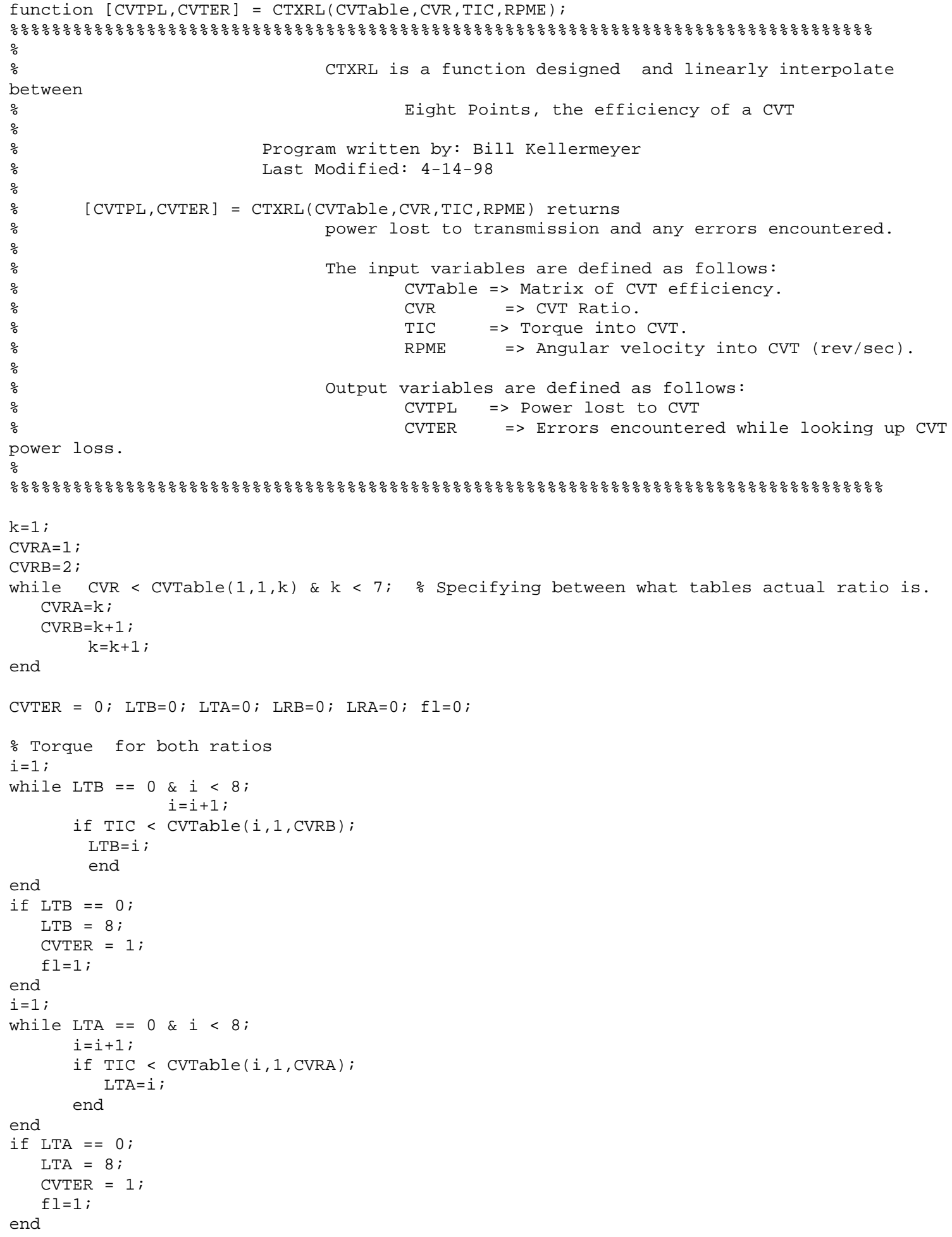




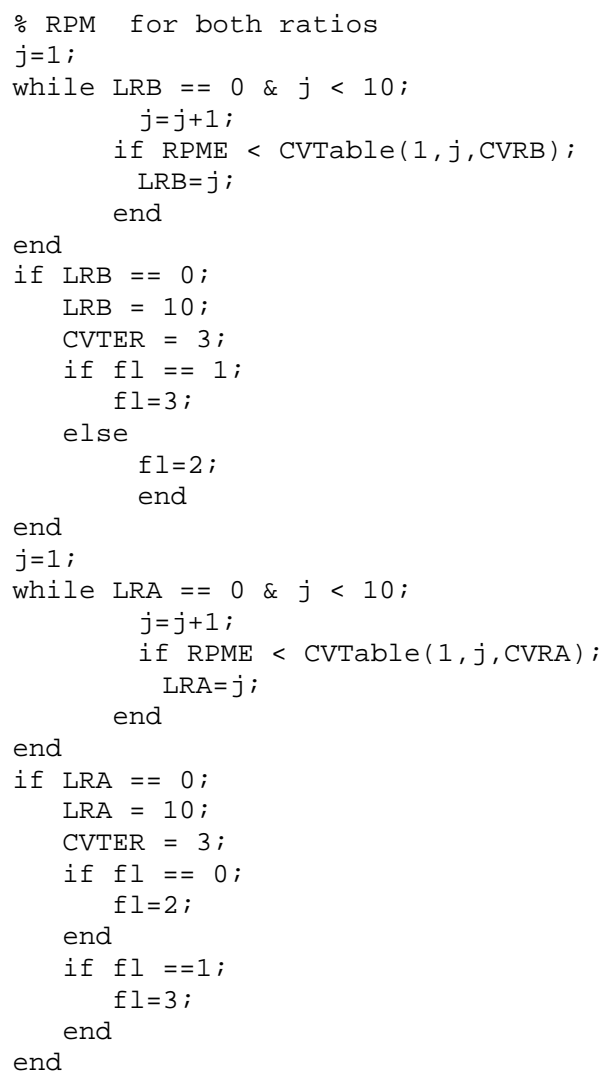




\section{Appendix I}

\section{Battery Simulation Module}

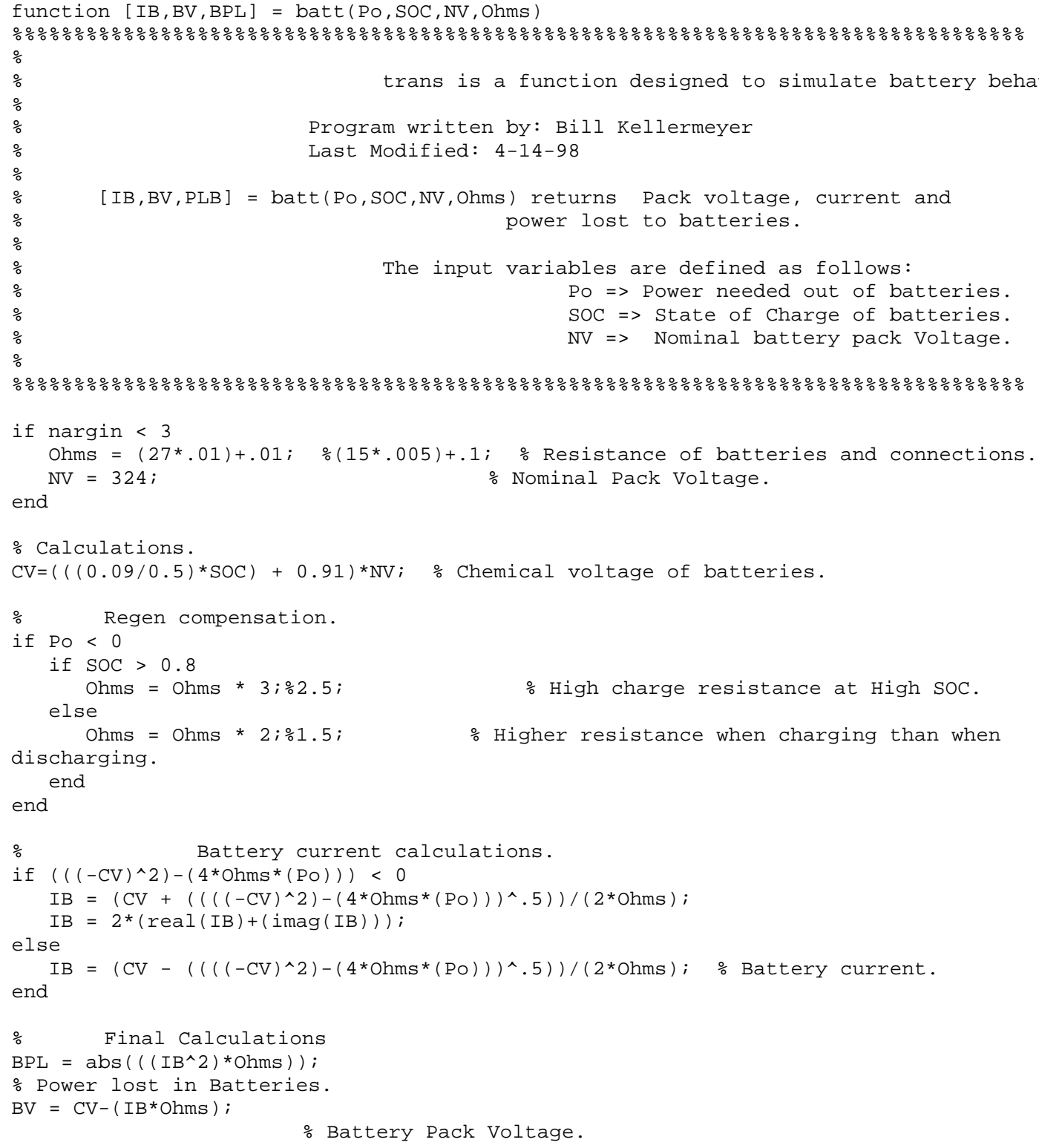

